U.S. Geological Survey Water Science StrategyObserving, Understanding, Predicting, and Delivering Water Science to the Nation

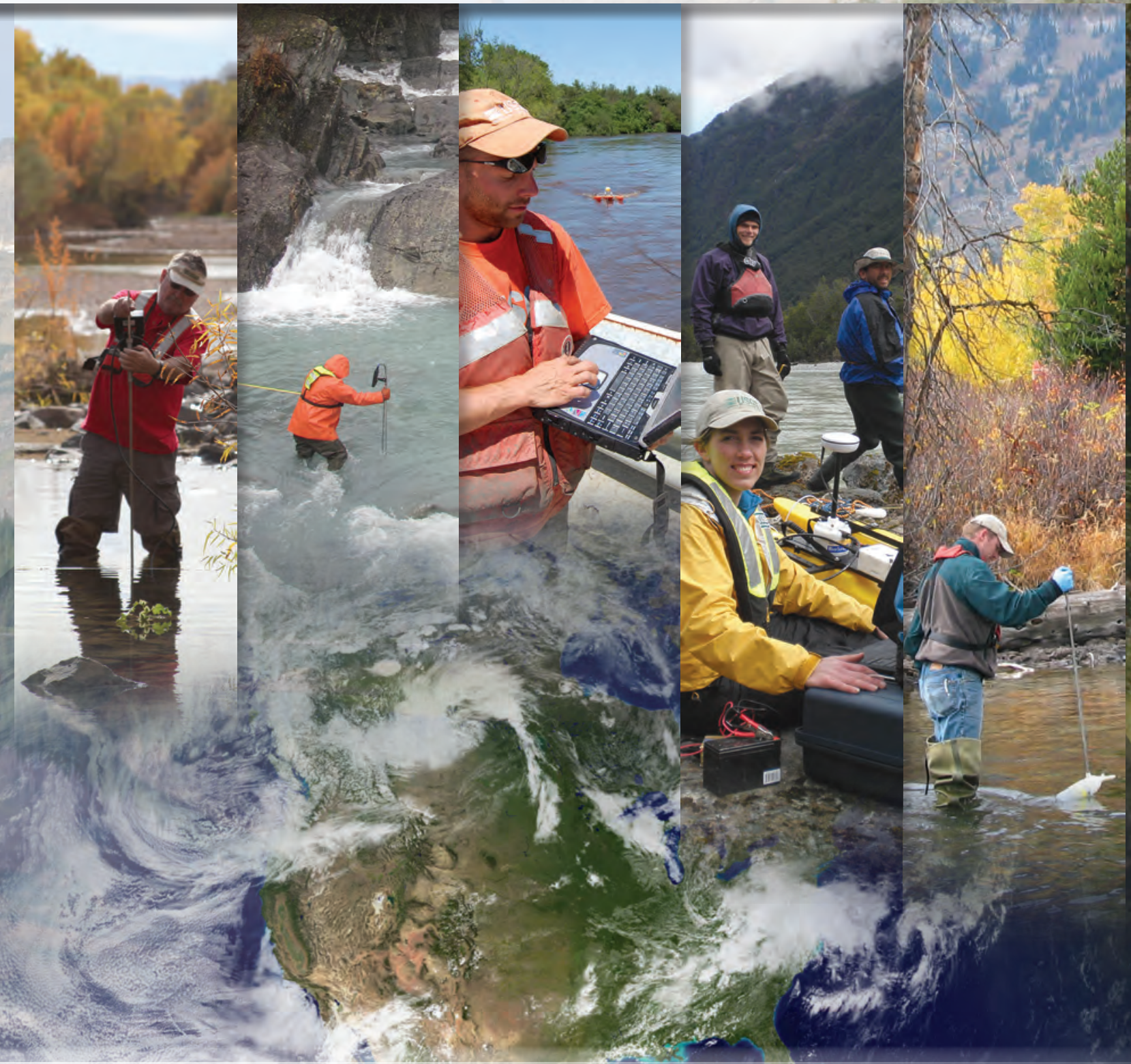

Circular 1383-G

U.S. Department of the Interior U.S. Geological Survey 


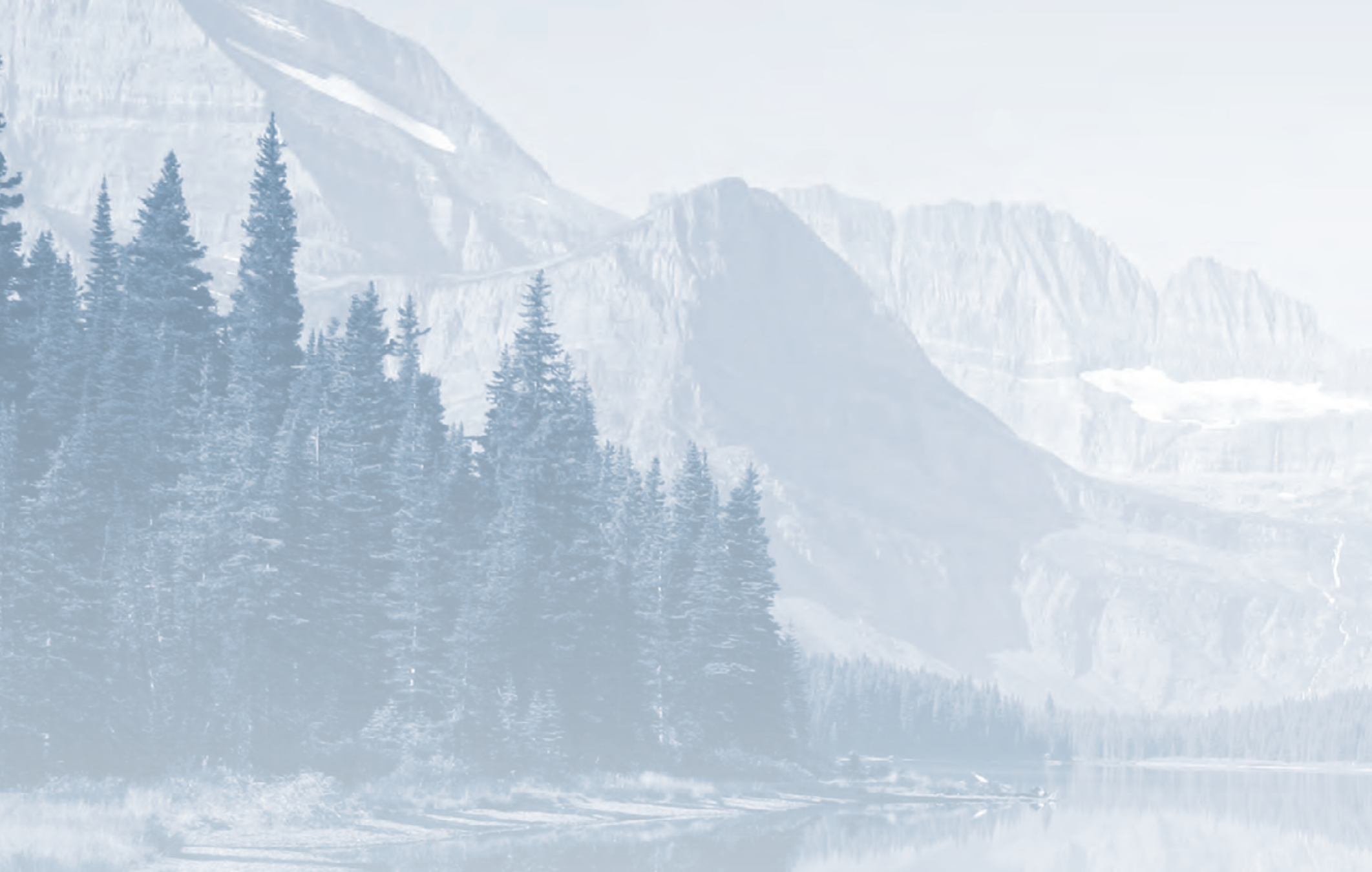

Cover. Clockwise left to right:

USGS hydrographer measuring discharge with a flowtracker at San Carlos River near Peridot, Arizona, Nov. 2010. Photograph by Norbert R. Duet, U.S. Geological Survey (USGS).

Solomon Gulch at top of Falls near Valdez, Alaska, Oct. 2010. Minor flood stage from Solomon Lake spill. Photograph by Jeffery M. Wiles, USGS.

USGS hydrographer measuring streamflow with Acoustic Doppler Current Profiler (ADCP), West Fork Cedar River near Finchford, lowa, June 2008. Photograph by Don M. Becker, USGS.

Molly Wood, USGS, making comparison ADCP measurements with Chilean and University of Idaho scientists on the Rio Murta in Chilean Patagonia, Jan. 2011.

USGS hydrographer sampling in Grand Teton National Park, Wyoming, Oct. 2006. Photograph by Melanie L. Clark, USGS.

The Blue Marble. Image by NASA Goddard Space Flight Center.

Background. Lake Josephine, Glacier National Park, Montana, Aug. 2005. Photograph by G. Lynn Wingard, USGS. 


\section{U.S. Geological Survey Water Science Strategy-Observing, Understanding, Predicting, and Delivering Water Science to the Nation}

By Eric J. Evenson, Randall C. Orndorff, Charles D. Blome, John Karl Böhlke, Paul K. Hershberger, Victoria E. Langenheim, Gregory J. McCabe, Scott E. Morlock, Howard W. Reeves, James P. Verdin, Holly S. Weyers, and Tamara M. Wood

Circular 1383-G 


\section{U.S. Department of the Interior \\ KEN SALAZAR, Secretary \\ U.S. Geological Survey \\ Marcia K. McNutt, Director}

U.S. Geological Survey, Reston, Virginia: 2013

For more information on the USGS - the Federal source for science about the Earth, its natural and living resources, natural hazards, and the environment, visit http://www.usgs.gov or call 1-888-ASK-USGS.

For an overview of USGS information products, including maps, imagery, and publications, visit http://www.usgs.gov/pubprod

To order this and other USGS information products, visit http://store.usgs.gov

Any use of trade, firm, or product names is for descriptive purposes only and does not imply endorsement by the U.S. Government.

Although this information product, for the most part, is in the public domain, it also may contain copyrighted materials as noted in the text. Permission to reproduce copyrighted items must be secured from the copyright owner.

Suggested citation:

Evenson, E.J., Orndorff, R.C., Blome, C.D., Böhlke, J.K., Hershberger, P.K., Langenheim, V.E., McCabe, G.J., Morlock, S.E., Reeves, H.W., Verdin, J.P., Weyers, H.S., and Wood, T.M., 2013, U.S. Geological Survey water science strategy-Observing, understanding, predicting, and delivering water science to the Nation: U.S. Geological Survey Circular 1383-G, 49 p. 


\section{Foreword}

In 2007, the U.S. Geological Survey (USGS) published a Bureau Science Strategy Facing Tomorrow's Challenges - U.S. Geological Survey Science in the Decade 2007-2017. It provided a view of the future, establishing science goals that reflected the USGS's fundamental mission in areas of societal impact such as energy and minerals, climate and land use change, ecosystems, natural hazards, environmental health, and water. Intended to inform long-term program planning, the strategy emphasizes how USGS science can make substantial contributions to the well-being of the Nation and the world.

In 2010, I realigned the USGS management and budget structure, changing it from a structure associated with scientific disciplines — Geography, Geology, Biology and Hydrology — to an issue-based organization along the lines of the Science Strategy. My aim was to align our management structure with our mission, our science priorities, our metrics for success, and our budget. An added benefit was that the USGS immediately appeared relevant to more Americans, and it became easier for those outside the agency to navigate our organizational structure to find where within the USGS they would find the solution to their problem. External partners rarely approached us with a problem in "geology," but they might need help with an issue in climate change or energy research.

The new organization is focused on seven science mission areas:

- Climate and Land Use Change

- Core Science Systems

- Ecosystems

- Energy and Minerals

- Environmental Health

- Natural Hazards

- Water

The scope of each of these new mission areas is broader than the science directions outlined in the USGS Science Strategy and together cover the scope of USGS science activities.

In 2010, I also commissioned seven Science Strategy Planning Teams (SSPTs) to draft science strategies for each USGS mission area. Although the existing Bureau Science Strategy could be a starting point for this exercise, the SSPTs had to go well beyond the scope of the existing document. What is of value and enduring from the work of the programs that existed under the former science disciplines needed to be reframed and reinterpreted under the new organization of the science mission areas. In addition, new opportunities for research directions have emerged in the five years since the Bureau Science Strategy was drafted, and exciting possibilities for cooperating and collaborating in new ways are enabled by the new mission focus of the organization.

Scientists from across the Bureau were selected for these SSPTs for their experience in strategic planning, broad range of experience and expertise, and knowledge of stakeholder needs and relationships. Each SSPT was charged with developing a long-term (10-year) science strategy that encompasses the portfolio of USGS science in the respective mission area. Each science strategy will reinforce others because scientific knowledge inherently has significance to multiple issues. Leadership of the USGS and the Department of the Interior will use the science vision and priorities developed in these strategies for program guidance, implementation planning, accountability reporting, and resource allocation. These strategies will guide science and technology investment and workforce and human capital strategies. They will inform our partners regarding opportunities for communication, collaboration, and coordination.

The USGS has taken a significant step toward demonstrating that we are ready to collaborate on the most pressing natural science issues of our day and the future. I believe a leadership aligned to support these issue-based science directions and equipped with the guidance provided in these new science strategies in the capable hands of our scientists will create a new era for USGS of which we can all be proud.

Marcia McNutt

Director 


\section{About This Report}

The Water Science Strategy expands on the U.S. Geological Survey (USGS) Science Strategy, "Facing Tomorrow's Challenges-U.S. Geological Survey Science in the Decade 2007-2017" (U.S. Geological Survey, 2007), which developed seven integrated science Mission Areas. This water strategy builds on the strengths of water science in the USGS and links to other science disciplines and Mission Areas of the Bureau and our many partners outside of the USGS. In addition, it recognizes that "in the coming decades of the 21 st century the United States faces serious and complex water problems. Constraints on availability of water-quantity and quality - will impact what we do and where we do it as a society. To face these problems the Nation will need more, new, and improved water science, information and tools to manage and adapt to these constraints" (National Research Council, 2009). This report is addressed primarily to policymakers who will determine the future resources with which the USGS has to conduct its work, so that they will be apprised of the technical and societal issues that the Bureau will face in the future.

The USGS Science Strategy, “Facing Tomorrow's Challenges-U.S. Geological Survey Science in the Decade 2007-2017" (U.S. Geological Survey, 2007) included a science direction on "A Water Census of the United States-Quantifying, Forecasting, and Securing Freshwater for America's Future." The Water Census is to inform the public and decisionmakers about (1) the status of freshwater resources and how they are changing; (2) water use for human, environmental, and wildlife needs; (3) freshwater availability related to natural storage and movement; (4) means of identifying water sources not commonly thought to be a resource; and (5) forecasts of likely outcomes of water availability and quality. Six specific strategic actions were put forth in the Science Strategy to address the aspects of a water census. The "U.S. Geological Survey Water Science Strategy_-Observing, Understanding, Predicting, and Delivering Water Science to the Nation," takes the fairly broad strategic actions of the Water Census and develops the steps and actions to move the USGS forward to a strategic focus. 
The Water Mission Area is one of seven science areas that will lead to integrated science across the various USGS disciplines to address societal earth science needs. A Water Science Strategy Planning Team (SSPT) was charged with developing a long-term (10-year) strategic science plan for the USGS Water Mission Area and the programs that support it. This Science Strategy looks at the issues facing society and develops a strategy that observes, understands, predicts, and delivers water science by taking into account the water science and core capabilities of the USGS; the document also looks forward over the next 5 to 10 years toward building new capabilities, tools, and delivery systems to meet the Nation's water-resource needs. This Science Strategy serves as a guiding document for USGS leadership in science planning and execution and will be used as a basis for budget initiatives and national and regional guidance. Through observing components of the water cycle, we can better quantify the water resource in terms of abundance and quality. Understanding the water cycle leads to development of better tools for assessing all aspects of the water resource, from water availability, to flooding, to degradation of surface waters and groundwater. Predicting modifications of the water cycle from factors such as human effects on watersheds and climate variability is important for decisionmaking to ensure the sustainability and resilience of communities and ecosystems. Finally, USGS science related to observing, understanding, and predicting components of the water cycle must be delivered to managers, policymakers, and the public in understandable and relevant ways to be an effective force in managing the water resource.

The goals, objectives, and strategic actions presented in this report are a result of many meetings and forums with stakeholders and input from USGS scientists and staff, along with discussions with collaborators and partners of water science outside the Bureau. This information was considered in forming the Priority Actions discussed in the section by that name of this report. "Priority Actions" attempts to take the crosscutting objectives and strategic actions in the section entitled "Water Science Goals and Objectives" and integrate them into science for the future to meet water needs of the 21 st century. The Water SSPT recognized that water needs include sustaining ecosystems along with human uses. Competing uses of water including human consumption, industry, agriculture, and ecosystems are exacerbated by the challenges we face with population growth, energy demands, climate variability, and other factors. The science needed to address these issues requires a diverse workforce with expertise in hydrology, geology, physics, chemistry, and biology. 


\section{Contents}

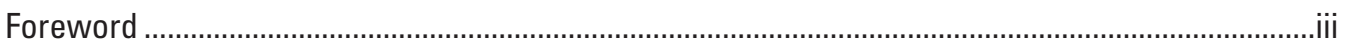

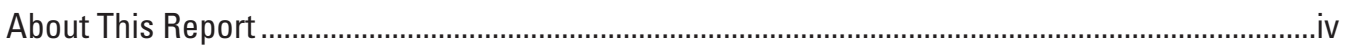

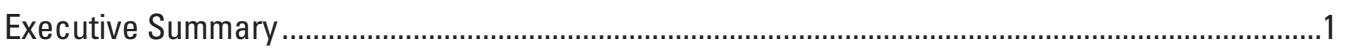

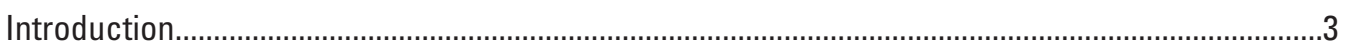

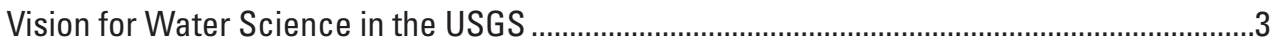

Societal Issues and Water Science …………………….......................................................

Core Capabilities: Strengths, Partnerships, and Science IntegrationWhat We Do Now that is Important and Needs to Continue .................................................

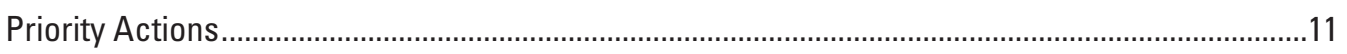

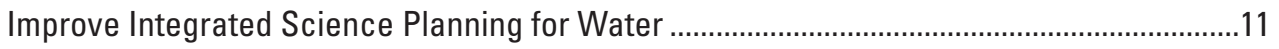

Expand and Enhance Water-Resource Monitoring Networks..................................................11

Characterize the Water Cycle Through Development of State-of-the-Art 3-D/4-D Hydrogeologic Framework Models at Multiple Scales ..............................................12

Clarify the Linkage Between Human Water Use (Engineered Hydrology) and the Water Cycle (Natural Hydrology)...............................................................................15

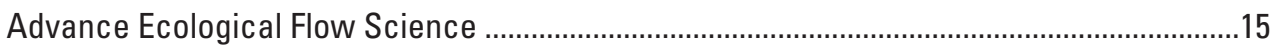

Provide Flood-Inundation Science and Information ..............................................................16

Develop Rapid Deployment Teams for Water-Related Emergencies.......................................16

Conduct Integrated Watershed Assessment, Research, and Modeling ..................................17

Deliver Water Data and Analyses to the Nation.................................................................17

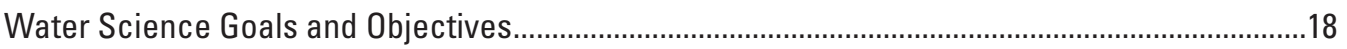

Goal 1: Provide Society the Information It Needs Regarding the Amount and Quality of Water in All Components of the Water Cycle at High Temporal and Spatial Resolution, Nationwide ..........................................................................................18

Objective 1: Advancement of Hydrologic Monitoring Networks and Techniques..........23

Objective 2: Advancement of Monitoring Networks and Techniques for

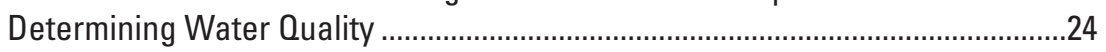

Objective 3: Assessment of Water Resources and their Suitability to Meet Human and Ecosystem Needs .............................................................................25

Goal 2: Advance Understanding of Processes that Determine Water Availability..................25

Objective 1: Comprehensive Understanding of Geological Controls of Water Availability, and Improved Integration of Geologic and Hydrologic Multidimensional Models

Objective 2: Comprehensive Understanding of the Effects of Climate Variation on Water Availability at Multiple Spatial and Temporal Scales...

Objective 3: Comprehensive Understanding of the Interactions Among Aquatic Ecosystems, Hydrology, and Hydrochemistry.

Objective 4: Comprehensive Understanding of Human Interactions with Water Availability 
Goal 3: Predict Changes in the Quantity and Quality of Water Resources in Response

to Changing Climate, Population, Land Use, and Management Scenarios..

Objective 1: Development and Application of Models To Predict Potential Effects of Changes in Population, Land Use, Climate, and Management Practices Upon Future Water Availability Considering Human and Ecological Needs......32

Objective 2: Prediction of the Availability of Alternative (Impaired) Water Resources, and the Effects of Using These Water Sources on the Environment

Goal 4: Anticipate and Respond to Water-Related Emergencies and Conflicts

Objective 1: Identification of Current and Future Threats to Communities from Water-Related Hazards

Objective 2: Development and Deployment of Observational Systems for Identifying and Tracking Hydrologic Hazards, Making Operational Decisions During Extreme Hydrologic Events, and Providing Data for Recovery

Objective 3: Through an Understanding of the Conditions Leading to Water Shortages that Result in Conflicts, Provide Assistance to Communities in Finding Science-Based Solutions When Conflicts Occur.

Objective 4: Providing Tools that Allow Managers to Detect and Respond to Emergencies Related to Water-Quality Degradation of All KindsNatural, Accidental, and Intentional.

Goal 5: Deliver Timely Hydrologic Data, Analyses, and Decision-Support Tools

Seamlessly Across the Nation to Support Water-Resource Decisions.

Objective: Development of New, Integrated Information Dissemination in Formats Appropriate for the 21st Century to Aid Scientists and Decisionmakers

Communicating Science to Society: Inform—Involve—Educate . .41

Local Communication and Outreach ...................................................................................

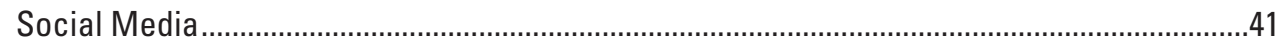

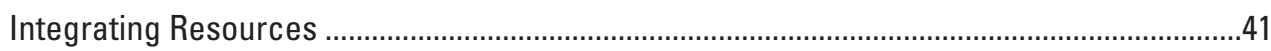

Crosscutting Science with Other USGS Mission Areas..................................................................42

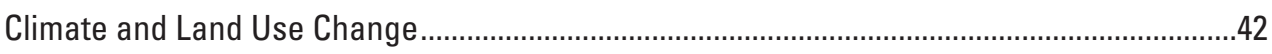

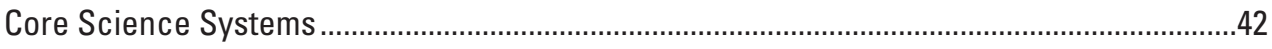

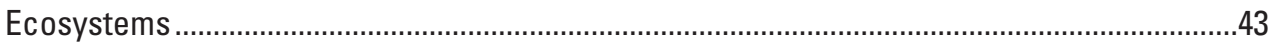

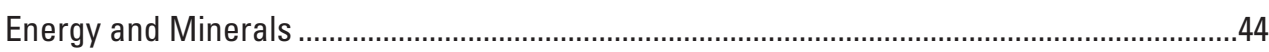

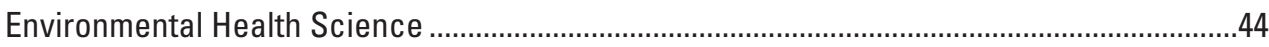

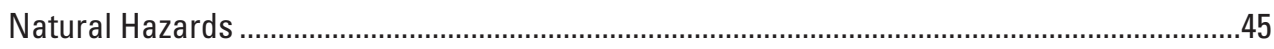

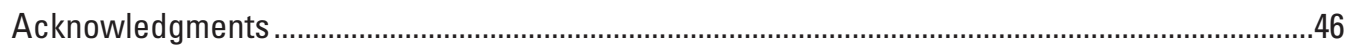

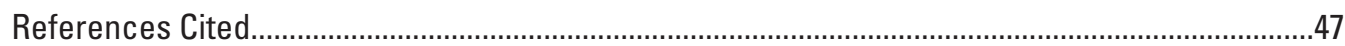




\section{Figures}

1. Graph showing Colorado River Basin water supply, 1914-2007.

2. Graph showing trends in population and freshwater withdrawals by source, 1950-2005

3. Diagram showing time scales of various geologic, climatic, and human events.

4. Graph and photograph showing vertical distribution of ages and lead concentrations in a sediment core from the bottom of an impounded lake.

5. Example of a super gage is White River at Hazleton, Indiana

6. Schematic showing boundary extents of a basin-fill aquifer and the aquifer's confining layer containing impermeable bedrock

7. Photograph showing Bonneville Dam, the first of 14 dams in place on the Columbia River main stem, between Oregon and Washington

8. Diagram showing the water cycle.

9. Plot of dissolved oxygen concentration data at Oswego diversion dam and photograph of Oswego diversion dam on the Tualatin River near West Linn, Oregon ...22

10. Graph showing nuclear magnetic resonance, gamma, and electromagnetic conductivity logs from a borehole completed in sand and gravel on Cape Cod, Massachusetts.

11. Cross section showing surficial aquifer on the Delmarva Peninsula, Delaware, Maryland, and Virginia; map view and cross section of simulated traveltimes of groundwater from recharge to discharge in a watershed in New Jersey; and diagram showing natural attenuation processes that can occur when organic contaminants come into contact with oxygenated compounds in the aquifer, causing microbially mediated reactions that transform the contaminants into other chemicals that are less harmful.

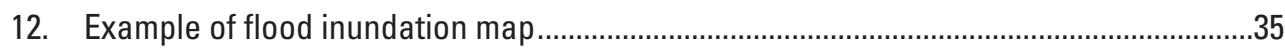

13. Photograph of a tributary of the Kalamazoo River near Marshall, Michigan, July 2010, and flood-inundation map for a 15-mile reach of the Kalamazoo River from Marshall to Battle Creek, Michigan, July 2010

14. Screenshot showing real-time data collected from the U.S. Geological Survey streamgage on the Potomac River at Point of Rocks, Md. (1410000002), and photograph of the streamgage.

\section{Tables}

1. Links of priority actions to goals and strategic actions ................................................12

2. List of goals and strategic actions.......................................................................... 


\section{Highlights}

The Water Budget

Geochronology/Paleohydrology —Interpreting the Past as Key to the Future ..........10

Real-Time Data and the "Super Gage" ...................................................................13

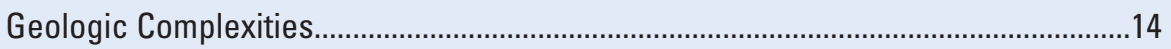

Use of Continuous Water-Quality Monitors for Real-Time Regulatory Decisionmaking-The Tualatin River Success Story

Trends in Hydrogeophysics.

27

Land Use and Contaminant Hydrogeology and Geochemistry

Prediction in Earth Science

30

Kalamazoo River Oil Spill and Flood

33

USGS WaterAlert.

37

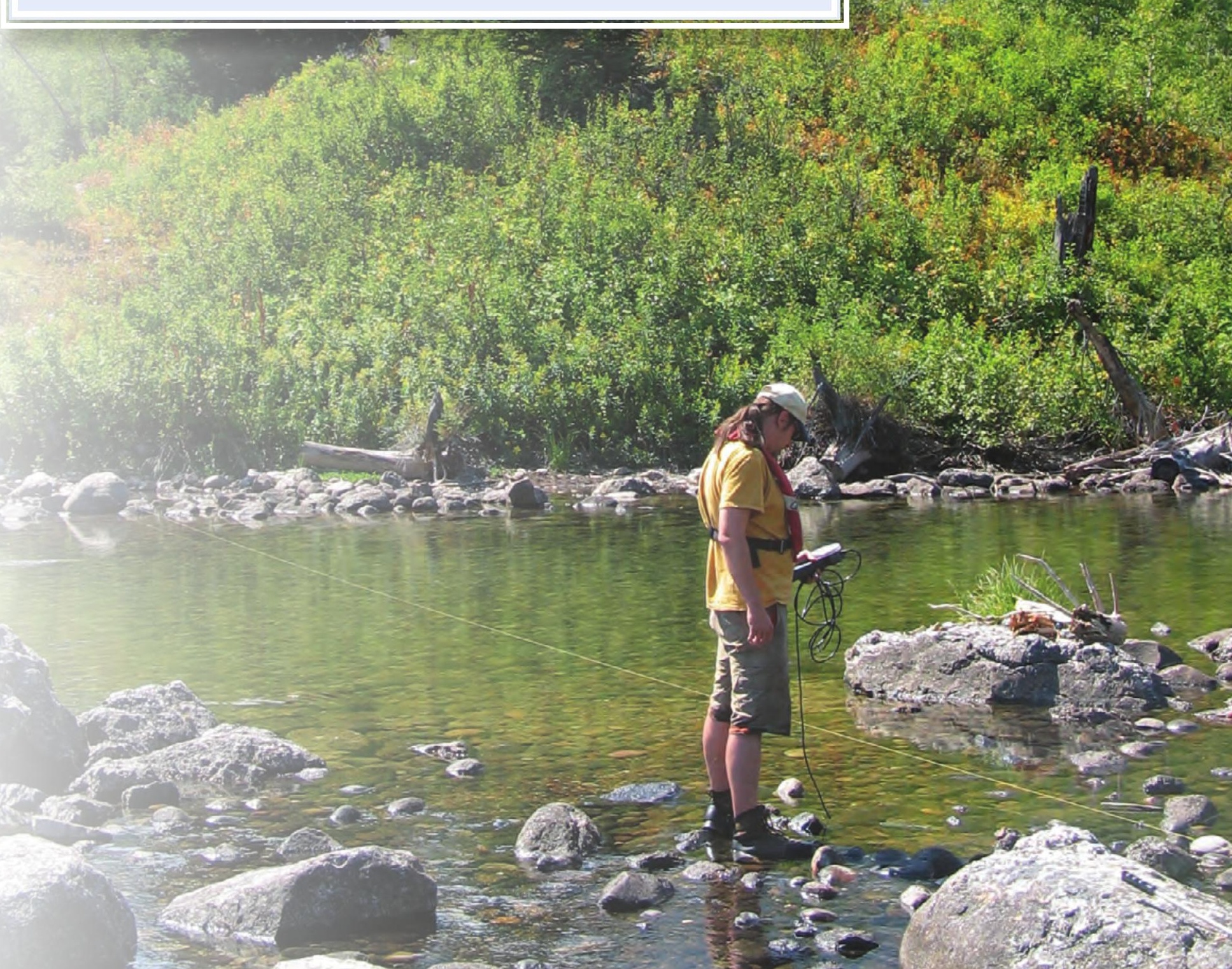




\section{Abbreviations}

$\begin{array}{ll}\text { ACWI } & \text { Advisory Committee on Water Information } \\ \text { AHPS } & \text { Advanced Hydrologic Prediction Service } \\ \text { CUAHSI } & \text { Consortium of Universities for the Advancement of Hydrologic Science } \\ \text { EM } & \text { electromagnetic conductivity } \\ \text { EMI } & \text { electromagnetic induction conductivity } \\ \text { FEMA } & \text { Federal Emergency Management Agency } \\ \text { FIMI } & \text { Federal-Inundation Mapping Initiative } \\ \text { IDA } & \text { Instantaneous Data Archive } \\ \text { InSAR } & \text { Interferometric Synthetic Aperture Radar } \\ \text { IWRSS } & \text { Integrated Water Resources Science and Services } \\ \text { NADP } & \text { National Atmospheric Deposition Program } \\ \text { NASA } & \text { National Aeronautics and Space Administration } \\ \text { NAWQA } & \text { National Water Quality Assessment } \\ \text { NCGMP } & \text { National Cooperative Geologic Mapping Program } \\ \text { NGO } & \text { nongovernmental organization } \\ \text { NHD } & \text { National Hydrography Dataset } \\ \text { NIDIS } & \text { National Integrated Drought Information System } \\ \text { NMR } & \text { nuclear magnetic resonance } \\ \text { NOAA } & \text { National Oceanic and Atmospheric Administration } \\ \text { NWC } & \text { National Water Center } \\ \text { NWIS } & \text { National Water Information System } \\ \text { NWS } & \text { National Weather Service } \\ \text { SSPT } & \text { Science Strategy Planning Team } \\ \text { TMDL } & \text { Total Maximum Daily Load } \\ \text { USACE } & \text { U.S. Army Corp of Engineers } \\ \text { USDA } & \text { U.S. Department of Agriculture } \\ \text { USEPA } & \text { U.S. Environmental Protection Agency } \\ \text { USGS } & \text { U.S. Geological Survey } \\ \text { WSC } & \text { Water Science Center } \\ \text { WestFAST } & \text { Western States Federal Agency Support Team } \\ \text { Western States Water Council }\end{array}$




\title{
U.S. Geological Survey Water Science Strategy- Observing, Understanding, Predicting, and Delivering Water Science to the Nation
}

\author{
By Eric J. Evenson, Randall C. Orndorff, Charles D. Blome, John Karl Böhlke, Paul K. Hershberger, Victoria E. \\ Langenheim, Gregory J. McCabe, Scott E. Morlock, Howard W. Reeves, James P. Verdin, Holly S. Weyers, \\ and Tamara M. Wood
}

\section{Executive Summary}

This report expands the Water Science Strategy that began with the USGS Science Strategy, "Facing Tomorrow's Challenges-U.S. Geological Survey Science in the Decade 2007-2017" (U.S. Geological Survey, 2007). This report looks at the relevant issues facing society and develops a strategy built around observing, understanding, predicting, and delivering water science for the next 5 to 10 years by building new capabilities, tools, and delivery systems to meet the Nation's water-resource needs. This report begins by presenting the vision of water science for the USGS and the societal issues that are influenced by, and in turn influence, the water resources of our Nation. The essence of the Water Science Strategy is built on the concept of "water availability," defined as spatial and temporal distribution of water quantity and quality, as related to human and ecosystem needs, as affected by human and natural influences. The report also describes the core capabilities of the USGS in water science- the strengths, partnerships, and science integrity that the USGS has built over its 134-year history.

Nine priority actions are presented in the report, which combine and elevate the numerous specific strategic actions listed throughout the report. Priority actions were developed as a means of providing the audience of this report with a list for focused attention, even if resources and time limit the ability of managers to address all of the strategic actions in the report. Priority actions focus on the following:

- Improve integrated science planning for water.

- Expand and enhance water-resource monitoring networks.

- Characterize the water cycle through development of state-of-the-art 3-D/4-D hydrogeologic framework models at multiple scales.
- Clarify the linkage between human water use (engineered hydrology) and the water cycle (natural hydrology).

- Advance ecological flow science.

- Provide flood-inundation science and information.

- Develop rapid deployment teams for water-related emergencies.

- Conduct integrated watershed assessment, research, and modeling.

- Deliver water data and analyses to the Nation.

The body of the report is presented as a hierarchal set of 5 goals, 14 objectives, and 27 strategic actions that the USGS should undertake to advance water science over the next ten years. The goals deal with the following:

1. Providing society the information it needs regarding the amount and quality of water in all components of the water cycle at high temporal and spatial resolution, nationwide;

2. Advancing our understanding of processes that determine water availability;

3. Predicting changes in the quantity and quality of water resources in response to changing climate, population, land use, and management scenarios;

4. Anticipating and responding to water-related emergencies and conflicts; and

5. Delivering timely hydrologic data, analyses, and decisionsupport tools seamlessly across the Nation to support water-resource decisions. 


\section{Introduction}

\section{Vision for Water Science in the USGS}

The USGS will provide unbiased knowledge of the Nation's water resources to support human well-being, healthy ecosystems, economic prosperity, and anticipate and help resolve impending water-resource conflicts and emergencies.

The USGS Water Mission Area, through integrated activities with other USGS Mission Areas and partners, will serve society through water-resource monitoring, assessment, modeling, and research to provide tools that managers and policymakers can use for the following:

- Preserving the quality and quantity of the Nation's water resource, which is critical to the survival of our society, the support of our economy, and the health of our environment;

- Balancing water quantity and quality in relation to potential conflicting uses among human consumption, industrial use and electric power production, agricultural use, mineral and energy extraction, and ecosystem needs;

- Understanding, predicting, and mitigating water-related hazards such as floods, droughts, and contamination events, as well as understanding the effects of climate variability on the water resource, to foster more sustainable and resilient communities and ecosystems; and

- Quantifying the vulnerability of human populations and ecosystems to water shortages, surpluses, and degradation of water quality.

To manage water resources and to meet human and environmental needs, it is necessary to understand the effects of water quantity, timing, and quality on these systems. The USGS is in a position to provide data, understanding, and prediction tools regarding the responses of human water-resource management systems and ecosystems to hydrologic variability and change.

\section{Societal Issues and Water Science}

Water is essential to life on our planet and is the most widely used natural resource. Our own species cannot go more than 36 hours without water before our lives are endangered. Water is essential to every biological function of life. Water provides energy, food, habitat, hygiene, recreation, transportation, waste assimilation, and more.

Water availability, defined.-Spatial and temporal distribution of water quantity and quality, as related to human and ecosystem needs, as affected by human and natural influences.

The foundation for this science strategy is based on the fundamental importance (or value) of water availability in its broadest sense. Water availability, as defined here, encompasses aspects of water supplies (quantity and quality) and water needs. Water supplies are governed by a complex system of natural and human-induced processes, ranging in scope from local to global. Many of the processes affecting water supplies have changed in the past, and will continue to change in the future, on various time scales. Water needs are diverse, and they are increasingly in conflict. Water is a critical commodity for human consumption, agriculture, energy, and industry. Water is a fundamental requirement for ecosystem health, biodiversity, and resilience, and it has important recreational and aesthetic values. In many areas of the world, one or more of these aspects of water availability is under stress. Yet, the diversity of values associated with water availability makes it difficult to assess, predict, and manage water resources effectively. Improvements are needed in the characterization and understanding of water quantity and water quality if we are to maintain our society and quality of life.

Water supplies are not evenly distributed across the landscape. At all scales ranging from small subwatersheds to the Nation as a whole, water storage, movement, and quality are heterogeneous. Similarly, water needs are highly variable spatially and temporally. It is increasingly the case that water needs and water supplies are not well matched. For example, electric power plants, community water systems, and cities occupy relatively small areas in comparison to the catchment areas that ultimately supply the water they need. In many localities, water needs are being met by depleting resources that took an extended period of time to accumulate (for example, groundwater in aquifers recharged over hundreds of years). Even in some large areas of the United States, such as the Colorado River Basin, consumptive water use and losses now equal or exceed water supply (fig. 1). Therefore, it is essential to understand the spatial and temporal interactions between water supplies and needs at all scales.

Competition over water has involved conflicts over differing human uses and human uses versus ecosystem values throughout time. It is an unavoidable outcome of growing populations and increasing demands. Important issues regarding water availability include understanding and quantifying the vulnerability of human populations and ecosystems to water shortages and surpluses. Water-quality concerns include toxic chemicals, pathogens, excess nutrients and sediments, salinity, and oxygen depletion. As society has developed, questions about the quantity and quality of water have evolved from simple to complex issues in need of investigation and answers. As the population in the United States has increased, pressures on water supplies have increased. Of interest, water withdrawals in the United States increased steadily until 1980 and then declined and leveled off, indicating that some critical choices were made about water use in the last 30 years (fig. 2).

Water can also present itself as a hazard to society in the form of droughts, floods, and debris flows. Scarcity or overabundance of water causes some of society's most dangerous, 


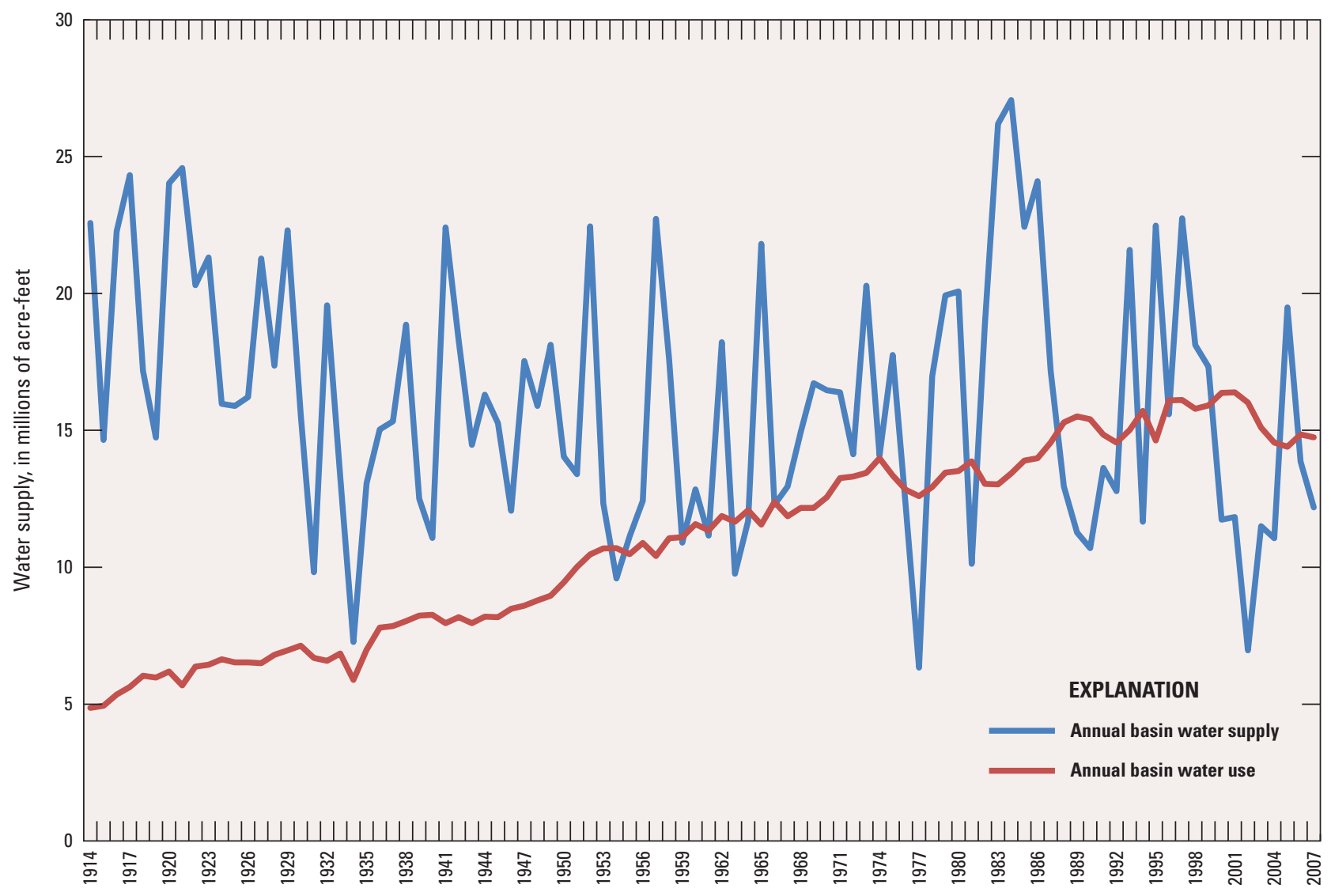

Figure 1. Colorado River Basin water supply, 1914-2007 (Bureau of Reclamation, 2011).

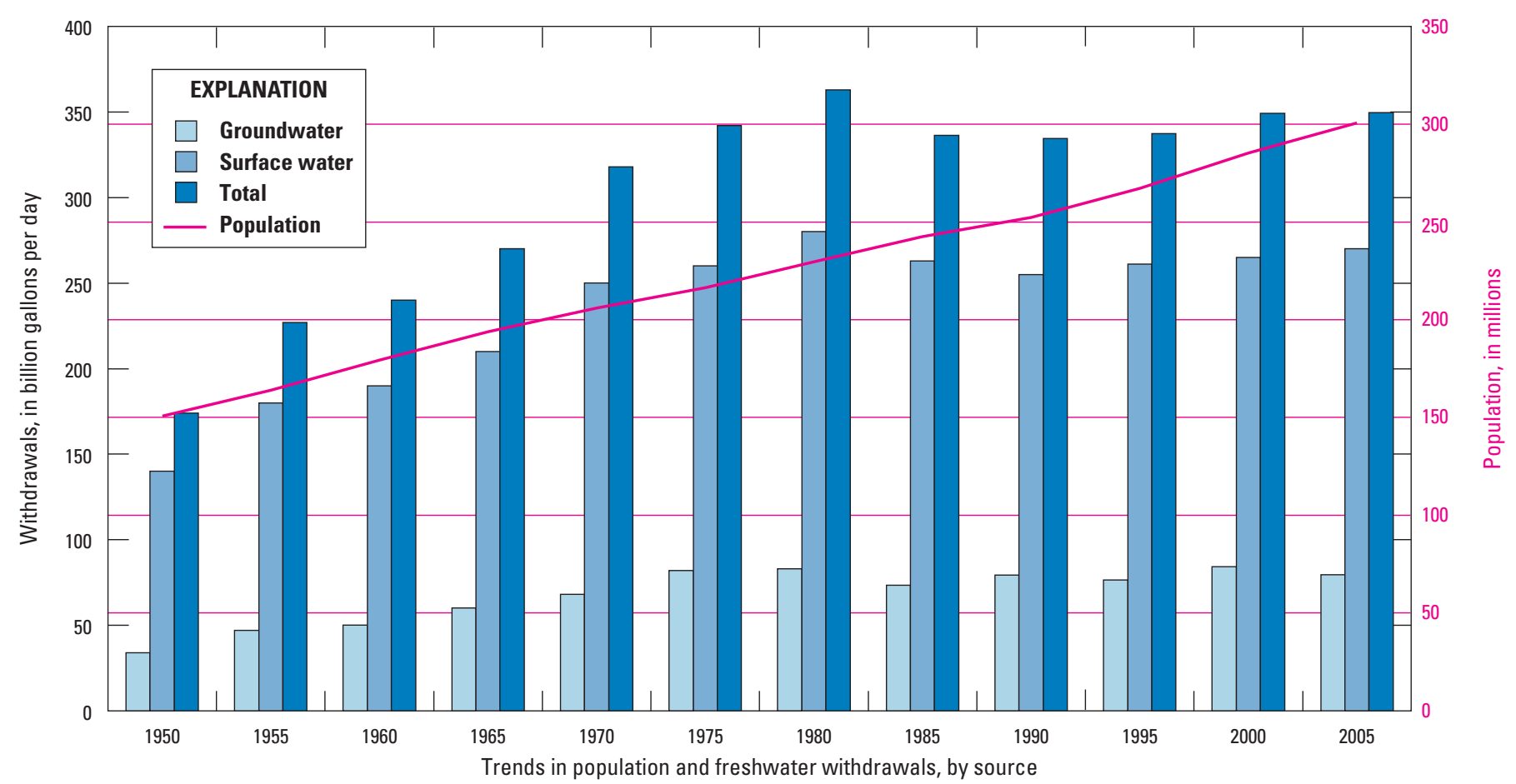

Figure 2. Trends in population and freshwater withdrawals by source, 1950-2005 (Kenny and others, 2009). 
costly, and damaging situations to human life and property. Droughts and floods rank first and second, respectively, as the most costly natural hazards we face (Bryant, 2005). It is of vital importance for our Nation to understand, predict, and mitigate these hazardous situations, and the science of hydrology is critical to undertaking this endeavor. These situations prompt questions related to the magnitude and frequency of extreme events, the landscapes and property that are at risk, and the ability of water to assimilate the wastes and chemicals accidentally or intentionally introduced into it.

To fully understand the importance of our Nation's water resources, society must assess a multitude of water-resource issues, ask the pertinent questions, and find the critical answers that will address our concerns. Broadly, the first set of societal questions relate to the need to observe the water resource.

- Where does our water come from?

- How much water do we have?

- How much water do we use?

- Is our water supply safe for people, industries, and ecosystems?

- What are the trends in our supplies of and demand for water?

- Do we have adequate information to make waterresource decisions?

Next, society moves to questions about our level of understanding and ability to predict the resource.

- How much water does our society need for the future, and is that amount sustainable?

- How can we protect our water supply, both quantity and quality, for the future?

- What can the past tell us about the future of water availability? Can human effects be clearly distinguished from natural variability? Can critical thresholds or "tipping points" be recognized or predicted?

- What new tools will be needed to improve assessment, understanding, and prediction of water availability in the future?

- Do we understand the processes near hydrologic boundaries or interfaces (for example, groundwater/ surface water, sediment/water, freshwater/seawater, and shallow/deep flow systems)?

- What are potential benefits and limitations of increased reliance on "unconventional" water resources (for example, deep saline groundwater; brackish coastal waters; enhanced water storage, recovery, and reuse)?

- How can contamination of groundwater and surface water be prevented or mitigated?

\section{The Water Budget}

Water budgets are a means of evaluating how much water is available in each "compartment" of the water cycle and whether the uses of that water are sustainable over time.

"A water budget simply states that the rate of change on water stored in an area, such as a watershed, is balanced by the rate at which water flows into and out of the area" (Healy and others, 2007).

By quantifying the various compartments of a watershed's water budget, hydrologists take the first steps in assessing water availability. One form of the waterbudget equation is

$$
\begin{aligned}
& P+Q^{s w}{ }_{i n}+Q^{g w}{ }_{i n}+Q^{s w} \text { human }_{i n}+Q^{g w} \text { human }_{\text {in }}= \\
& E T+\Delta S^{\text {sw }}+\Delta S^{\text {snow }}+\Delta S^{g w}+Q^{\text {gw }}{ }_{\text {out }}+R O+Q^{b f}+
\end{aligned}
$$

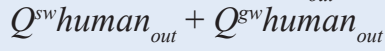

where

$$
\begin{aligned}
& P \quad \text { is precipitation, } \\
& Q^{s w} \text { in surface-water flow into the } \\
& \text { watershed, } \\
& Q^{g w}{ }_{i n} \quad \text { is groundwater flow into the } \\
& \text { watershed, } \\
& Q^{\text {sw }} \text { human }_{\text {in }} \quad \text { is water returned by humans to } \\
& \text { surface water, } \\
& Q^{g w} \text { human }_{\text {in }} \text { is water returned by humans to } \\
& \text { groundwater, } \\
& \text { ET is evapotranspiration, } \\
& \Delta S^{\mathrm{sw}} \quad \text { is change in surface-water storage, } \\
& \Delta S^{\text {snow }} \quad \text { is change in snow and ice storage, } \\
& \Delta S^{g w} \quad \text { is change in groundwater storage, } \\
& Q^{g w}{ }^{w} \text { iut } \text { is groundwater flow out of the } \\
& \text { watershed, } \\
& R O \text { is surface runoff, } \\
& Q^{b f} \quad \text { is base flow out of the watershed, } \\
& Q^{\text {sw }} \text { human }_{\text {out }} \text { are water withdrawals by humans } \\
& \text { from surface water, and } \\
& Q^{\text {gw }} \text { human }_{\text {out }} \text { are water withdrawals by humans } \\
& \text { from groundwater. }
\end{aligned}
$$

By measuring or estimating the amount of water for each of these terms over time for watersheds across the Nation, hydrologists can provide users with the capability to calculate water budgets for their areas of interest. The water-budget equation can become as detailed as the user requires if general terms in the equation are separated into component parts representing processes within the watershed. For example, in this equation, surface-water flow out of the basin has been separated into the components of streamflow: runoff and base flow. 
- How can water-related hazards be prevented or mitigated?

- What principles should guide optimization of water availability for multiple uses (that is, drinking water,

Streamgage 03479000 Watauga River near ecosystems, agriculture/energy/industry), and how Sugar Grove, North Carolina, December 8, 2010. should water management adapt to changing conditions?

Photograph by John A. Mazurek, USGS. 


\section{Core Capabilities: Strengths, Partnerships, and Science Integration- What We Do Now that is Important and Needs to Continue}

The Water Science Strategy is based on four guiding principles: observe, understand, predict, and deliver. Integrated observations of the entire water cycle are the cornerstone for water-availability science in terms of quantity and quality. Understanding the water cycle is a hallmark of the unbiased science that the USGS is known for. The science we produce is applied to societal relevance by predicting changes to water availability in response to events such as sea-level rise and climate and land-use change, and informing society during water conflicts and emergencies such as floods, droughts, and waterquality degradation. To sustain the resource and contribute to safety in society, water data and science must be delivered to the public and other scientists. These guiding principles are reflected throughout this strategy and the development of its goals, objectives, and strategic actions.

The USGS is the premier water-monitoring and science Bureau within the Federal Government. The USGS works within the Water Mission Area through a variety of programs that serve to observe, understand, and predict components of the water cycle, which are the guiding principles of this report. The guiding principles are critical to societal issues involving water resources. Core capabilities include the following:

- Observe.-The USGS operates and maintains national hydrologic monitoring networks consisting of more than 8,000 streamgages, 1,900 continuous waterquality monitoring stations, and 250 precipitation monitoring stations, and monitors 20,000 groundwater observation wells. USGS programs that support these networks include the Water Cooperative Program, National Streamflow Information Program, National Stream Quality Accounting Network, as well as others. Nationwide assessments and discontinuous monitoring of water storage, movement, and quality are conducted periodically by various USGS programs. The USGS also maintains the Nation's only comprehensive program for estimating water use. The USGS operates a system of state-of-the-art water-quality laboratories for aqueous chemistry, isotope hydrology, microbiology, and sediment. The USGS laboratory capabilities include the National Water Quality Laboratory, producing more than 30,000 analyses per year. USGS laboratories have pioneered efforts to establish protocols for the collection and analysis of constituents that occur at very low concentrations. The USGS Hydrologic Instrumentation Facility provides hydrologic instrumentation, hardware, and software to support water-resource science. Support also is provided through development, testing, evaluation, repair, calibration, and quality control of hydrologic instrumentation. The USGS is the steward of Landsat - the world's longest continuously acquired collection of space-based moderate-resolution land remote-sensing data. Nearly four decades of imagery provide a unique resource for water-resource understanding and research. Landsat images are also invaluable for rapid response to water-related emergencies. In addition, the use of extensometers coupled with satellite radar (InSAR) imagery is a technique used by the USGS to characterize and model aquifer system compaction and land subsidence. Furthermore, the USGS has an institutional commitment to make the data collected by the Bureau available to the public, including Internet access through the Web pages of the National Water Information System.

- Understand.-The USGS carries out numerous scientific investigations designed to improve understanding of processes affecting water availability that can lead to more informed decisions by water managers dealing with national, regional, and local water-resource issues. Many such investigations are carried out through the USGS network of Water Science Centers and through a variety of programs such as the Water Cooperative Program, the Groundwater Resources Program, the National Water-Quality Assessment Program, and the Toxic Substances Hydrology Program. The USGS also maintains a strong research presence in water-resource science through its National Research Program. The USGS conducts intensive research and develops new tools and concepts for use by the scientific community at large. USGS research adds value to monitoring and assessment activities, provides unbiased interpretations of specific water-resources issues, and advances general knowledge of hydrologic principles. An important feature of USGS research is the synergy of local studies, national surveys and syntheses, laboratory experiments, and method-development activities that are dispersed among its varied programs. USGS scientists also contribute expertise and maintain proficiency by interacting externally with academia, industry, and other government agencies.

- Predict.-The USGS provides data, information, and tools that are useful to predicting long- and short-term changes within the water cycle. Historical data from hydrologic networks, combined with other tools such as paleohydrology, can provide information on trends such as the effect of climate change on timing of seasonal streamflow in rivers - an important consideration for flood control and water supply. The USGS produces, maintains, and freely distributes numerous computer programs that are used for research and predictions in hydrology and geochemistry. Examples include SPARROW, a model that computes delivery of 
water-quality constituents in rivers and streams, based on watershed characteristics; MODFLOW, considered the international standard for simulating and predicting groundwater conditions and groundwater/surface-water interactions; PHREEQC, one of the most popular codes used for modeling chemical reactions and movement in groundwater; and GSFLOW, a rapidly developing integrated tool for understanding and predicting transient stream responses to precipitation and complex watershed processes, and many other codes.

- Deliver-The USGS is known for long-term storage and delivery of real-time and historical hydrologic data. The USGS National Water Information System (NWIS) database includes millions of data entries for surface water, groundwater, and water quality that are easily accessible through the World Wide Web. USGS real-time water data are served more than 20 million times per month. The USGS also delivers numerous scientific reports and journal articles on our Nation's water resources every year; these publications are the product of a stringent peer review system and are almost without exception publicly available through multiple outlets, including the Internet.

The USGS is distinguished for its proficiency in the following:

- Measurements of streamflow.

- Flow statistics.

- Flood monitoring and post-flood data recovery.

- Flood-frequency analysis.

- Measurement and understanding of groundwater at local and regional scales.

- Understanding geologic framework controls on groundwater.

- Development of computer models of water, sediment, and chemical transport.

- Understanding aquifer-system compaction and land subsidence.

- Age-dating of water and sediments.

- Chemical and isotopic tracer techniques in hydrologic and biogeochemical investigations.

- Water-quality sampling and analysis.

- Relating water quality to causative factors.

- Development of water-quality statistical models.

- Field methods, data collection, and preservation of hydrologic information.

- Water-use estimation.

- Development of water-information databases.
- Training the next generation of water scientists and technicians.

Along with this proficiency, however, is acknowledgment of the uncertainty in water science. Scientists struggle with uncertainty in terms of how to adequately assess it; how to understand uncertainty; how to control it; and how to effectively communicate the uncertainty of the science with science information products. Understanding uncertainty in water science is essential for resource managers and others who use water data and information in decision making. Uncertainty is an inherent factor in hydrologic data collection, estimation techniques, and simulation modeling. Errors associated with measurement techniques arise from the inability to accurately measure specific aspects of the hydrologic system, such as streamflow, the water level in a well, or soil properties that control evapotranspiration and runoff. Uncertainty arises from the inadequacy of data collection networks to fully characterize natural spatial and temporal variability associated with hydrology, geology, climate, and land use. Uncertainty also is present in simulation models because it is impossible to thoroughly reproduce a natural hydrologic system in a model.

An additional USGS objective is to reduce uncertainty in the highest priority water data and information. Improvements in the spatial and temporal coverage of data collection networks, the techniques for measuring flows, and improved estimation techniques with data layers that account for more of the factors that influence variability will lead to reduced uncertainty in the information provided to the public. Additionally, the USGS will make a strategic effort in the future to estimate or quantify uncertainty associated with its information products.

USGS strengths that benefit the Water Mission Area and underscore the above four guiding principles include national quality-assurance standards and policies; the long-term retention of hydrologic data, reports, and other products; and the unbiased science that underlies every mission activity of the Bureau. Two other major strengths of the USGS are a business model that supports a high level of partnering with other agencies, academia, and the private sector; and a diverse workforce of scientists and physical-science technicians from multiple disciplines that allows the Bureau to bring an integrated scientific approach to water-resource problems.

USGS water science starts within Water Science Centers, located in every State and in Puerto Rico. These Water Science Centers build important relationships with State and local agencies that are vital to the management of water resources in the United States. These Water Science Centers are supported by a regional and national structure that includes offices dedicated to the development of models, methods, tools, databases, and quality-assurance measures to support the Water Science Centers and maintain consistency in USGS work. Many of the national priorities of the USGS Water Mission Area are carried out through the network of Water Science Centers. Another hallmark of the USGS is the nationwide consistency that it brings to water data collection, analysis, and interpretation. This consistency allows the valid comparison of data 
across many locations and at multiple scales. Water science is furthered by the USGS National Research Program, which advances the science of hydrology to keep the USGS on the cutting edge. Finally, collaboration and joint project investigations with other USGS Mission Areas lend strength to USGS integrated science. The USGS is a multidisciplinary scientific Bureau: disciplines represented within the Bureau include hydrology, engineering, geology, geography, ecology/biology, meteorology, and social sciences. With a workforce of more than 8,000 employees with diverse backgrounds, education, and experience, the USGS can bring an integrated approach to the Nation's water-resource issues. The interdisciplinary nature of the USGS workforce and organizational structure brings strength to its capability. Critical to understanding and optimizing water availability is knowledge about how geology, climate, and humans interact with the water cycle at all time scales (fig. 3). An important component of such research is analysis of former conditions (historical and pre-historical) for insights about modern processes and trends. A few examples of where the USGS has worked effectively to help answer interdisciplinary questions include research into how climate affects water movement and storage, how geology affects movement of water and persistence of contaminants, how streamflow affects aquatic and riparian ecosystems, and how energy and mineral-resource development affect water resources, among many other questions.

An additional key strength of the USGS is its development of partnerships in the conduct of its water science.

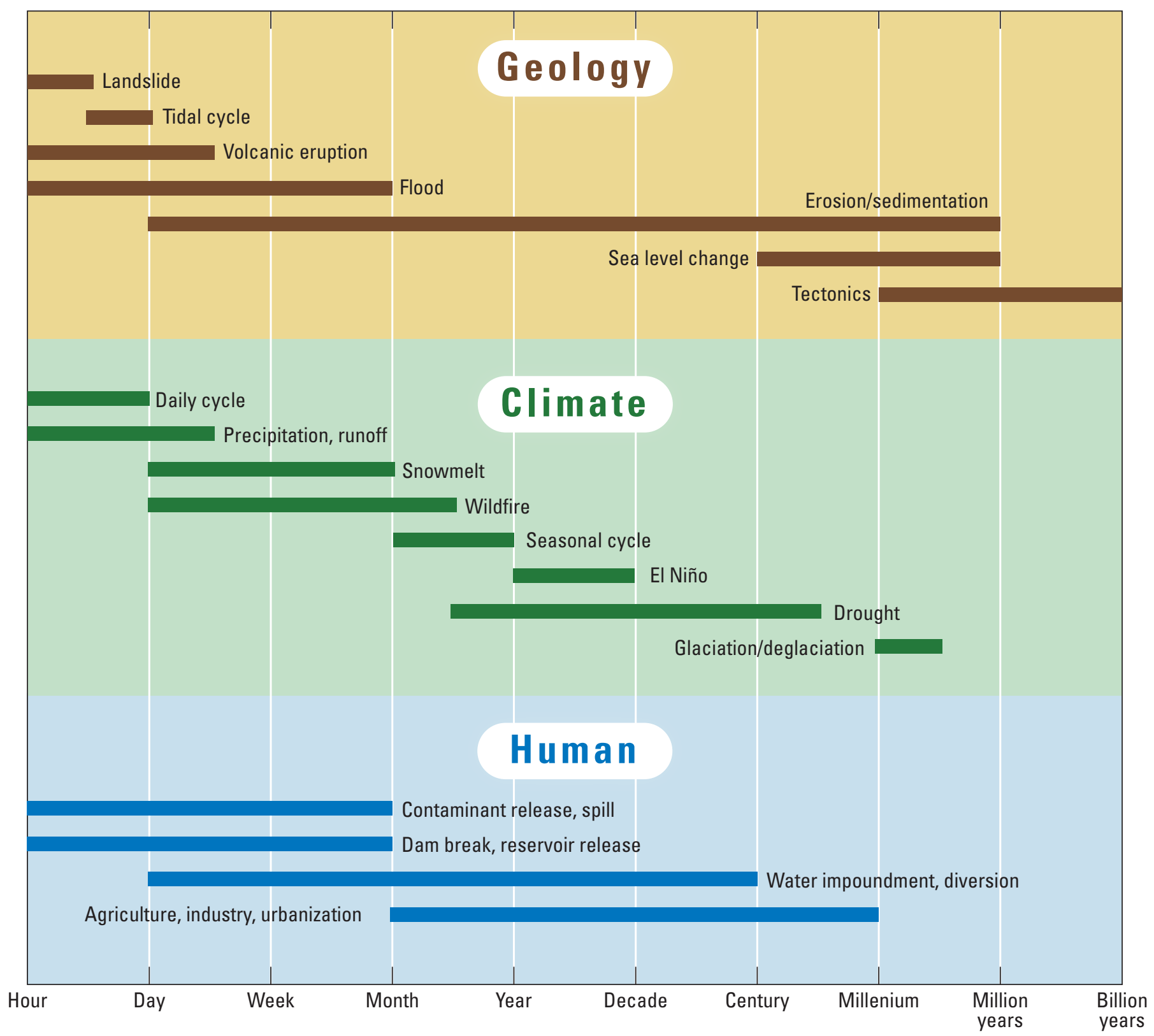

Figure 3. Time scales of various geologic, climatic, and human events. 
Through the Cooperative Water Program, the USGS partners with more than 1,800 State, Tribal, county, local, regional, and watershed agencies in accomplishing its mission. Key Federal partners include Bureau of Reclamation, U.S. Fish and Wildlife Service, National Park Service, Bureau of Land Management, Bureau of Indian Affairs, U.S. Department of Defense (including U.S. Army Corps of Engineers), U.S. Environmental Protection Agency (USEPA), National Oceanic and Atmospheric Administration (NOAA) and National Weather Service, U.S. Department of Agriculture (USDA), National Atmospheric and Space Administration (NASA), National Geospatial Intelligence Agency, National Science Foundation, and U.S. Department of Energy. USGS scientists also work with numerous academic institutions, providing training and collaboration for faculty and students. Without these partnerships, the Water mission of the USGS could not be fulfilled. The USGS is always seeking opportunities to strengthen and expand its network of partners. To this end, the USGS will increase its role in the future in interagency collaborative work through institutions such as the Advisory Committee on Water
Information (ACWI), the Integrated Water Resources Science and Services (IWRSS) consortium, and the National Integrated Drought Information System (NIDIS). The USGS Water Mission Area brings hydrologic understanding to questions that logically intersect with the missions of these partner agencies. A good example of how partnership could be strengthened around mutual interests in the future is an opportunity to work with the USDA to integrate studies of agriculture and water availability. USDA expertise, models, and data for crop systems, soils, and drainage could be coordinated with USGS expertise in groundwater and surface-water movement and quality to yield important insights for best management practices relating to water use and water quality. Similarly, collaborative work with NOAA could result in integrated studies of climate, precipitation, and watershed processes, with each agency providing strength in its areas of expertise. Collaboration with NASA could further improve understanding of earth and hydrologic processes through remote sensing and spatial imagery. Collaborative work with USEPA could improve understanding of linkages between contaminant distributions,

\section{Geochronology/Paleohydrology - Interpreting the Past as Key to the Future}

Information about the past can provide insights about events and processes that may affect the future. USGS scientists use a variety of techniques for determining ages of groundwater, rocks, and sediments (geochronology) that can be used to reconstruct the past, where historical records are absent or incomplete, on time scales ranging from months to millions of years. Ages of such materials are estimated from laboratory measurements of radioactive isotopes and other environmental tracers-including both natural and artificial constituents - and by examining the fossil record.

Concentrations of natural radioactive carbon-14 in flooddeposited sediments can be used to determine recurrence intervals of catastrophic floods or debris flows on time scales of thousands of years, thus providing important information about hazards that may not be available from historical records (paleohydrology). Carbon-14 content of dissolved carbon can be used to determine where aquifers contain groundwater that recharged thousands of years ago and where modern recharge is limited.

Similarly, ages of stratified sediments in lakes, reservoirs, and estuaries can be used to determine sedimentation rates, document climate change effects on water levels and nutrients, and reconstruct past changes in concentrations of sediment-bound constituents such as toxic metals and organic contaminants. For example, figure 4 shows the vertical distribution of ages and lead concentrations in a sediment core from the bottom of an impounded lake (Callender and Van Metre, 1997). Changes in lead concentrations of

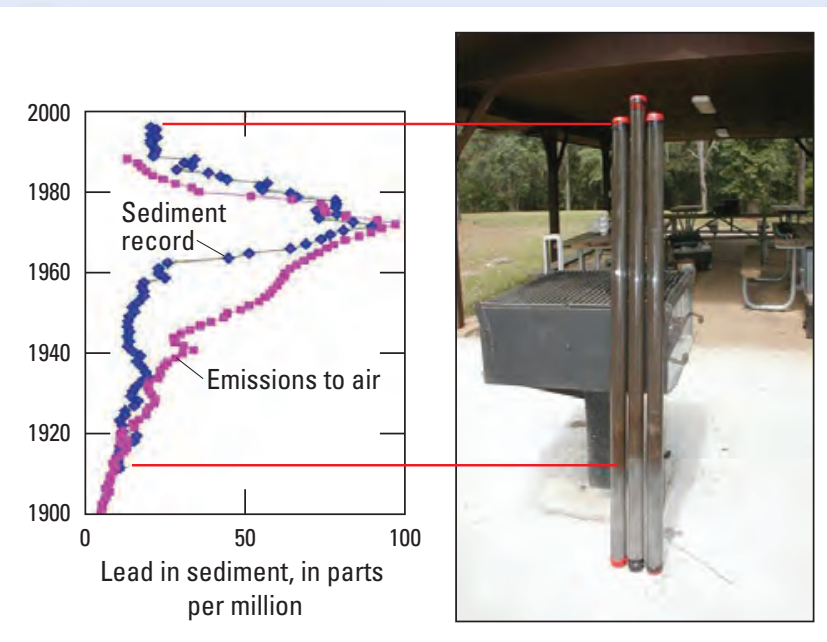

Figure 4. Vertical distribution of ages and lead concentrations in a sediment core from the bottom of an impounded lake (Callender and Van Metre, 1997).

sediments that accumulated on the lake floor during the 20th century were related to the history of lead emissions to the atmosphere, which decreased abruptly after lead reduction in gasoline in the 1970s. Sediment ages were estimated from the distribution of radioactive cesium-137. Lead emissions are in relative units (scale not shown). Applications of geochronologic techniques commonly reflect team efforts involving specialized laboratories, multidisciplinary field investigations, and computer simulation capabilities. 
hydrogeologic processes, and human and ecosystem effects. Partnership opportunities extend well beyond Federal agencies to academia and nongovernmental organizations (NGOs). USGS does, and should in the future, look to these prospects for mutual advancement of hydrologic science. The USGS through the National Cooperative Geologic Mapping Program (NCGMP) STATEMAP component partners with State geological surveys to provide geologic maps and frameworks important for identification and characterization of the Nation's aquifers. NCGMP had determined that most geologic maps in the United States are related to groundwater issues (Orndorff and others, 2008). In the recent past the USGS has advanced the area of environmental flow science through a liaison position with the Nature Conservancy. The USGS has worked to advance access to hydrologic information through joint opportunities with the Consortium of Universities for the
Advancement of Hydrologic Science (CUAHSI). The USGS is also a partner in the Western States Federal Agency Support Team (WestFAST). WestFAST is a collaboration between 11 Federal agencies with water management responsibilities in the West. WestFAST was established to support the Western States Water Council (WSWC), and the Western Governors Association in coordinating Federal efforts regarding water resources. The USGS views WestFAST as a prime model of partnerships in action and should be replicated in other venues. The USGS also benefits from being informed, involved, and educated by other agencies and organizations on the science, monitoring, tools, and strategies they are developing. The USGS sees these and similar collaborative efforts as vital to successful water-resources science endeavors and important for the future of the Nation's water availability.

\section{Priority Actions}

This report details the strategic science directions for the Water Mission Area. The section entitled "Water Science Goals and Objectives" specifically outlines the strategic actions. In "Water Science Goals and Objectives," five goals of the Water Science Strategy speak to emerging issues identified by the USGS and major stakeholders. Priority Actions provides a short discussion emphasizing the highest priority actions that incorporate multiple goals, expanding on them, and in places integrating them with the work of the other Mission Areas (table 1). Priority actions were developed as a means of providing the audience of this report with a list for focused attention, even if resources and time limit the ability of managers to address all of the strategic actions in the report. Priority actions aggregate virtually all of the 27 strategic actions into eight areas where future changes could have the greatest impact. The first priority action, "Improve integrated science planning for water," influences all strategic actions and requires no additional resources to implement, only a change in planning philosophy. For this reason, it is not included in table 1 with the other eight priority actions.

\section{Improve Integrated Science Planning for Water}

Understanding the hydrology of the United States requires a multitude of scientific disciplines, working in concert, to produce the water-resource information that our society needs. To work effectively requires the integration of expertise and knowledge, along with deliberate and careful planning. The USGS can and should take a leadership role in this kind of integrated science planning for water resources. The USGS should renew the way it plans and implements water science by recognizing that program integration entails joint planning, joint funding, and coordinated program execution toward a common goal. The USGS and science branches within other agencies need to plan together so that we and other agencies can execute programs in concert and generate products collaboratively. The USGS should look for opportunities where its Water programs can intersect and build synergy with other science programs. The USGS can do more science and make better use of its resources if it improves the integration of its water-science planning and execution where these opportunities exist.

The Water Census provides the USGS with the opportunity to integrate our efforts on groundwater, surface water, water quality, biology, ecology, geography, remote sensing, geology, and climate variability to answer key questions about water availability. This opportunity extends well outside of the USGS to other Federal, State, regional, and local agencies who have complimentary programs and goals. The USGS should lead the way and demonstrate how science disciplines plan together for deliberate outcomes in water-availability science that are achieved through coordinated program implementation.

\section{Expand and Enhance Water-Resource Monitoring Networks}

Monitoring networks that generate hydrologic data are the foundation of any understanding of the Nation's hydrologic systems; they provide information that is critical for defining, using, and managing our water resources. The USGS has a real-time network of more than 8,000 streamgages that monitor stage and streamflow; 1,400 wells that monitor groundwater levels in real time; and more than 1,900 locations where real-time water-quality parameters such as dissolved oxygen, $\mathrm{pH}$, temperature, and specific conductance are monitored. However, the coverage of these networks (particularly 
groundwater and water quality) is neither funded consistently at the national level nor ideally distributed across the landscape; further, water quality and quantity information collected by other qualified resource partners is not currently included in USGS datasets. To assist the Nation with a better understanding of the quantity and quality of our surface-water and

Table 1. Links of priority actions to goals and strategic actions.

Priority Action. Expand and enhance water-resource monitoring
networks

Goal 1, Strategic Action 4

Goal 2, Strategic Action 9

Goal 3, Strategic Actions 13, 16, 18

Goal 4, Strategic Actions 19, 22

Goal 5, Strategic Action 25

Priority Action. Clarify the linkage between human water use (engineered hydrology) and the water cycle (natural hydrology)

Goal 1, Strategic Actions 2, 3, 6, 8

Goal 2, Strategic Actions 10, 11, 12, 13

Goal 3, Strategic Actions 14, 15, 16, 17, 18

Goal 4, Strategic Actions 22, 23, 24

Goal 5, Strategic Actions 25, 26, 27

Priority Action. Advance ecological flow science

Goal 1, Strategic Action 1

Goal 2, Strategic Actions 11, 13

Goal 3, Strategic Action 14

Goal 5, Strategic Actions 25, 26, 27

Priority Action. Provide flood-inundation science and information

Goal 1, Strategic Actions 1, 2, 3, 4

Goal 4, Strategic Actions 19, 20, 21, 22

Goal 5, Strategic Actions 26, 27

Priority Action. Develop rapid deployment teams for water-related emergencies

Goal 1, Strategic Actions 1, 2, 3

Goal 4, Strategic Actions 20, 21, 22, 23, 24

Goal 5, Strategic Action 27

Priority Action. Conduct integrated watershed assessment, research, and modeling

See Goals 1-4

Priority Action. Deliver water data and analyses to the Nation

Goal 4, Strategic Action 19

Goal 5, Strategic Actions 25, 26, 27 groundwater systems, it is the goal of the USGS to maximize our monitoring capabilities in the following ways:

- Design and develop a more nationally consistent, federally funded backbone network of surface-water, groundwater, and water-quality monitoring stations that is supplemented by the use of qualified records collected and furnished by local, State, or other Federal agencies.-This concept has been explored and embraced by the Subcommittee on Ground Water under the Advisory Committee on Water Information (ACWI) as part of its National Ground Water Monitoring Network design and should be expanded to include surface-water and water-quality monitoring stations as well. The design of these networks must be linked to allow the capacity to monitor changes in the combined hydrologic system.

- Capitalize on existing streamgage infrastructure to install "super gages" that integrate many types of monitoring sensors and thus record and transmit many kinds of data parameters at key monitoring locations.-Examples can include meteorological data, chemical data related to water quality, and physical data such as water temperature, water velocity, and suspended-sediment data measured through optical or hydroacoustic surrogates. Super-gage locations should be targeted to provide real-time data specifically designed to improve understanding of watershed processes and to address specific water-resource issues such as climate and land-use effects, waterrelated human health issues, floods and droughts, or hazardous-substance spills.

- Consider customer requirements for hydrologic monitoring data to ensure that USGS hydrologic monitoring networks meet multiple Bureau mission requirements and serve as broad a base of user needs as possible.-Examples can include working with NOAA and State and local emergency management to ensure streamgage data meet flood forecasting and warning requirements, and considering the data needs of large water consumers when examining groundwater observation well network optimization.

\section{Characterize the Water Cycle Through Development of State-of-the-Art 3-D/4-D Hydrogeologic Framework Models at Multiple Scales}

Characterizing and predicting water availability at the spatial and temporal scales needed to understand and manage water resources require the integration of hydrologic and earth science data with state-of-the-art geologic, geophysical, and geochemical models. Geological information mapped at the surface must be projected into the subsurface (3-D) to 


\section{Real-Time Data and the "Super Gage"}

The USGS operates and maintains national hydrologic monitoring networks consisting of more than 8,000 streamgages that typically provide water stage data and volumetric streamflow data. Often, other parameters are monitored at streamgage sites, such as water temperature, precipitation, and water quality. The physical infrastructure of a streamgage and the data recording and telemetry instrumentation it contains makes the streamgage an ideal platform for measuring and transmitting a variety of parameters-simultaneously, in real time - to examine unique trends in water resources in a critical resource area such as agricultural and urban land-use effects, water-related human health issues, floods and droughts, or hazardous-substance spills. The USGS has developed the "super gage" concept to describe such streamgages.

An example of a super gage is White River at Hazleton, Indiana (USGS streamgage 03374100). This is a large-river site with a drainage area of 11,305 square miles of primarily agricultural land. Parameters collected at this streamgage are the following:

- Physical water parameters: stage, streamflow, water velocity, water temperature, and suspended sediment (using measurements of turbidity as a surrogate).

- Water-quality parameters: dissolved oxygen, specific conductance, $\mathrm{pH}$, and nitrate.

The USGS and partner agencies will use these data to assess environmental impacts of agricultural and other land-use practices through a better understanding of short-term, long-term, and seasonal trends and through more accurate water-quality modeling.

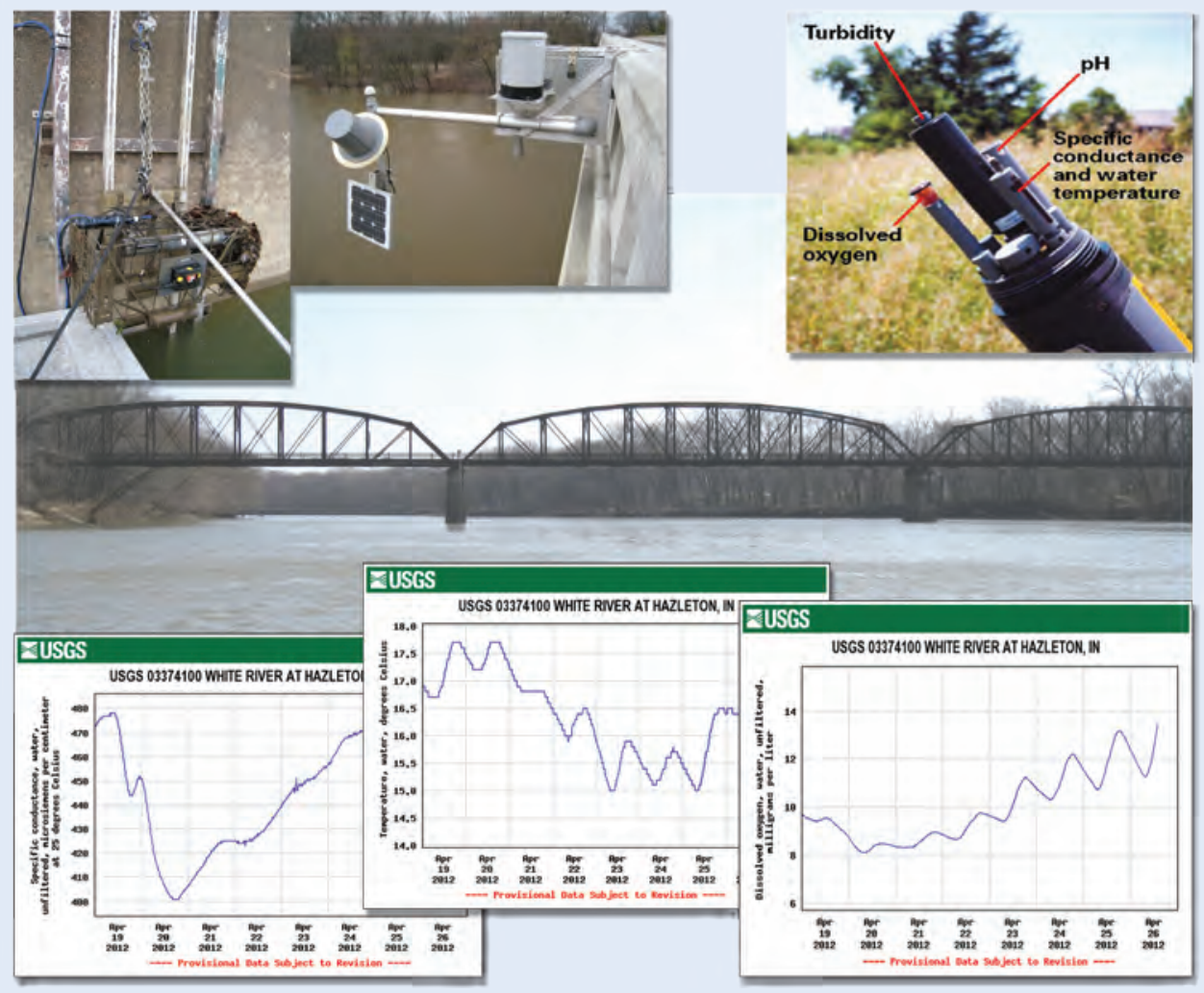

Figure 5. Example of a super gage is White River at Hazleton, Indiana (U.S. Geological Survey streamgage 03374100).

determine the features (such as faults or fine-grained layers that are impermeable) that influence groundwater storage, flow, and quality. These features (the geologic framework) need to be translated into hydrogeologic properties that may vary with time (4-D).

The Merriam-Webster online dictionary defines "dimension" as a measure in one of three or four coordinates determining a position in space and time. Two dimensional (2-D) space in modeling is represented with a simple geometric shape with length and width ( $x$ and $y$ dimensions, respectively), whereas three dimensions or 3-D includes the representation of depth ( $z$ dimension). Unlike 2-D space, the use of 3-D incorporates volume and depth. Modeling of fourdimensional space includes the factor of time ( $t$ dimension) or motion to a 3-D object, entity, or unit. For example, instead of characterizing the static subsurface geology of an aquifer system, 4-D geologic modeling can provide a better understanding of how the rock properties (including water/rock interactions, fluid saturation, and geochemistry) can change over time. 


\section{Geologic Complexities}

Water, and its movement through the water cycle to the land surface and subsurface, is dependent on the interplay of geologic and hydrologic frameworks through time. This interaction also affects both water quantity and quality. The geologic frameworks of both surface-water and groundwater systems can be quite diverse, ranging from streams, lakes, and aquifers that are surrounded by surficial deposits to those dominated by fractured bedrock and even volcanic deposits. Faulting and fracturing, dissolution in carbonate rocks, alteration, and thermal history also can affect the physical properties of surficial- and bedrock-dominated groundwater systems.

Using geology as a template, a hydrogeologic framework forms a foundation for the modeling of hydrologic properties that control flow direction, storage, and quality. For example, in the Santa Rosa Plain in northern California, geologic drillhole data and geophysical gravity modeling have provided the boundary extents of a basin-fill aquifer and the aquifer's confining layer containing impermeable bedrock (Sweetkind and others, 2010; fig. 6). Three-dimensional modeling and drillhole data also can be used to determine the hydraulic permeability of an aquifer and reveal how permeability can abruptly change across the basin.

Hydrogeologic models demonstrate the importance of integrating geologic, geospatial, and hydrologic data and using improved methods for modeling the data across multiple scales.

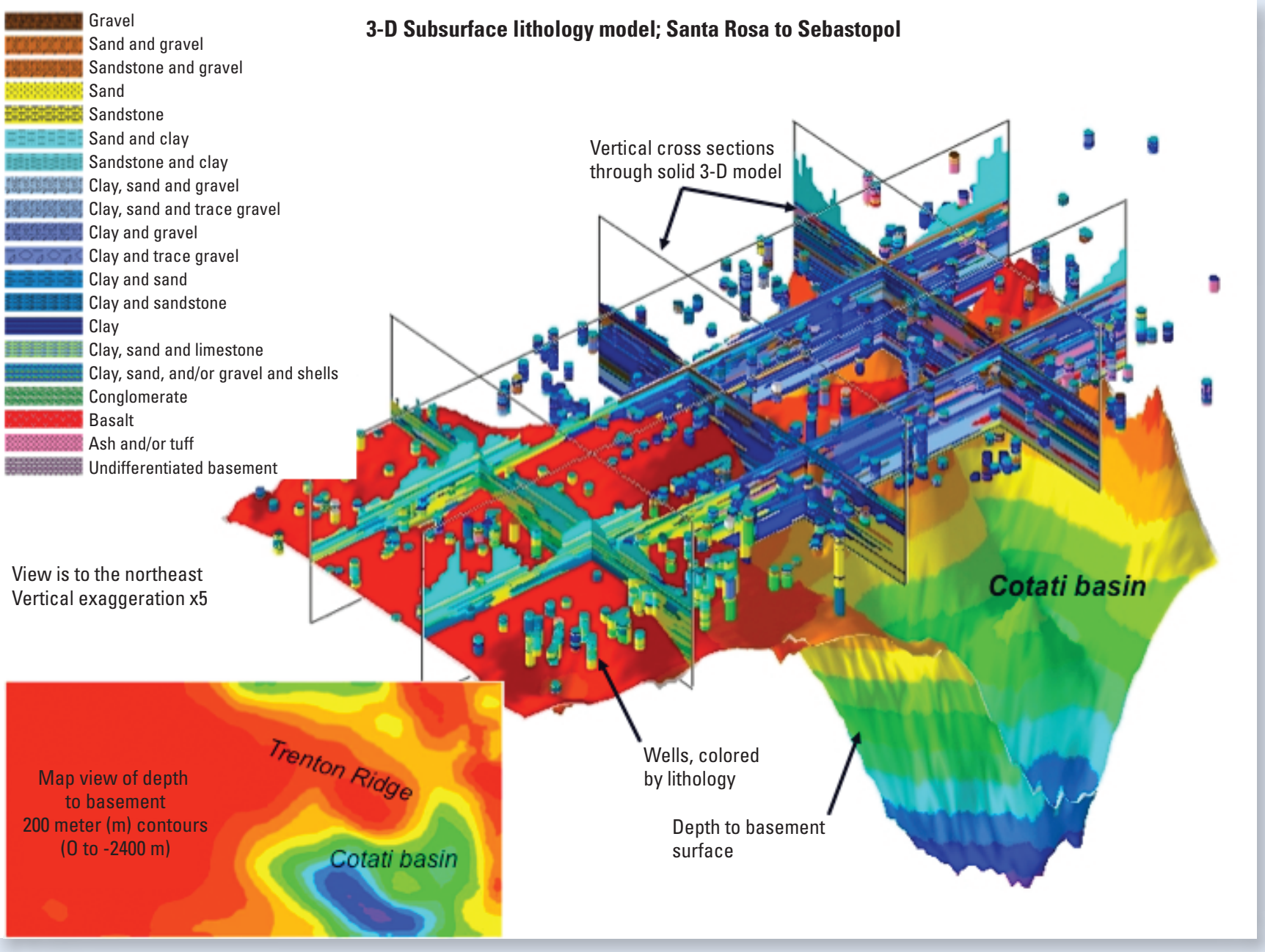

Figure 6. Boundary extents of a basin-fill aquifer and the aquifer's confining layer containing impermeable bedrock (Sweetkind and others, 2010). 
The spatial domain of the hydrogeologic framework models will need to extend from near the ground surface (for example, models for characterizing surface-water/groundwater interactions) to the bottom of deep aquifers (for example, regional flow models for characterizing brackish waters). The models will integrate the natural variability of physical, chemical, and hydrologic properties at all spatial and temporal scales. This integration also must involve the use of multidirectional approaches and interdisciplinary feedback to answer complex questions such as, "How do earth science systems affect water movement and chemical transport?" Emerging societal issues will demand a better understanding and assessment of the changing hydrogeologic and biogeochemical conditions commonly associated with stressed or marginal-water aquifers. Characterizing the depth of freshwater circulation in gas shale exploration or contamination issues associated with concealed faults resulting from hydrofracking or $\mathrm{CO}_{2}$ sequestration are two societally relevant examples.

The assignment of hydrologic properties to geologic framework models also will promote the development of new tools, techniques, and concepts, given the challenge of modeling the subsurface with properties where few direct observations are available. Integration of 3-D framework and property models may include the discretization of temporal data into 4-D subsurface grids for predicting real-time flow-pathway, storage-capacity, and water-quality data. This interdisciplinary integration provides a means of testing and enhancing our understanding and knowledge of the hydrogeologic processes controlling the water cycle. Discretization of framework- and property-model data also can be incorporated into studies only marginally related to water availability and quality, such as studies of the various effects of mineralization and maturation on oil and gas resources.

\section{Clarify the Linkage Between Human Water Use (Engineered Hydrology) and the Water Cycle (Natural Hydrology)}

The USGS is the premier water-use science Bureau in the Nation; however, the Bureau has yet to realize its full potential for collecting, analyzing, integrating, and reporting water-use information. An extensive analysis of the water-use program in the USGS and potential improvements for the future was published by the National Research Council as "Estimating Water Use in the United States: A New Paradigm for the National Water-Use Information Program" (Committee on USGS Water Resources Research, 2002).

The USGS should aggressively implement the National Research Council recommendations and take definitive action to integrate water use with its information on the rest of the water cycle through actions that include integrating water-use databases; using modeling and statistical designs in wateruse estimation; improving the geospatial information on site-specific water-use features; revitalizing consumptive-use estimation; quantifying and locating interbasin transfers; and linking water-use information with water budgets, watershed and aquifer analyses, and StreamSTATS. StreamSTATS is a web-based geographic information system that allows users to easily obtain streamflow statistics, drainage-basin characteristics, and other information for user-selected sites on streams. These data also should be linked to assessments of marginal resources, water-quality criteria for different uses, treatment options, and factors affecting conservation and reuse.

\section{Advance Ecological Flow Science}

Ecological, or environmental, flows are defined as the quantity, timing, and quality of water flows required to sustain freshwater and estuarine ecosystems and the human livelihoods and well-being that depend on these ecosystems. These water flows broadly include streamflows and the variation of water levels in lakes, streams, and wetlands because the variation in water levels, not solely volumetric flows, are recognized to play an important ecological role (fig. 7). Ecological flow science incorporates several of the strategic actions within the Water Mission Area strategic plan and may serve as a powerful integrating theme for work within the Water Mission Area and between the Water and Ecosystems Mission Areas. The quantification of ecological flows is built on observed streamflow records across diverse settings, from

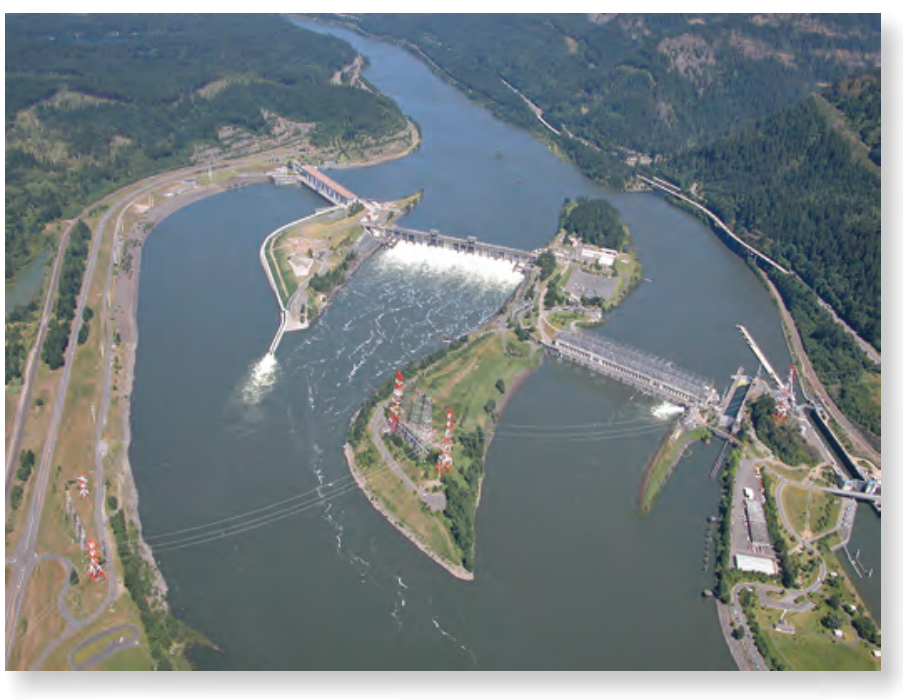

Figure 7. Bonneville Dam, the first of 14 dams in place on the Columbia River main stem, between Oregon and Washington. Dams provide flood control, power generation, and water supplies for irrigation and human consumption; however, they dramatically alter ecological flows and impact native floral and faunal assemblages. For example, the dams on the Columbia River represent barriers for the migration of threatened and endangered salmonids. The U.S. Geological Survey is involved in integrated biological, hydrological, and geological studies to understand the recovery of ecological systems after the removal of derelict hydroelectric facilities, including two dams on the Elwah River in Washington State. 
a range of stream sizes, for a sufficient length of time. Understanding flow processes, processes controlling water quality, and interrelations between water flow, water quality, and ecology is required to develop stream-ecosystem relations and to determine relevant flow attributes that can be used to classify streams into types. Predictive modeling to extend streamflow records to ungaged locations and to estimate the interaction of future water withdrawals, land-use or climate variability, or other changes in condition is required to inform management decisions seeking sustainable ecological flows. The suite of core capabilities required for this work will need to be developed within the USGS, as will new techniques and methods to effectively provide this information and analysis to the Nation.

\section{Provide Flood-Inundation Science and Information}

Floods are the leading cause of natural-disaster losses in the United States. A powerful tool for flood response and mitigation is digital geospatial flood-inundation mapping that shows floodwater extent and depth on the land surface. The USGS has been developing a national flood-inundation program (http://water.usgs.gov/osw/flood_inundation/). The USGS, working with NOAA, the U.S. Army Corps of Engineers, Federal Emergency Management Agency (FEMA), other Federal, State, and local government agencies, universities, and the private sector, should continue development of a science-based flood-inundation mapping program that would include the following:

- Static flood-inundation map libraries, linked to USGS streamgages and National Weather Service (NWS) flood-forecast points, consisting of a set of flood extent and depth maps developed for predetermined stream stage intervals and served through the World Wide Web. Development of these libraries will require collection, processing, and dissemination of land use, elevation, and bathymetric data (LiDAR is a particularly important source of these data); development and application of 1-D and 2-D inundation models; streamflow data collection; and ongoing map maintenance. LiDAR data, in particular, will be needed to provide the best possible products and will require leveraging the use of existing and planned LiDAR datasets from within the USGS and from partner organizations.

- Development of state-of-the art dynamic, real-time flood-inundation applications to meet a host of partner and cooperator needs, from flood response and mitigation to dam- and levee-breach simulations. These applications involve a higher level of science and technologies than static maps, and the USGS can make substantial advances in this area.

- Development of a core science team of personnel from the USGS and other Federal and local partner agencies tasked with the development of flood-inundation tools that fulfill multiple Bureau missions and thus provide the most benefit to the Nation's communities and citizens at risk from floods.

\section{Develop Rapid Deployment Teams for Water- Related Emergencies}

The USGS should develop "rapid-deployment teams" and accompanying response plans that would ensure the Bureau properly responds to water-related emergencies and waterrelated conflicts. These multidisciplinary teams would draw expertise from USGS headquarters and science centers and would maintain a suite of scientific hardware and software to provide partner agencies with information during emergencies. The teams would activate and operate according to detailed response plans. Each plan would include information on the following:

- The monitoring of USGS real-time data and other resources to identify potential events that would require activation of a team. (This would include plans that would provide USGS staffing and resources to monitor conditions around the clock, all year.)

- Coordination with other relevant agencies such as NWS River Forecast Centers and FEMA Emergency Operation Centers on event monitoring and team activation.

- Criteria for triggering team activation.

- Personnel —including team expertise, size, structure, and organization.

- Scientific instrumentation and equipment, including vehicles (for example, boats, trucks, all-terrain vehicles, aircraft).

- Remote-sensing needs (for example, tasking acquisitions by satellites and aircraft).

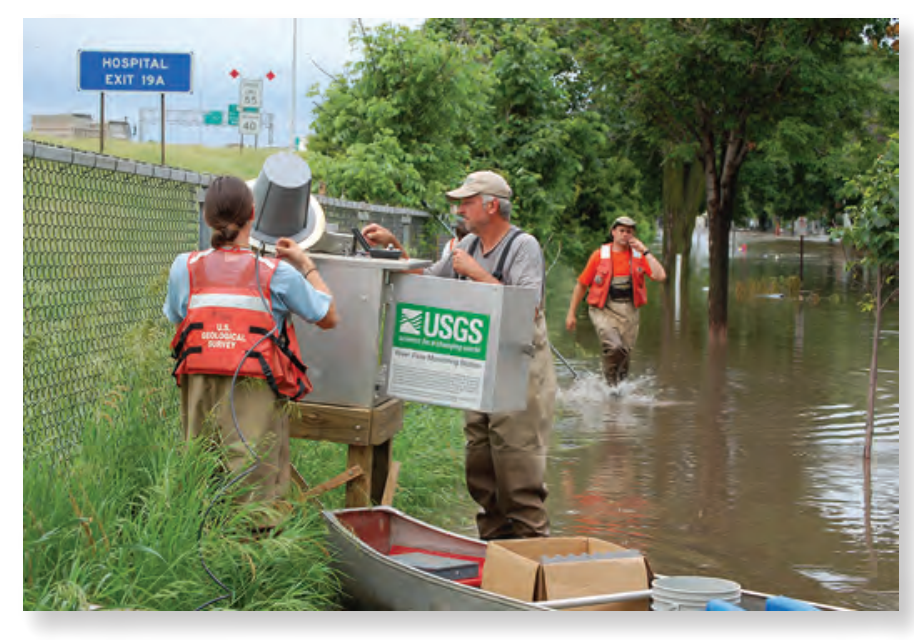


- Research priorities to mobilize the appropriate USGS research scientists to study the specific hazard and hazard impacts, with the goal of improving understanding and providing better planning, response, and recovery for future events by using science-guided principles.

This action builds upon USGS successes responding to major riverine flood events by installing "rapid-deployment" real-time streamgages in critical ungaged areas and by installing temporary submersible water-level sensors ahead of major hurricanes to record storm-surge flooding. Rapid-deployment team activities would best be coordinated through a multiagency effort. A potential location for such multiagency coordination is the Integrated Water Resource Science and Services (IWRSS) National Water Center (NWC) at the University of Alabama, Tuscaloosa. The NWC is intended to provide the USGS, NWS, and U.S. Army Corps of Engineers (USACE) an operations center for water analysis, forecasting, and decision support (Interstate Council on Water Policy, 2011).

\section{Conduct Integrated Watershed Assessment, Research, and Modeling}

To fully comprehend the water cycle, water availability, human and ecosystem responses, and management options, it will be important to incorporate a wide variety of information in a watershed context. A stepwise approach to such integration could include synthesis of available information for selected watersheds. Large-watershed syntheses would be aimed at highlighting key interactions between physical, chemical, geological, and biological processes in the context of natural and human influences, and identifying important gaps in data or understanding. This information would provide guidance for targeted studies to be carried out in a stable framework of small to large watershed research sites with multidisciplinary objectives. A long-range goal of such studies would be to have integrated models for predicting water availability and optimizing water management at the scale of large watersheds, or river basins. Progress toward this goal could include development and application of increasingly comprehensive statistical and numerical models for understanding monitoring data, such as real-time water-quality data at streamgages, and ecosystem responses to short-term climate and land-use stressors. Near-term products could include summary reports linking current data and factors affecting water availability in one or more watersheds that represent important water issues.

\section{Deliver Water Data and Analyses to the Nation}

To accomplish the priority actions, the USGS must develop integrated information systems and means for disseminating information appropriate for 21st-century technology. Science information has value, and this value is best realized when its quality is apparent and it is easy to access. Priority actions such as flood-inundation mapping and response to water-related emergencies will best be served with real-time information and use of World Wide Web and smart-phone applications. Water-related databases also can be integrated with other sciences to better understand water interactions with socioeconomic factors, ecosystems, human uses, agriculture, and industry. One area in which the USGS can take the lead is employing map interfaces for geospatial searches, a means that will predominantly be used by the public to locate information. For example, water information related to groundwater needs to be displayed to users in four dimensions for the hydrogeologic frameworks and the flow models. The USGS must build and promote the systems that can adequately serve and communicate this information. By setting up clearinghouses of information and models, scientists can find and apply the best information in understanding realworld issues. In turn, these models can be used for decision support throughout society.
Facing page: USGS hydrographers respond to the flood of June 11, 2008, in Cedar Rapids, lowa. Photographs by Don Becker, USGS.

Right: High school students participate in World Water Monitoring Day, Onondaga Creek, New York, October 7, 2010. Photograph by Scott Grover, USGS.

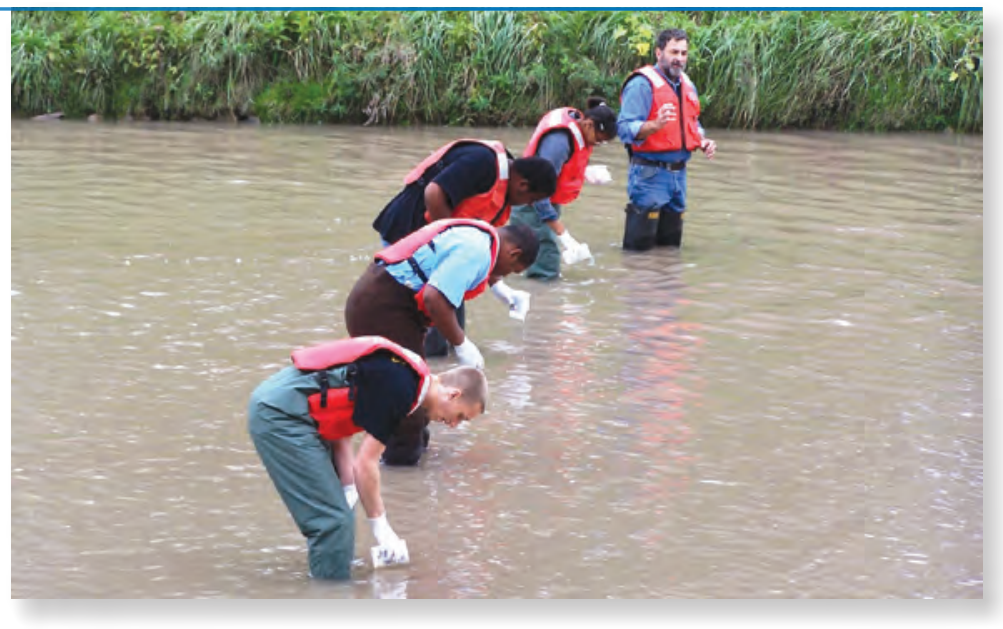




\section{Water Science Goals and Objectives}

The five goals of this Water Science Strategy speak to issues expected to emerge in the next 5 to 10 years and the scientific research and outcomes needed to address them. These issues were identified by the USGS through input from USGS employees and from major stakeholders. Each goal frames major societal water-resources questions relevant to the goal and then provides objectives to answer those questions; and for each objective, specific strategic actions are provided. The goals support the guiding principles of the Water Mission Area Science Strategy - observe, understand, predict, and deliverand are developed with integration of the other USGS science Mission Areas through their links to the water cycle (fig. 8). Each goal was developed with the understanding that spatial concepts from local to national scales, variation of time scales from daily to decadal to historical to geologic time, recognition of trends in data, world-class laboratories and monitoring networks, degrees of uncertainty, and development of new techniques and delivery of information are important. It is recognized through these goals that unbiased science outcomes are developed from keen observation and monitoring of complex systems and understanding those systems. The important scientific outcomes can then be applied to predicting changes in the water cycle into the future and informing during water emergencies and conflicts. The five science goals build upon existing USGS core capabilities and strengths and follow the four actions of observing, understanding, predicting, and delivering. Goal 1 is based mainly on integrated observations of the entire water cycle, looking at water availability in terms of quantity and quality. These observations follow onto the understanding of the water cycle of Goal 2, the excellent unbiased science that the USGS is known for. The science we produce is applied to societal relevance in Goals 3 and 4 by predicting changes to water availability in the water cycle in response to events such as sea-level rise, land-use change, and climate change, which may require alternative resources, and by anticipating water conflicts and emergencies such as floods, droughts, and declining water quality. To sustain the relevance of the USGS and contribute to safety in society, water data and science must be delivered to the public and other scientists; Goal 5 looks at current and emerging technologies to effectively deliver our science through integrated databases with other geoscience disciplines, interoperable models and decision-support tools, and social media.

The goals presented in this report are interconnected. For example, delivering information and science outcomes discussed in Goal 5 ties to all of the other goals. Data from Goal 1 need to be made available for all to use. The science generated in Goal 2, as well as the trends in data and conclusions on predicting future water availability and hazards in Goals 2, 3 and 4, also need to take advantage of emerging technology to be delivered to society. Table 2 lists the strategic actions for each goal so the reader can follow the flow of goals and the specific action for each.

\section{Goal 1: Provide Society the Information It Needs Regarding the Amount and Quality of Water in All Components of the Water Cycle at High Temporal and Spatial Resolution, Nationwide}

To answer society's basic questions about water availability, we need detailed observations of the Nation's water cycle. Assessing water availability involves understanding the storage and movement of water through the cycle, and this understanding can be achieved only through a robust system of observation networks and basic assessment tools that allow users to quantify each component of the cycle and assess trends in those components through time. Monitoring networks also are used to support models that estimate parameters for unmonitored areas and time periods. Society's questions about water availability include the following:

- Where does our water come from?

- How much water do we have?

- How much water do we use?

- Is our water supply safe for people, industries, and ecosystems?

- What are the trends in our supplies of and demand for water?

- Do we have adequate information to make waterresource decisions?

The availability of water is defined not only by quantity but also by quality. Many naturally occurring and humansynthesized substances limit the suitability of water for one or more important uses if they occur at high enough concentrations. For example, the U.S. Environmental Protection Agency (2009) estimates that more than one-third of U.S. streams and rivers are impaired or polluted. Changes in the quality of groundwater, which is the source of drinking water for 130 million Americans and 40 percent of U.S. irrigation water (Hutson and others, 2004), have been documented in every State; thus, it is critical to national water security that a commitment be made to establish and maintain a national network to measure the occurrence (concentration) of these substances in our water - consistently, and over the long term.

The design and establishment of water-monitoring networks can serve many purposes. Streamgages monitor flow that is useful for water supply, water quality, flood assessment, flood warning, watershed function analyses, and many other functions. Sometimes the design of a monitoring network is targeted at a specific aspect of the water cycle, such as the way the National Atmospheric Deposition Program (NADP) is targeted at monitoring the precipitation chemistry across the landscape. Another example of a targeted network is the USGS Hydrologic Benchmark Network, which monitors 
Table 2. List of goals and strategic actions.

Goal 1: Provide society the information it needs regarding the amount and quality of water in all components of the water cycle at high temporal and spatial resolution, nationwide

Objective 1: Advancement of hydrologic monitoring networks and techniques

Strategic Actions 1, 2, 3, 4

Objective 2: Advancement of monitoring networks and techniques for determining water-quality

Strategic Actions 5, 6, 7

Objective 3: Assessment of water resources and their suitability to meet human and ecosystem needs

Strategic Action 8

\section{Goal 2: Advance understanding of processes that determine water availability}

Objective 1: Comprehensive understanding of geological controls of water availability, and improved integration of geologic and hydrologic multidimensional models

Strategic Action 9

Objective 2: Comprehensive understanding of the effects of climate variation on water availability at multiple spatial and temporal scales Strategic Action 10

Objective 3: Comprehensive understanding of the interactions among aquatic ecosystems, hydrology, and hydrochemistry

Strategic Action 11

Objective 4: Comprehensive understanding of human interactions with water availability

Strategic Action 12, 13

Goal 3: Predict changes in the quantity and quality of water resources in response to changing climate, population, land-use, and management scenarios

Objective 1: Development and application of models to predict the potential effects of changes in population, land-use, climate, and management practices upon future water availability considering human and ecological needs

Strategic Actions 14, 15, 16, 17

Objective 2: Prediction of the availability of alternative (impaired) water resources, and the effects of using these water sources on the environment

Strategic Action 18

\section{Goal 4: Anticipate and respond to water-related emergencies and conflicts}

Objective 1: Identification of current and future threats to communities from water-related hazards

Strategic Actions 19, 20

Objective 2: Development and deployment of observational systems for identifying and tracking hydrologic hazards, making operational decisions during extreme hydrologic events, and providing data for recovery

Strategic Action 21

Objective 3: Through an understanding of the conditions leading to water shortages that result in conflicts, provide assistance to communities in finding science-based solutions when conflicts occur

Strategic Actions 22, 23

Objective 4: Providing tools that allow managers to detect and respond to emergencies related to water-quality degradation of all kindsnatural, accidental, and intentional

Strategic Action 24

Goal 5: Deliver timely hydrologic data, analyses, and decision-support tools seamlessly across the Nation to support water-resource decisions

Objective: Development of new, integrated information dissemination in formats appropriate for the 21 st century to aid scientists and decisionmakers

Strategic Actions 25, 26, 27

flows and stream-water quality in small, relatively undisturbed watersheds. This discussion is provided to draw attention to the need to consider the role of broad, national monitoring designs, as well as designs targeted at specific aspects of water resources. The network design should be suited to the answers being sought from the resulting information (Hirsch and others, 2006). 


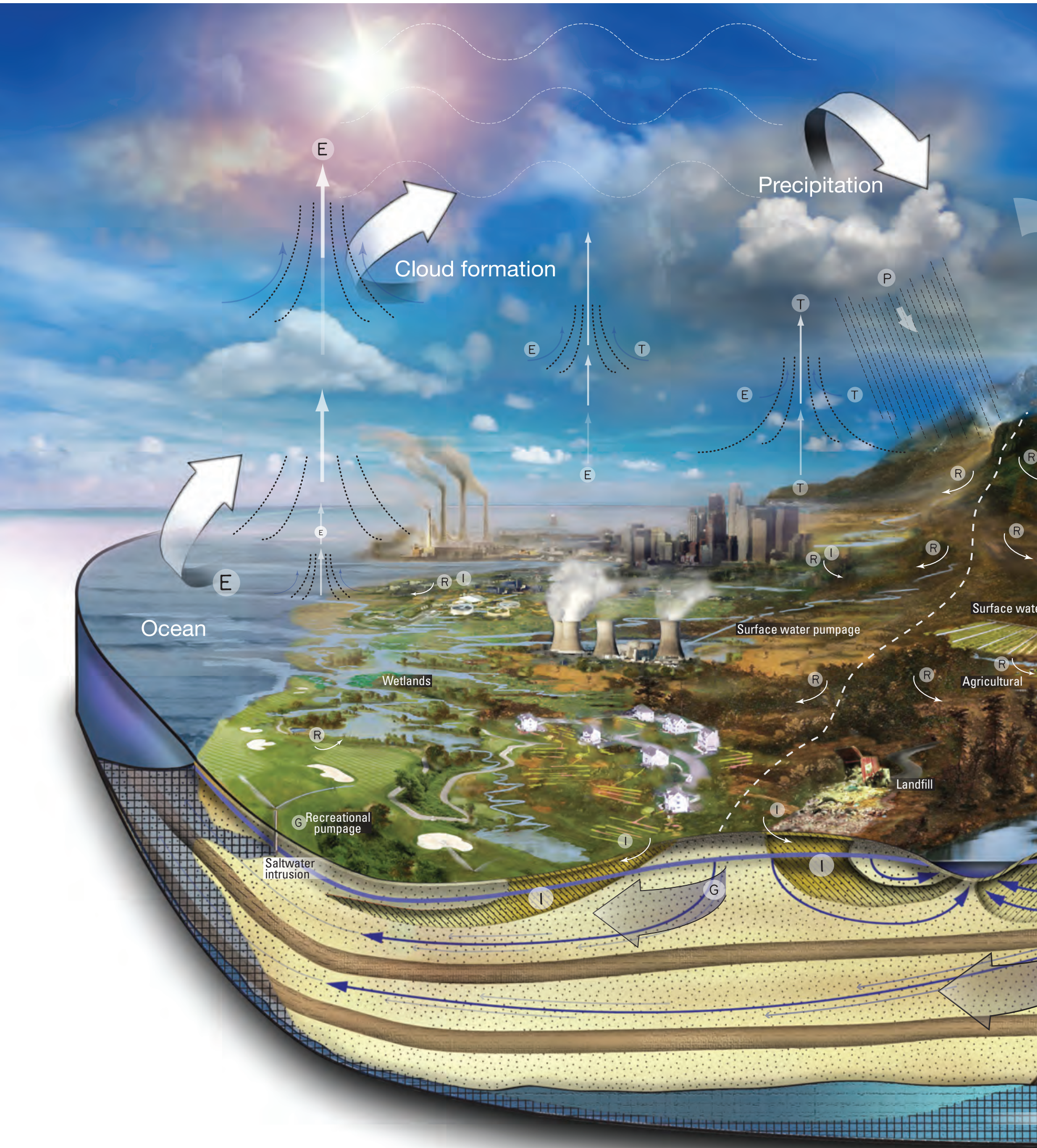

Figure 8. The water cycle. 


\section{Use of Continuous Water-Quality Monitors for Real-Time Regulatory Decisionmaking- The Tualatin River Success Story}

The Tualatin River water-quality monitors are an excellent example of how continuous water-quality monitors can be used for real-time regulatory management. Several Total Maximum Daily Loads (TMDLs) have been written for the Tualatin River, including one for ammonia. When this TMDL was revised in 2001, the wastewater discharger (Clean Water Services of Washington County, Oregon) was given the flexibility to discharge different ammonia loads depending on the capacity of the river to assimilate those loads.

This flexibility is exercised in real time with the use of continuous water-quality monitors operated by the USGS. Figure 9 shows a plot of the various dissolved oxygen parameters that are monitored or calculated for this purpose and the diversion dam at which one of the monitors is located. Two such monitors are located approximately 1.5 days traveltime downstream from large advanced wastewater treatment facilities. When the real-time dissolved oxygen monitors in the river indicate that the river has no extra assimilative capacity (dissolved oxygen concentration statistics are less than the State of Oregon minimum standard), then the treatment facilities are held to their most strict TMDL limits for ammonia. However, when the river has "extra" assimilative capacity-that is, when readings from the real-time instream dissolved oxygen monitors indicate oxygen levels are above the standard by a certain amount-then Clean Water Services has the flexibility to discharge ammonia loads that are higher than their strictest TMDL limits. In this way, the water-quality monitors are used for real-time continuous feedback regarding the water-quality status of the river and are used for real-time management and regulatory decisionmaking.

Figure 9. A, Plot of dissolved oxygen concentration data at Oswego diversion dam (U.S. Geological Survey streamgage 14207200; http://or.water.usgs.gov/tualatin/monitors/oswegodam_ do_30.htm/ and computed statistics that are used by managers to compare the water quality in the Tualatin River to the State of Oregon standard in real time. $B$, Photograph of Oswego diversion dam on the Tualatin River near West Linn, Oregon.
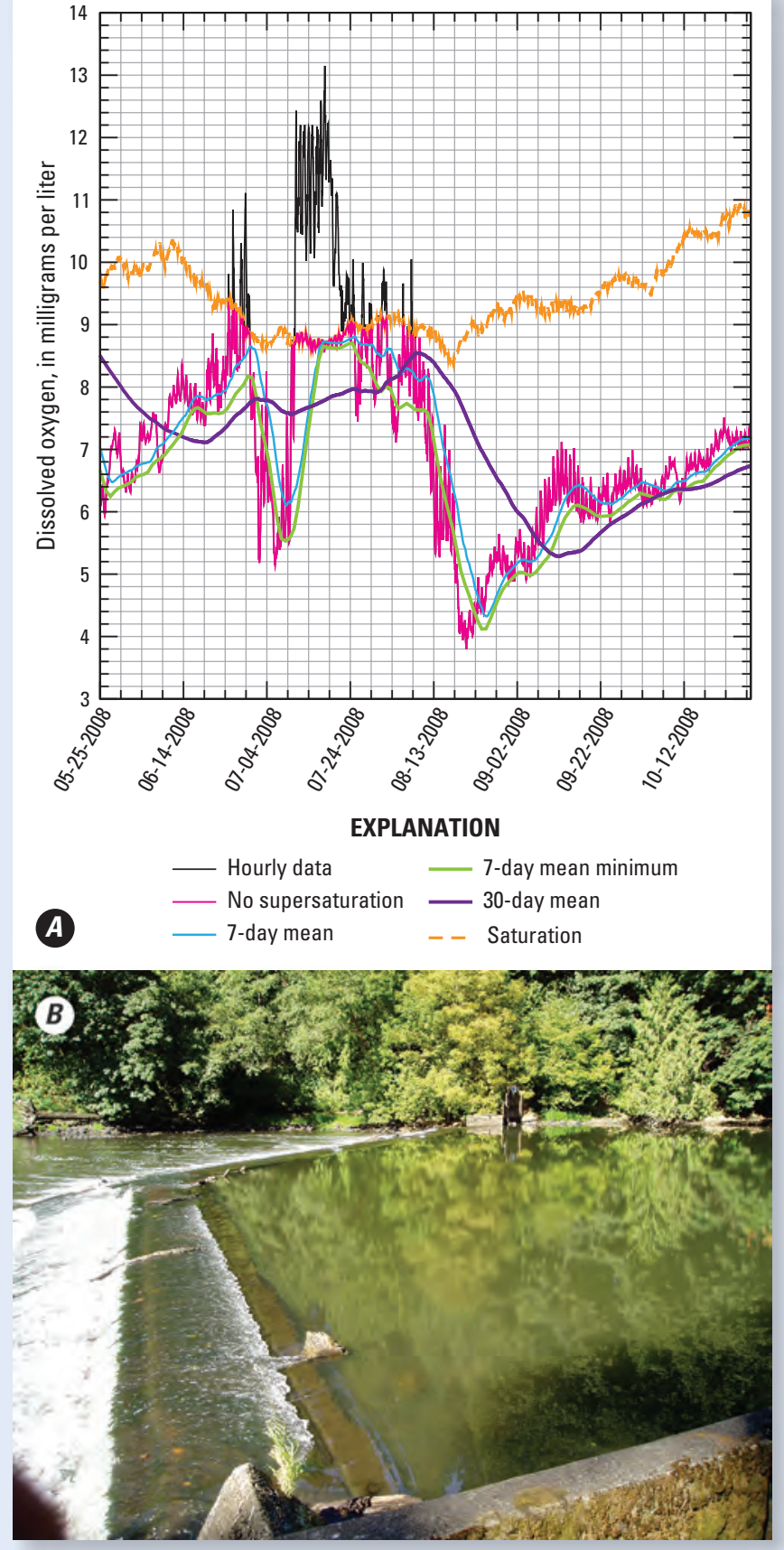


\section{Objective 1: Advancement of Hydrologic Monitoring Networks and Techniques}

Understanding water budgets and the water cycle is dependent on the accurate measurement of volumes within each compartment and the rate at which water moves between compartments. Routine measurement of these quantities typically is accomplished through networks of monitoring stations that measure the compartments and transfer rates of the water cycle such as groundwater storage; surface-water flow and storage (including lake levels, snowpacks and icepacks); precipitation; evapotranspiration; water use by humans for drinking, irrigation, energy, and other needs; and water returned to the cycle through wastewater streams. Additionally, techniques have been developed to augment networks and estimate components of the cycle that are difficult to measure, such as the transfer between surface water and groundwater. In addition to the demands placed on water supplies by humans, ecosystems have water needs that must be met if they are to be sustained, and quantification of those needs is required to complete an understanding of the water budget.

The USGS already operates networks that measure components of the water cycle. The USGS network of active streamgages includes more than 3,000 sites that have records of 30 years or more (http://waterwatch.usgs.gov). The USGS network of active groundwater-level network sites is composed of more than 20,000 wells that are sampled yearly or more frequently (http://groundwaterwatch.usgs.gov/). These networks provide a starting point, but improvements in spatial coverage, an expansion to more components of the water cycle, and the commitment to long-term records is required to meet the Nation's needs for these types of data. The USGS also collects and aggregates information on water withdrawals (http://water.usgs.gov/watuse). This information needs to be expanded to include information on conveyances, consumptive uses, and return flows.

A concept that should be further used in network design and operation is the development of a Federal core backbone network of stations and measurements supplemented by the use of records collected by and furnished by other agencies. This concept has been explored and embraced by the Subcommittee on Ground Water under the Advisory Committee on Water Information (ACWI) as part of their National Ground Water Monitoring Network design. It is strongly recommended that this concept be evaluated for all other hydrologic networks operated by the USGS to see where networks may be strengthened and extended through this type of design and the incorporation of qualified records furnished by other agencies.
More can be read about the work of the Subcommittee on Ground Water and their work on the National Ground Water Monitoring Network design at http://acwi.gov/sogw/pubs/tr/ index.html or in their publication "A National Framework for Ground-Water Monitoring in the United States" (Advisory Committee on Water Information, 2009).

In addition to monitoring networks, society demands hydrologic information at spatial and temporal scales that far exceed the capabilities of all water-resource agencies to provide direct measurements. These information needs can be fulfilled only through a robust capability to estimate parameters for unmonitored areas and time periods. Techniques should be developed to improve our ability to estimate hydrologic parameters where and when measurements cannot be made. These techniques include, but are not limited to, modeling the use of remote-sensing information. Remote-sensing data such as land use, land cover, elevation, evapotranspiration, snow cover, precipitation, vegetation indices, energy budget, gravity, and thermal infrared information should be fully integrated with monitoring information and models to extend understanding of the hydrologic systems and draw further relations between these data and hydrologic responses. A key requirement for hydrologic analysis of surface-water-network information is the National Hydrologic Dataset (NHD) maintained by the USGS, which allows spatial orientation of upstream and downstream features within a watershed context.

Strategic Action 1.-Maintain and enhance existing national networks that accurately measure, analyze, and report information about each of the compartments of the water cycle. Improve and expand networks and techniques to reduce uncertainty about the resource to an acceptable level and to expand our capability to estimate the resource in ungaged or unmeasured areas.

Strategic Action 2.--Seek ways to expand the Nation's understanding of the hydrologic resource not only through its own monitoring networks but also through optimizing the use of hydrologic data collected by and through other public agencies. Work through the Advisory Committee on Water Information (ACWI), as has been done through the National Ground Water Monitoring Network, to establish a systematic approach for the utilization of records furnished by others for all major quantity compartments of the water cycle.

Strategic Action 3.-Devote expanded resources to the integration of remote-sensing products into hydrologic modeling analyses for parameter estimation, forcing, and verification of modeled states and fluxes. Establish closer links between USGS hydrologists and remote-sensing experts, as well as with other agencies that collect, analyze, and use remotely sensed information for modeling.

Strategic Action 4.-Direct resources to defining a set of hydrologic parameters that can be researched in the paleorecord and developed into a time series of data for the purpose of deep-time trend analysis. At a minimum, this would include flood flows and recurrence; drought recurrence; changes in storage in lakes, wetlands, snow, and icefields; and changes in groundwater storage. 


\section{Objective 2: Advancement of Monitoring Networks and Techniques for Determining Water Quality}

The USGS should leverage its core capabilities and maintain and enhance its infrastructure of monitoring sites so as to determine the distribution of basic water-quality characteristics in the Nation's surface waters and groundwaters, as well as naturally derived and human-derived contaminants that have the potential to limit the use of water for drinking or limit its ability to support ecosystems. In conjunction with this effort, the USGS should determine the variability of these characteristics and contaminants on time scales from daily to seasonal to decadal. The USGS WaterQualityWatch Web site (http://waterwatch.usgs.gov/wqwatch/) provides a user interface to more than 1,600 active, real-time, continuous water-quality records and demonstrates the potential for these networks; however, major improvements in spatial coverage, the number of water-quality characteristics measured, data delivery, and commitment to long-term records is required to meet the Nation's needs for these types of data.

With regard to surface-water networks and use of current technology, several important water-quality parameters can be measured reliably by automated sensors (primarily, but not limited to, temperature, $\mathrm{pH}$, dissolved oxygen, specific conductance, nitrate, dissolved organic carbon, and turbidity). Several other important contaminants that cannot be measured directly with automated sensors can, nonetheless, be estimated with these sensors by using the sensor data as surrogates and deriving quantitative relations between sensor data and the contaminant of interest; for example, sediment concentration can be estimated from turbidity data (Rasmussen and others, 2009). The USGS National Real-Time Water Quality Web site (http://nrtwq.usgs.gov/) provides a user interface to sites where the surrogate approach is used to provide real-time, continuous, computed concentrations for sediment, nutrients, bacteria, and other constituents. Other contaminants that can limit the uses of water cannot be measured or estimated by means of automated sensor technology; to measure the concentration of these contaminants in water, a site must be visited and a physical sample collected and sent to a laboratory for analysis (http://waterdata.usgs.gov/nwis/). The suite of measurements included in a surface-water contaminant observation network will be site dependent, but potential contaminants include nutrients, trace elements, microbes, pesticides and other synthetic organic compounds, pharmaceuticals and personal care products, and algal toxins. Subnetworks should be defined based on measured parameters and techniques. For example, because temperature can be measured relatively cost effectively, the temperature network will likely contain the most sites, with many sites on smaller streams where the temperature response to climate variability has great effect on ecosystems. Continuous measurements of temperature, $\mathrm{pH}$, specific conductance, and dissolved oxygen can be collected efficiently at many streamgage sites, on rivers small to large.
The site-specific techniques for development of sediment surrogate models probably limit those measurements to fewer sites on larger rivers. The collection of discrete measurements is relatively expensive, so fewer sites, chosen for their national significance, will make up the contaminant network. Because technologies and techniques constantly change, the network will need ongoing updating and improvement to remain vital. Therefore, a function of maintaining the network should be the development, assessment, and - as appropriate - incorporation of new sensors, new laboratory methods, and new analytical techniques.

As stated previously, techniques should be developed to improve our ability to estimate and interpolate hydrologic parameters where and when measurements cannot be made. An example of a model that does this type of interpolation is the USGS SPARROW model (Preston and others, 2009; 2011), which has been used to predict amounts of nutrients and sediments in stream reaches at the scale of small catchments throughout entire major river basins. Examples of remotely sensed data as applied to spatial interpolation include the use of satellite imagery to estimate chlorophyll concentrations in surface-water bodies and the use of infrared imagery to estimate temperature. It is important to recognize, however, that all models and uses of remotely sensed data rely on observation and research for the quantitative descriptions of the sources and processes that affect water quality; ultimately, all models and application of remotely sensed data need to be validated with measurements made on the ground. Thus, an ongoing, comprehensive monitoring network, as well as research aimed at quantitatively describing the processes that affect water-quality characteristics, are critical to defining and increasing the accuracy of water-quality predictions made with these types of models and data applications.

Similar to the surface-water-quality network, a groundwater-quality network needs to be more fully developed, and a function of maintaining the network should be the development, assessment and - as appropriate - incorporation of new sensors, new laboratory methods, and new analytical techniques. A vision for this network was provided by ACWI Subcommittee on Ground Water (Advisory Committee on Water Information, 2009), that calls for monitoring wells in places where the groundwater is not disturbed by pumping or land use and sites where development has affected groundwater. Additionally, the ACWI calls for coverage in shallow groundwater-where surface development is most likely to affect quality - and deep aquifers that are tapped for public supply. The suite of measurements included in a groundwatercontaminant observation network will be site dependent, but the quality of shallow groundwater can be affected by nutrient contamination, chloride or bromide because of saltwater intrusion in coastal areas, pesticides and other synthetic organic compounds, and trace elements. In deep aquifers, naturally occurring contaminants such as major ions, radionuclides, and trace elements can affect the suitability of the water for some uses. 
Strategic Action 5.-Commit to long-term data collection at a core set of nationally important surface-water-quality sites that would constitute a national surface-water-quality observation network, incorporating all available measurement techniques, including the use of automated sensors, the use of surrogates, the use of discrete measurements, in addition to coordinating with the hydrologic networks of Strategic Action 1.

Strategic Action 6.-Develop robust water-quality spatial modeling tools and make use of remotely sensed information to interpolate data from the national observation networks to high spatial resolution.

Strategic Action 7.-Commit to long-term data collection at a core set of nationally important groundwater-quality sites that would constitute a national groundwater-quality observation network. Design the network to measure the quality of the Nation's principal and regionally important aquifers, coordinating with the hydrologic networks of Strategic Action 1. To the extent possible, take advantage of the existing infrastructure provided by the network of USGS groundwater-level sites where data collection has been ongoing.

\section{Objective 3: Assessment of Water Resources and their Suitability to Meet Human and Ecosystem Needs}

A vital aspect of any resource evaluation should include monitoring and assessment. The earlier objectives within this goal statement have been devoted to monitoring activities. This objective is focused on assessment of data and other information. The design of the various hydrologic networks described above must be linked to allow the capability to monitor changes in the combined hydrologic system. Assessment of hydrologic information generally takes the following direct forms: analysis of trends, comparison of data between areas of differing hydrologic stress, analysis of the uncertainty associated with measurements, and integration of hydrologic data with information that describes or explains hydrologic functions. Descriptive information can include land cover, land use, geology, ecology, species distributions, climate, population and other socioeconomic information, and water use. Emphasized here is the need to assemble and integrate information that helps the USGS describe the hydrology and the factors that influence it or are, in turn, influenced. The USGS should work with agencies, organizations, and academia at various levels to bring such data into an interactive system that facilitates robust assessment of hydrologic information.

Strategic Action 8.-Working through USGS resources and in collaboration with others, expand USGS capabilities to assemble, integrate, and serve information that assists in the assessment of hydrologic data, with the intent of improving the ability to detect trends, draw comparisons between differing hydrologic settings, lessen uncertainty, and improve the description of hydrologic functions.

\section{Goal 2: Advance Understanding of Processes that Determine Water Availability}

Management of water resources for multiple purposes will be improved by increased understanding of processes affecting water movement, storage, quality, and use, through a combination of new tools, concepts, and discoveries. New insights about such processes will be gained by spatial and temporal studies at a wide range of scales, from nationalglobal syntheses to local, intensive investigations (including experiments and theoretical models). To accomplish these tasks, the USGS will balance and integrate complementary approaches to water science, such as monitoring, assessment, statistical models, deterministic simulations, field and laboratory experiments, and fundamental research on concepts and methods.

Knowledge about interactions of geology, climate, humans, and ecosystems with the water cycle is critical to understanding and optimizing water availability. Most efforts to predict or manage water resources require a clear understanding of how water availability has already been affected by human activities and what are the underlying causes of stress on the various components of the water cycle. Interdisciplinary approaches and studies are needed to address these important issues. A few examples include (1) how climate affects water movement and storage, (2) how agriculture, energy, and mineral resource development affect (and depend upon) water resources, (3) how streamflow affects aquatic, riparian, and coastal ecosystems, and (4) how geology affects contaminant transport and attenuation. Both water and energy have important national-security implications, and ensuring our water and energy supplies will require USGS-wide multidisciplinary scientific and technical expertise and approaches.

An essential component of future research on water availability will involve application of innovative technologies to generate new types of data and large datasets. Some examples of water-related research tools for which the USGS is known and should continue to develop include (1) chemical and isotopic techniques for geochronologic and process-related research in geology, hydrology, and biology; (2) geophysical and geochemical characterization of aquifer properties; (3) remote sensing to quantify terrestrial water balance and ecosystem change; (4) computer simulation of groundwater flow and chemical transport; and (5) statistical models of water-quality variation in relation to hydrology and land use. New insights will be obtained from these approaches through new data acquisition and database management tools along with the integration of data and research across disciplines. Selected questions that address research to improve understanding include the following:

- What principles should guide optimization of water availability for multiple uses (that is, drinking water, ecosystems, agriculture/energy/industry), and how should water management adapt to changing conditions? 
- What can the past tell us about the future of water availability?

- Can human effects be clearly distinguished from natural variability?

- Can critical thresholds or "tipping points" be recognized or predicted?

- What special processes must be considered near hydrologic boundaries or interfaces (for example, air/water, sediment/water, groundwater/surface water, saltwater/freshwater, impounded/flowing waters, or local/ regional groundwater-flow systems)?

- How can groundwater and surface-water contamination be prevented or mitigated?

- What new tools will be needed to improve assessment, understanding, and prediction of water availability in the future?

\section{Objective 1: Comprehensive Understanding of Geological Controls of Water Availability, and Improved Integration of Geologic and Hydrologic Multidimensional Models}

Water movement, storage, and quality are intimately related to surface and subsurface geology and geochemistry. Movement of water and solutes through watersheds from the land surface through soils, bedrock, aquifers, and stream corridors depends on the interplay of geologic framework properties and hydrologic conditions through time. Water/rock reactions affect water quality naturally and control the occurrence and persistence of artificial contaminants. Conversely, research on hydraulic, geochemical, and isotopic properties can provide critical insights about flow paths, traveltimes, and water/rock interactions. Although general principles of geological controls of water movement and water quality are largely understood, modeling and prediction of flow and transport remain difficult because they require the incorporation of geological and hydrological data at multiple scales and resolutions.

Improvements are needed to characterize complex systems and to integrate physical and chemical geological properties with flow and transport data and simulations. Construction of new hydrogeological frameworks for modeling geologicalproperty data and their effects on water movement and quality in 3-D and 4-D (changing with time) requires integration of new and existing geologic-map data with subsurface geophysical, geochemical, and associated rock-property data (Gundersen and others, 2011; Jacobsen and others, 2011). Improved geophysical imaging of the subsurface is needed to provide

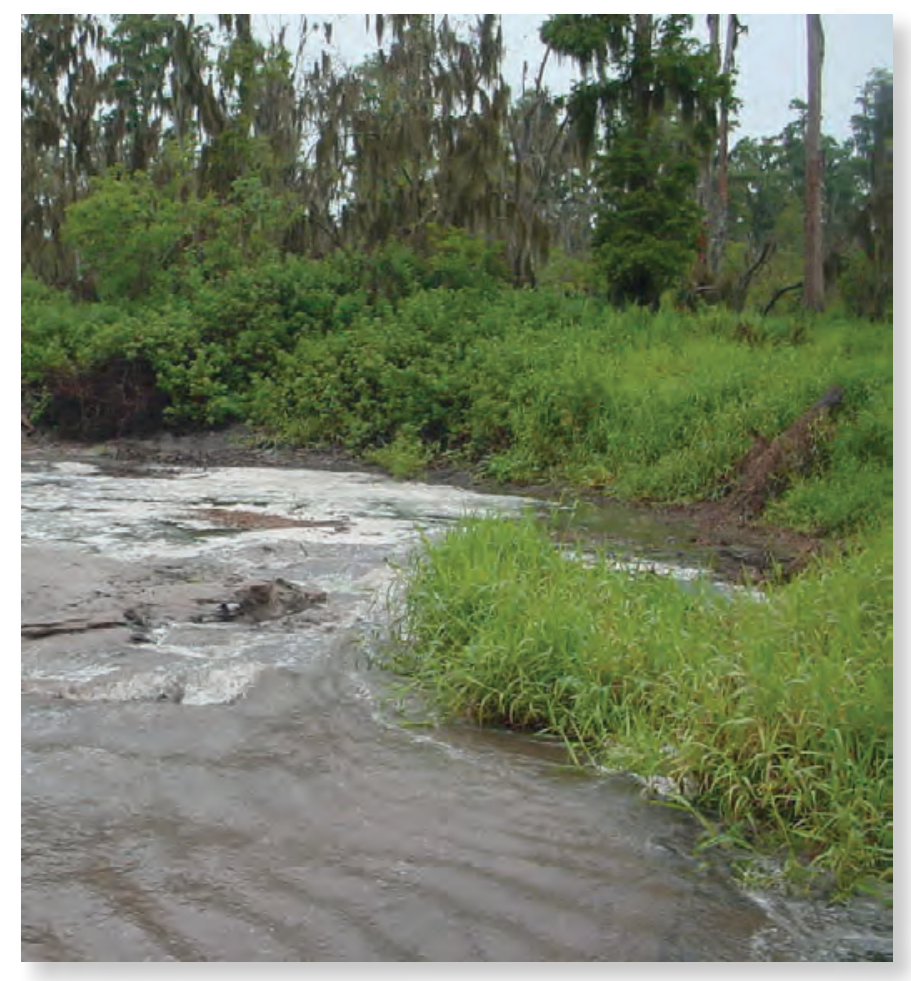

Flow from a storm event fills up a buried karst feature along the dry riverbed near Bartow, Florida, June 12, 2006. Photograph by Patty Metz, USGS.

information on critical interfaces that control water availability, such as fault structures, geologic contacts, and boundaries between fresh and saline waters. Examples of needed geologic studies include ascertaining (1) hydraulic properties affecting groundwater flow at multiple scales in complex (heterogeneous) geologic settings, such as fractured crystalline rocks, karst and epikarst, confining units, fault zones, volcanic rocks, stream corridors and floodplains, sub-estuarine formations, and permafrost; (2) geochemical and mineralogic properties affecting water/rock interactions, microbial communities, and biogeochemistry (for example, redox conditions); and (3) distribution and sources of salinity and natural contaminants, such as arsenic, heavy metals, and radioactive elements. Achieving this objective also will require more advanced mathematical and statistical spatial analysis tools to accurately predict and model the natural variability inherent in geological systems.

Strategic Action 9.-Produce new 3-D and 4-D hydrogeological framework models and property databases that are integrated with flow and transport models and data to effectively trace water movement and water-quality changes in complex systems under varying hydrologic conditions. 


\section{Trends in Hydrogeophysics}

Current trends in relation to hydrogeophysics and water science focus on three main areas: properties, processes, and scale.

Properties.-In the past, geophysical characterization provided direct insight into geologic structure and properties but only indirect insight into hydrologic properties. Today (2012), there is a trend toward direct measurement of hydrologic parameters by use of geophysical tools. The prime example of this trend is the emerging interest in nuclear magnetic resonance (NMR) methods (for example, magnetic resonance sounding and borehole NMR; see fig. 10). At this time, the USGS is an "early adopter" of these methods, which involve use of a surface unit and a borehole system. These methods provide estimates of saturation, total porosity, and permeability. In the case of the borehole tool, one can also extract mobile/immobile pore fractions important for understanding and modeling hydrologic behavior (for example, rate-limited mass transfer).

Processes.-Application of geophysical methods in time-lapse mode to monitor hydrologic processes is a productive area at the intersection of geophysics and water science. Permanent resistivity arrays are being used to monitor engineered remediation (for example, biostimulation) in 4-D, and resistivity/induced polarization (IP) and distributed temperature systems are being used to monitor tracer tests, natural processes (for example, hyporheic exchange, groundwater discharge to coastal bays and estuaries, unsaturated zone dynamics), and aquifer-management operations (for example, aquifer storage and recovery).

Scale.-There is a trend toward multiscale characterization and monitoring, facilitated by the advent of mobile measurement platforms. Towed seismic land streamers are used for multichannel analysis of surface waves, refraction, and even some reflection surveys, and towed multifrequency electromagnetic and shallow electrical resistance tomography/ground penetrating radar systems provide broad-scale geoelectrical information at the study scale (for more than depths of about 20-30 meters). The transfer to civilian Federal agencies of military unmanned aviation technology developed since 9/11 has the potential to revolutionize our ability to acquire multisensor data in support of a wide range of science needs. It is expected that the application of unmanned aerial vehicle systems will soon have a transformative effect on USGS science.

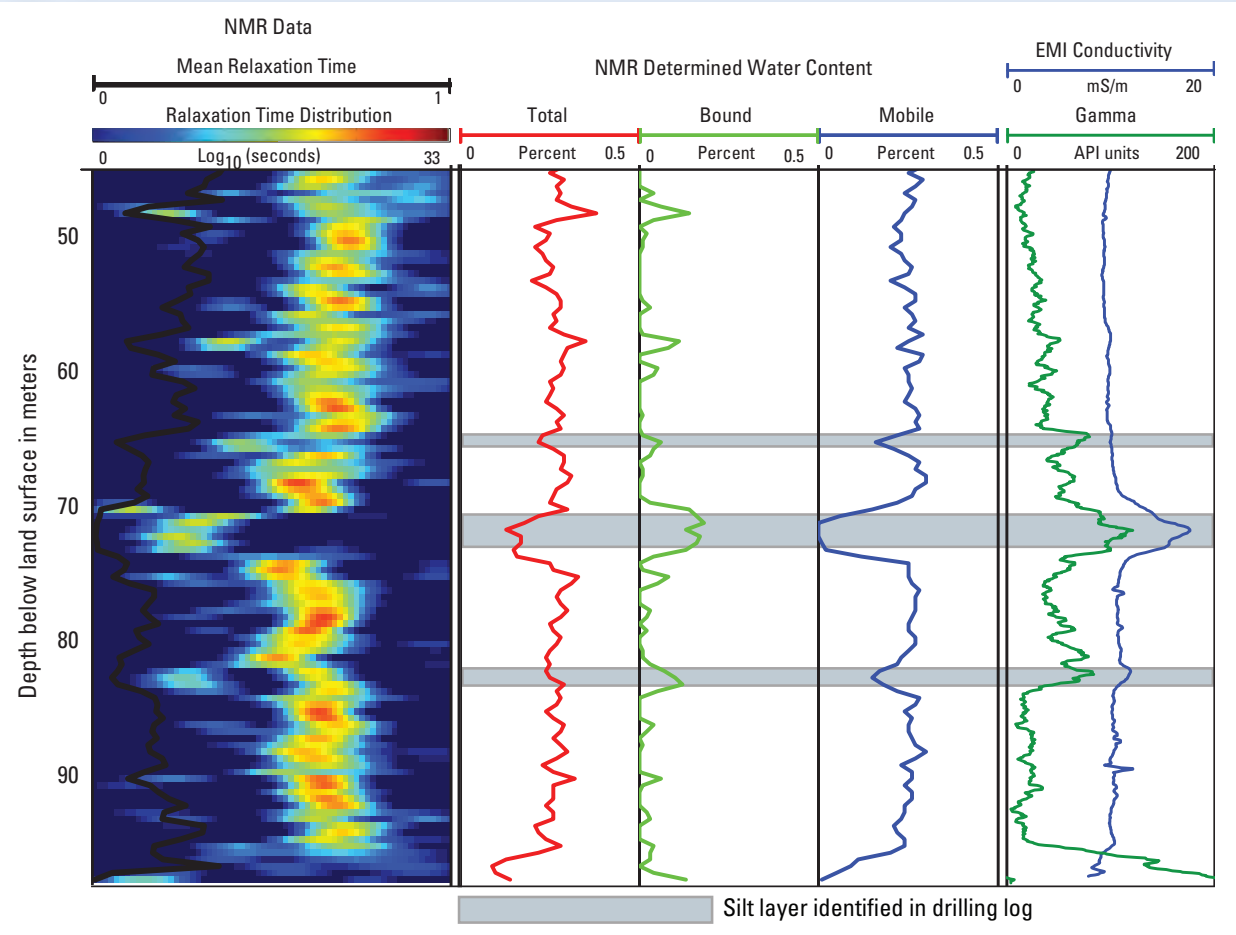

Figure 10. Nuclear magnetic resonance (NMR), gamma, and electromagnetic conductivity (EM) logs from a borehole completed in sand and gravel on Cape Cod, Massachusetts (Johnson and others, 2011). The NMR data, which measure how hydrogen nuclei spin in response to a magnetic field and can determine how much and where water is stored in porous media, indicate decreased total water and increased proportion of bound water in silt zones identified by the gamma and electromagnetic induction conductivity (EMI) traces and drilling logs, as indicated by the shaded boxes. 


\section{Objective 2: Comprehensive Understanding of the Effects of Climate Variation on Water Availability at Multiple Spatial and Temporal Scales}

Water availability is affected by weather and climate variation over a wide range of time scales, including seasonal and glacial-interglacial cycles. Such variations can affect precipitation, evapotranspiration, streamflows and chemical loads, terrestrial weathering and erosion rates, aquatic life cycles, sea level and coastal aquifer salinities, and so forth. Watershed responses to short-term climate variability can obscure underlying trends related to longer-term changes in climate, land use, and management actions, thus affecting management decisions and monitoring plans. Watershed responses to longterm climate trends may be superseded locally by effects of land use or other human activities some of which may, in turn, be driven by human responses to climate issues. It is an important challenge to distinguish long-term trends from shortterm variability. Descriptions and predictions of water-cycle processes and probabilities of extreme events must account for short-term variability that is superimposed on various types of longer-term nonstationarity (systematic changes that may or may not continue in the same way as in the past).

Understanding of past hydrological responses to climate change can improve our ability to distinguish between natural and human influences on water availability, especially when combined with improved understanding of water use and other human effects. Combined with improved trend analysis and simulation tools, information about the past can be used to improve water-availability projections and assessments of potential management options for the future. Trends from the past cannot be projected confidently into the future without accounting for the complex processes that link causes and effects. Whereas many factors are incorporated into sophisticated climate models that may be used to predict hydrologic responses at global to regional scales, further research on past conditions including historical and geological time scales will play a critical role in improving those models through improvements in understanding of processes, model testing, and calibration. Relatively short-term climatic variations and responses are evaluated using historical data such as streamflow, snow cover, and groundwater and lake levels, including changes in the timing of seasonal patterns "hydrologic phenology". Knowledge about longer-term hydrologic changes such as past lake levels, stream flood heights and frequencies, and groundwater recharge rates ("paleohydrology") will require observations derived from geology, geomorphology, paleontology, and various techniques for dating groundwater and sediment.

Strategic Action 10.- Use data and studies of hydrological variability on historic and prehistoric (geologic) time scales, along with data and models of human effects on watersheds, to improve understanding and anticipation of climate effects on water availability.

\section{Objective 3: Comprehensive Understanding of the Interactions Among Aquatic Ecosystems, Hydrology, and Hydrochemistry}

Sustainable aquatic ecosystems depend on suitable hydrological and hydrochemical conditions. Conversely, healthy ecosystems can help to maintain water availability. Important biological ecosystem components range from microbes to macrofauna and macroflora. Hydrological and hydrochemical changes in lakes, streams, and wetlands can alter physical habitats, complex life cycles, trophic interactions, nutrient supplies, and contaminant exposures. Coastal marine ecosystems are affected by changing inputs of freshwater and associated constituents from streams and groundwater. In turn, sustainable ecosystems can mitigate physical and chemical disturbances, such as floods and contaminant spills. Holistic science approaches are needed to (1) describe the natural variability of aquatic systems, (2) assess hydrodynamic and ecological conditions over a wide range of climatic conditions, (3) evaluate ecological responses resulting from adaptive management strategies for ecological flows, and (4) incorporate ecosystem approaches into whole-watershed management.

An aquatic ecosystem is characterized by its hydrology, chemistry, geomorphology, hydroclimatology, and a suite of biological and socioeconomic parameters. To a large extent, water-ecosystem interactions involve rapidly changing conditions (for example, snowmelt, floods, daily and seasonal light and temperature changes, and solute and sediment fluxes during runoff events). Ecosystem responses to change may be nonlinear, exhibiting abrupt shifts at critical thresholds or tipping points. Improvements in understanding these complex systems therefore will require intensive measurements and integrative environmental models.

Strategic Action 11.-Conduct integrated research relating water availability to sustainable aquatic ecosystems, including the timing of streamflow variations, hydrodynamics of groundwater/surface-water interactions, water quality and biogeochemistry, competing human demands, and relations to ecosystem structure and health.

\section{Objective 4: Comprehensive Understanding of Human Interactions with Water Availability}

Movement, storage, and quality of groundwater and surface water have been altered substantially by agriculture, urbanization, energy and mineral production, waste disposal, and other human activities. Although many of these activities and their effects are widely documented, it remains difficult to predict their actual effects across a range of geologic and climatic settings and time scales. Because detailed studies cannot be done everywhere, an improved understanding of interactions between land use and hydrogeology is needed to predict effects of human activities and to design appropriate monitoring strategies for detecting change; thus, it is important for the USGS to continue research on natural and 
human-related processes affecting water quantity and quality, including the ability of natural systems to tolerate or remediate human impacts.

Large amounts of money and effort are spent annually to capture, store, and reuse water supplies, to prevent or clean up contaminants that threaten water availability (for example, excess nutrients, sediment, toxic metals, and synthetic organic compounds), and to restore impaired ecosystems. Strategies include agricultural best management practices, monitored natural attenuation, in situ remediation, stormwater retention, stream and wetland restoration, and dam removal, as well as conservation measures that include enhanced recharge, groundwater storage, recovery, and reuse. Yet, relatively little co-located effort is devoted to monitoring and studying the outcomes of these practices. Remediation models and strategies are relatively weak in relation to the hydrogeologic conditions that promote or impede intended outcomes. An improved understanding of the linkages between human actions,

hydrogeological conditions, and ecosystem responses will lead to improved targeting and optimization of control efforts and a better use of adaptive management strategies. For example, the USGS can provide the science needed to guide decisions regarding unconventional fossil energy resources (coal-bed methane, tight gas sands, shale gas, and shale oil) through a variety of monitoring, modeling, and assessment studies that are natural extensions of activities described in this report. USGS expertise in hydrologic flow and 3-D/4-D geologic modeling to characterize the subsurface serves to answer society's questions on these processes. Spatially and temporally targeted assessments, including water quality, can be used to monitor the effects of operations at drill sites.

Addressing this objective will require a combination of basic research on fundamental processes as well as collaborative studies of systems that have been targeted for different management actions. The USGS can add value not only by studying the effects of such actions but also through direct involvement in conservation and remediation technology development, including design and testing under real-world field conditions. Results of such efforts will yield insights into processes and controlling factors, and they can be used in adaptive management strategies. Collaborative possibilities exist with the USDA, the USEPA, regional and local agencies, nongovernmental organizations, international entities, and industry.

Strategic Action 12.-Conduct monitoring, research, and modeling activities, in coordination with various water-related management actions, to improve understanding of benefits, limitations, and adaptive strategies.

Comprehensive understanding of natural and artificial stressors and their effects on water availability can be used to design potential management strategies for protection and sustainability of water resources through regulatory or economic measures. However, management success ultimately will depend on less tangible or predictable socioeconomic factors, such as aesthetics, population growth and movement, competing priorities, values, and costs. Given some understanding of existing and impending water-availability issues and management options, how decisions will be made and implemented, and how different options will be accepted by society (for example, conservation, reuse, redistribution, and treatment) are questions to be answered. Although this is a complex subject with high uncertainty, it is critical that such considerations be incorporated with other principles of water availability in research aimed at identifying realistic solutions.

Strategic Action 13.- Through internal and external collaboration, incorporate socioeconomic drivers such as competing uses, values, and costs into water-availability research, assessments, and models.

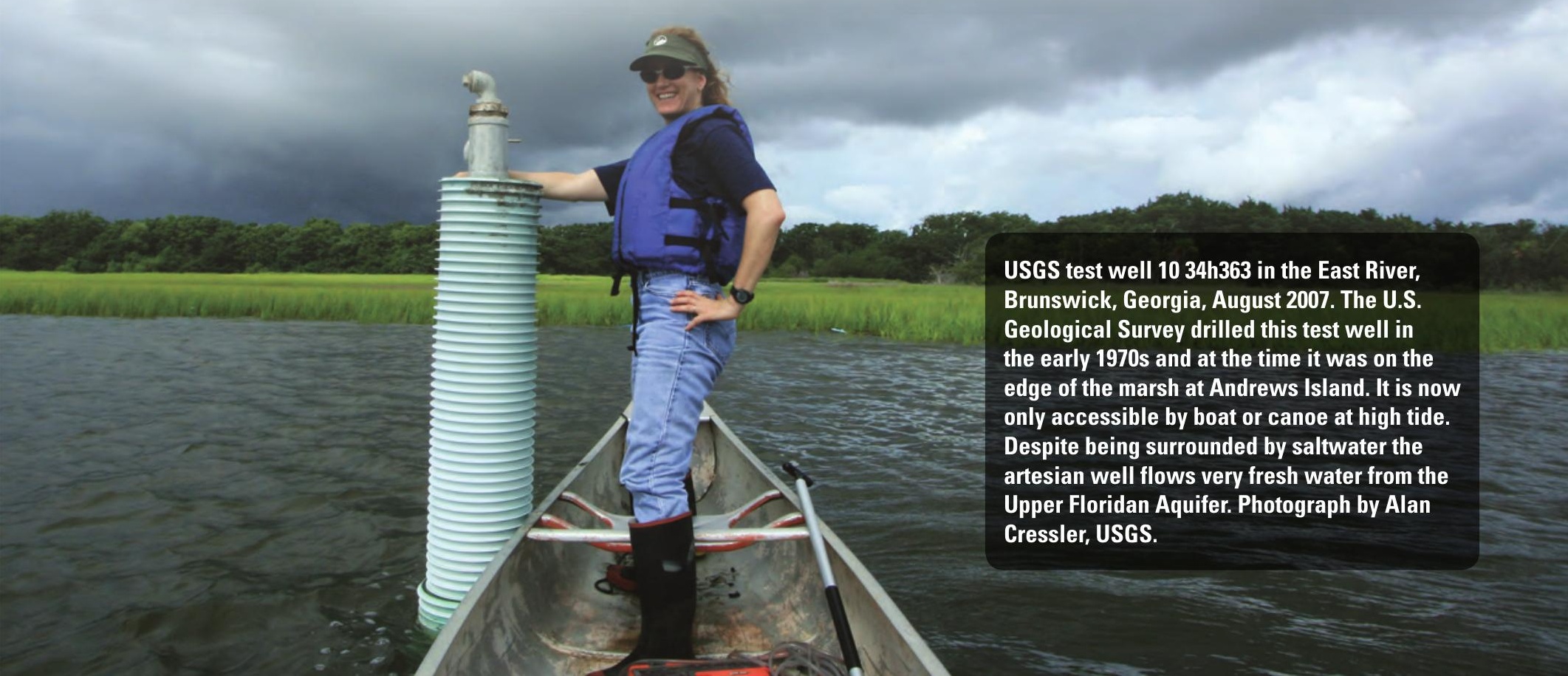




\section{Land Use and Contaminant Hydrogeology and Geochemistry}

Contaminants are introduced into groundwater and surface water by various processes, and the persistence of contaminants can be highly variable depending on the environment. USGS research includes studies to improve understanding of the sources, movement, and fate of contaminants in aquatic systems. This research includes development of new tools and methods, as well as local and regional process studies and computer models.

"Point-source" contaminants typically come from small source areas such as oil spills, landfills, mine drainages, wastewater disposal sites, and unconventional fossil energy development site. Nonpoint-source contaminants are more widely distributed and may be related to specific land uses (for example, agricultural nutrients, pesticides), regional or global atmospheric emissions (for example, mercury), and the like. For example, figure $11 A$ illustrates recharge of nitrate (orange colors) beneath agricultural fields and its movement along groundwater flow paths toward downgradient wells and a stream (Dubrovsky and others, 2010).

Management options for preventing or minimizing the effects of nitrate on downgradient drinking-water sources and ecosystems will depend on the input history, groundwater flow paths and traveltimes, the rate of reaction of nitrate with aquifer material, and other factors. For example, streams are largely fed by groundwater discharge, which can deliver contaminants that entered the watershed at various times in the past. Figure 11B shows a map view of simulated traveltimes of groundwater from recharge to discharge in a watershed in New Jersey (Kauffman and others, 2001). Groundwater that recharges far from streams can spend decades or more in an aquifer before discharging; thus, contaminants introduced into the aquifer may take decades or more to be flushed from the system. The simulation-model parameters were constrained by groundwater ages estimated from concentrations of tritium and helium isotopes in wells.

Another important consideration is the reactivity of the contaminant during its passage through the system. Interactions between a groundwater contaminant plume, surrounding uncontaminated groundwater, and solid aquifer materials can limit the progress of the plume through the aquifer, a process called natural attenuation. Figure $11 C$ illustrates natural attenuation processes that can occur when organic contaminants come into contact with oxygenated compounds in the aquifer, causing microbially mediated reactions that transform the contaminants into other chemicals that are less harmful (Steefel and others, 2005). Understanding processes at the microscale is important for understanding and predicting contaminant migration at the aquifer or watershed scale. Simulating such processes at the watershed scale is a challenge. USGS studies in contaminant hydrology therefore integrate effects of land use, climate, geology, hydrology, geochemistry, microbiology, ecology, and water use to develop general principles and predictive tools for evaluating management options.

\section{Yellowstone River near Custer, Montana, August 2011.} Photograph by Peter R. Wright, USGS. 


\section{Land Use and Contaminant Hydrogeology and Geochemistry-Continued}

\section{$\boldsymbol{A}$}

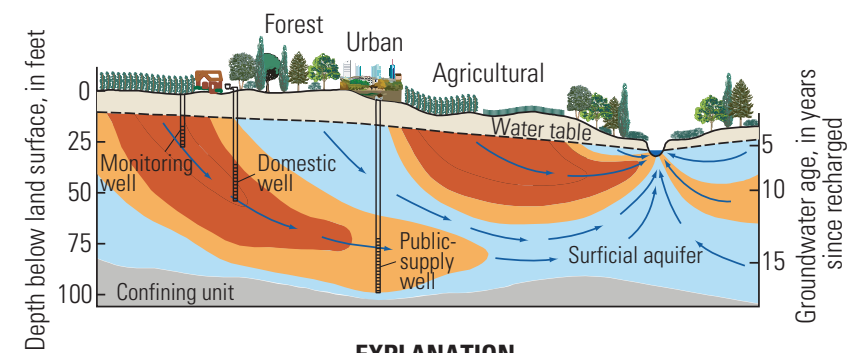

EXPLANATION

\begin{tabular}{|l}
$\square$ \\
Unsaturated zone
\end{tabular}

itrate concentration, in milligrams per liter as nitrogen

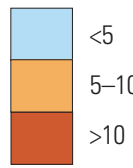

\section{B EXPLANATION}

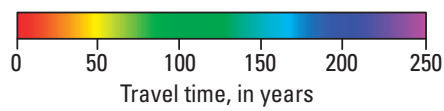
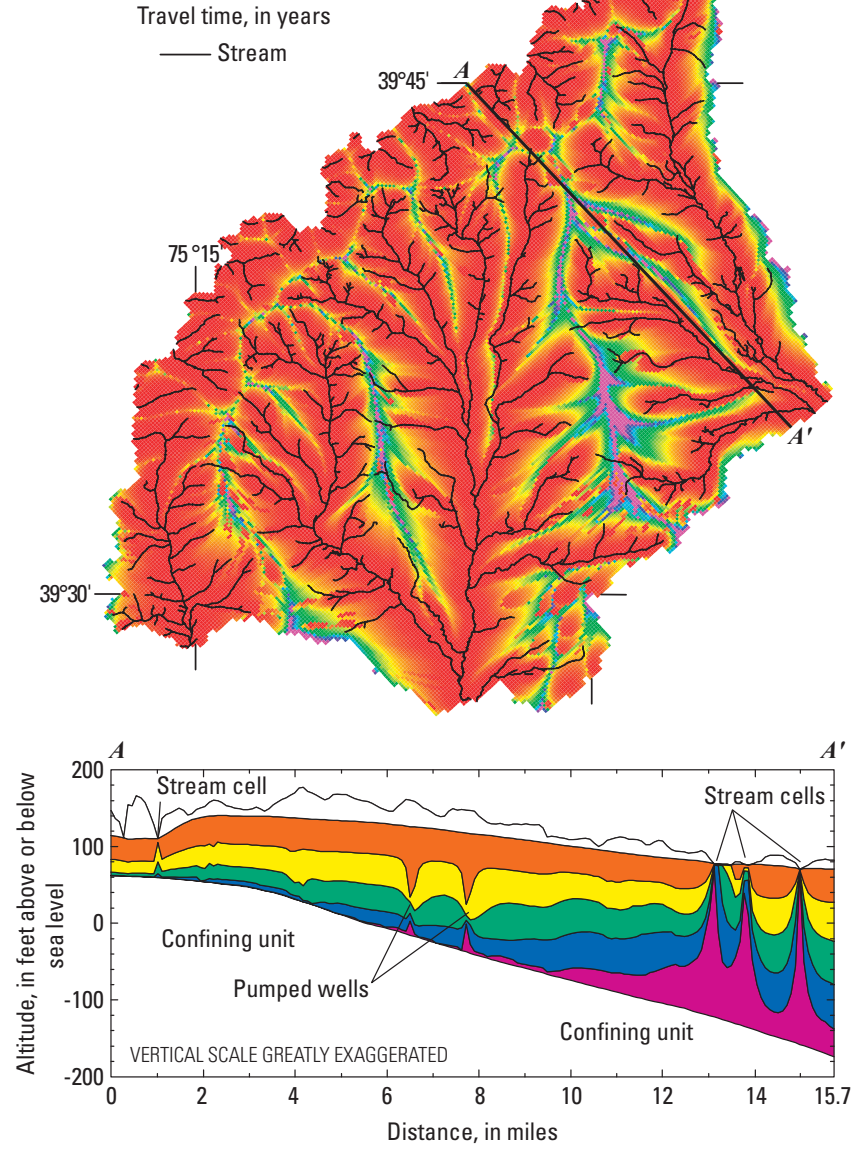

Figure 11. $A$, Surficial aquifer on the Delmarva Peninsula, Delaware, Maryland, and Virginia. $B$, Map view and cross section of simulated traveltimes of groundwater from recharge to discharge in a watershed in New Jersey (Kauffman and others, 2001). C, Natural attenuation processes that can occur when organic contaminants come into contact with oxygenated compounds in the aquifer, causing microbially mediated reactions that transform the contaminants into other chemicals that are less harmful (Steefel and others, 2005). groundwate flow

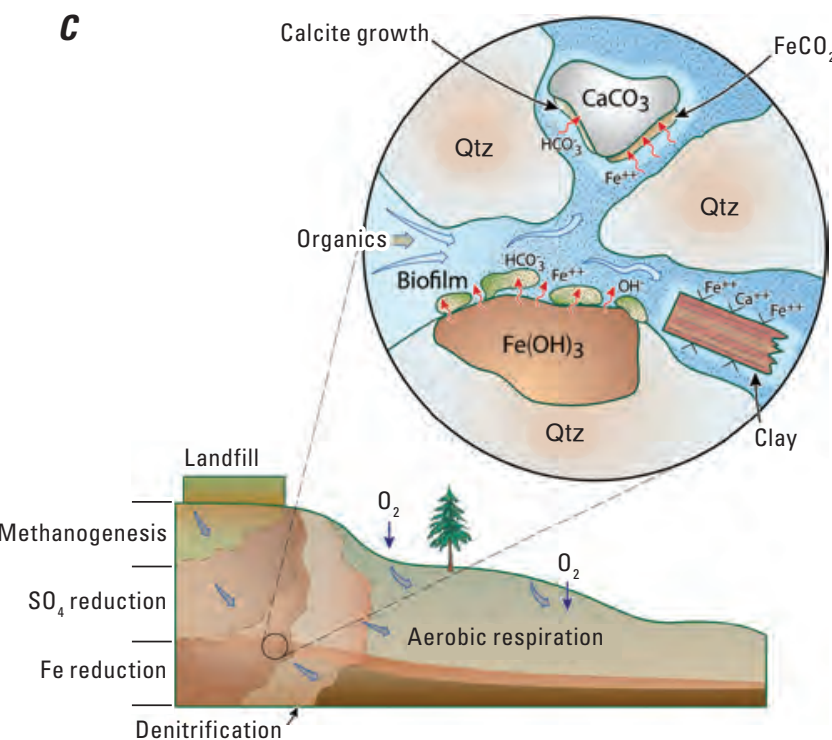

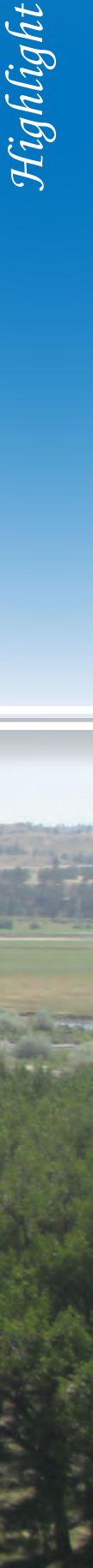




\section{Goal 3: Predict Changes in the Quantity and Quality of Water Resources in Response to Changing Climate, Population, Land Use, and Management Scenarios}

The role of prediction in the USGS is to (1) generate understanding of earth processes by developing and testing hypotheses and (2) provide information to decisionmakers and the public to help "minimize loss of life and property, manage our natural resources, and protect and enhance our quality of life" (Larson, 2009). Prediction does not necessarily imply a precise forecast of the future, but can involve examination of potential future scenarios and ranges of options. Prediction is inextricably tied to the observing, understanding, and delivering goals outlined in this document. Predictions are developed from understanding and are based on field observations, in turn, predictions are used to help develop understanding and to guide sampling and monitoring location and frequency. Prediction relies on mathematical or physical models that capture the essential elements of the water-resources system. The USGS plays a role in all aspects of model development. USGS scientists formulate conceptual and mathematical models describing various aspects of water-resources systems, develop methods to solve or approximate mathematical models, devise physical and numerical experiments, apply models to predict system response on a range of spatial scales from local to global, analyze results from predictive models, and communicate results within the scientific community and to the public.

In addition to the major societal questions raised in the introduction, prediction also addresses the following questions:

- What future water-resources conditions and issues should we anticipate based on our understanding of hydrologic principles, water-related trends, and expected changes in human activities, climate, and ecosystem condition?

- How can we best manage water resources in the context of identified trends and expected future conditions?

- What alternative water sources may be available to meet future human, industrial, and ecological needs?

Objective 1: Development and Application of Models To Predict Potential Effects of Changes in Population, Land Use, Climate, and Management Practices Upon Future Water Availability Considering Human and Ecological Needs

Quantifying one aspect of a resource a single time does not provide enough information regarding the effects of changing conditions on water resources to enable good management decisions (see, for example, Bredehoeft, 2002). The USGS will continue to develop and apply laboratory experiments and mathematical (deterministic, statistical) models to quantify all aspects of water availability and account for changing conditions. Substantial progress in developing accurate predictions about water availability will be aided by focused effort on integrated models that combine different parts of the water cycle that traditionally have been modeled separately. These integrated models allow for more comprehensive study of the factors controlling water availability and improved prediction by including coupled and often nonlinear processes. Use of integrated models acknowledges the observed relations between different parts of the hydrologic system (see, for example, Winter and others, 1998).

Integrated modeling is also important for relating water quantity and movement with water quality and ecosystem health. For example, prediction models may be developed to include the geomorphic effects of land use and management on infiltration, runoff, and sediment transport, which have direct implications for water quality and aquatic life in areas subject to urbanization, agriculture, grazing, forestry practices, and water-retention projects. Such models should include aspects of geology, climate, hydrology, biology, and human factors. Important challenges to modeling such complex coupled systems include the verification of model results and incorporation of data from diverse sources, which will require coordinated efforts in research and database management.

Strategic Action 14.-Develop and apply predictive models for coupled systems integrating geology, hydrology, water quality, and ecosystems, including potential effects of nonlinear behavior and feedback.

On a national scale, regional assessments and prediction models are important to the understanding of water availability and, ultimately, the effective management of water resources. Local-scale processes also are important in understanding, for example, groundwater/surface-water interaction under changing flow conditions, groundwater pumping leading to undesirable lowering of groundwater levels, and the interaction of water-quality characteristics and processes, especially in locations affected by point- or nonpoint-source contamination. In addition, responses to changing conditions can occur over a range of time scales from hours or less to millennia and more, thus, studies spanning a full range of spatial and temporal scales are needed to quantify water availability and to predict future water availability. Moreover, methods to bridge relevant scales are needed to predict how local processes influence regional water availability and how regional settings may influence local hydrologic response.

Strategic Action 15.-Develop and apply 3-D and 4-D (transient) hydrologic prediction models at a range of spatial scales (local to regional) and temporal scales (short to long timeframes), including methods to bridge these scales.

Predictive models are inherently uncertain, and mathematical and statistical techniques continue to be developed to estimate this uncertainty (Hill and Tiedeman, 2007; Beven, 2009). Estimating and communicating uncertainty 
to decisionmakers and other users of the information from predictive models will improve decisionmaking and lead to questions that can ultimately improve understanding of the underlying physical, chemical, or biological processes. Performing post-audits of past model predictions can identify areas for improvement and lead to better predictions in the future.

Strategic Action 16.-Develop and apply improved methods to estimate uncertainty in model simulations, and routinely assess and communicate model uncertainty to end users.

Anticipation of potential future conflicts over water resources requires improved predictions of future water demands. These predictions require understanding of the relations between future demands and population, land use, and climate change, as well as improved understanding of the social-science factors influencing water use. Improved wateruse data and complementary water-use science (Committee on USGS Water Resources Research, 2002) would allow the USGS to more accurately and effectively predict future water availability under different scenarios and provide needed information on which to base sound decisions.

Strategic Action 17.-Work with partners to develop improved methods for prediction of future water-use demand and develop strategies to track, validate, and update water-use predictions through time.

\section{Objective 2: Prediction of the Availability of Alternative (Impaired) Water Resources, and the Effects of Using These Water Sources on the Environment}

For areas experiencing water conflicts or shortages, alternative sources such as saline water, contaminated water, or water reclamation and reuse, may serve as additional water resources. Alternative (impaired) water resources may be used for purposes that do not require high-quality water, or they may be treated to improve their quality to acceptable levels. For example, wastewater and runoff from paved areas is captured in Las Vegas, Nevada, and either used directly for appropriate needs or processed and returned to the main surface-water reservoir for use by the city (Fishman, 2011). El Paso, Texas, another water-stressed city, is using the largest desalinization plant in the world to desalinate brackish groundwater to help meet water demand (El Paso Water Utility, 2011). Availability of alternative water resources depends, in part, on the chemical composition of the water, which determines how the water can be used and what technology and expense will be required to treat it. Exploitation of alternative sources also may have consequences. For example, the desalinization process produces brines that must be disposed of, and water reuse has been associated with water-quality impacts (for example, Rosen and others, 2011). To quantify the potential water availability from alternative sources, their distribution and composition must be assessed and understood, and the effects of using such sources should be predicted. The rerouting of water and the potentially complex interactions between water withdrawals, return flows, brine disposal, and water reuse must be predicted to understand the hydrology of systems reliant on water reuse and alternative water sources.

Strategic Action 18. - Develop and apply methods to quantify the potential for expanded future use of alternative water sources (saline water, marginal water, and reused water, among others).

\section{Prediction in Earth Science}

Prediction has been an aim of earth science since its inception and was clearly identified as important for both developing understanding and anticipating system behavior. In discussing the role of prediction in earth science, Kleinhans and others (2010) note,

“In his System of the Earth, James Hutton (1785), one of the founding fathers of earth science, proposed 'to examine the appearances of the earth, in order to be informed of operations which have been transacted in time past. It is thus that, from principles of natural philosophy, we may arrive at some knowledge of the order and system in the economy of this globe, and may form a rational opinion with regard to the course of nature, or to events which are in time to happen."'

\section{Drought conditions on the Blacks Fork near Little America, Wyoming, September 2007. Photograph by Jerrod Wheeler, USGS.}

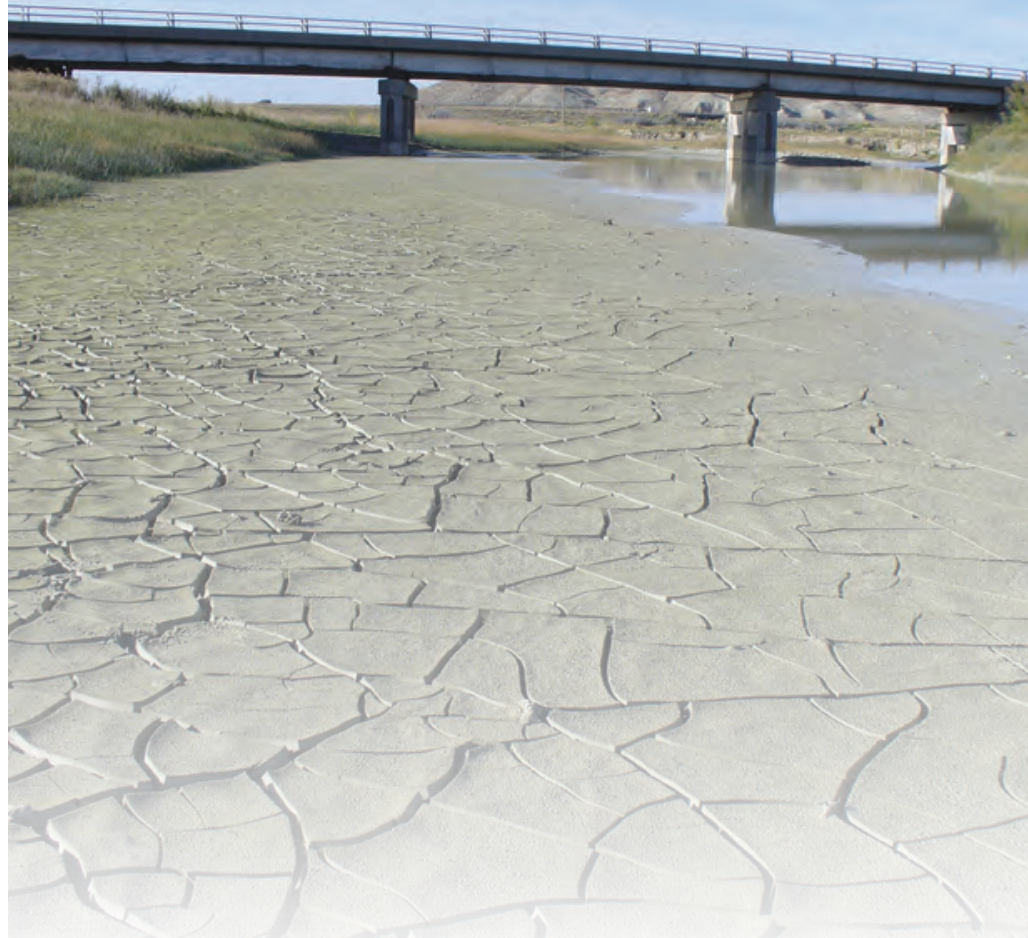




\section{Goal 4: Anticipate and Respond to Water- Related Emergencies and Conflicts}

Water-related emergencies and conflicts exact a costly toll on the Nation. Water-related emergencies are commonly caused by extreme events, such as floods and droughts, and can exacerbate underlying conflicts stemming from water competition. Managers and policymakers need science-based information and tools to anticipate and respond to waterrelated emergencies and conflicts. In doing so, the vulnerability of communities and ecosystems to extreme hydrologic events can be reduced. From the introduction to this document, the relevant major societal questions are as follows:

- How much water does our society need for the future, and is that amount sustainable?

- How can we protect our water supply, both quantity and quality, for the future?

- What can the past tell us about the future of water availability? Can human effects be clearly distinguished from natural variability? Can critical thresholds or "tipping points" be recognized or predicted?

- What new tools will be needed to improve assessment, understanding, and prediction of water availability in the future?

- What principles should guide optimization of water availability for multiple uses (that is, drinking water, ecosystems, agriculture/energy/industry) and how should water management adapt to changing conditions?

The foregoing are augmented by these questions:

- What are the potential water-related emergencies and conflicts that society may face in the next 10 years?

- What scientific information and data are needed to better anticipate and respond to the impacts of waterrelated emergencies on humans and ecosystems?

- What important hydrologic trends have implications for the occurrence of water-related emergencies, and what are their causes?

- How can we use these identified trends to prepare for future water-related emergencies?

- What gaps in scientific understanding and data need to be filled to help water managers and policymakers reduce the vulnerability of communities and ecosystems to water-related emergencies and conflicts?

- How can water-related hazards be prevented or mitigated?
- How can we protect our water supply, both quantity and quality, for the future?

USGS scientists should use unanticipated events as research opportunities. We need to be prepared to exploit sudden extremes (floods, spills, dam failure or removal) or longer-term disturbances (biofuel expansion, water storage or diversion projects, remediation projects, $\mathrm{CO}_{2}$ sequestration, natural gas exploitation) to gain new insights about basic processes. This should be in addition to emergency response actions aimed at minimizing danger or damage.

\section{Objective 1: Identification of Current and Future Threats to Communities from Water-Related Hazards}

To become more resilient to water-related hazards, communities need to identify their potential exposure to those hazards to devote appropriate resources to hazard planning, mitigation, response, and recovery. The USGS can provide resources and tools that identify current and future hydrological hazards to communities, including riverine and coastal flooding, riverine and coastal erosion hazards, droughts, mud and debris flows, lahars, and dam and levee breaches (including intentional breaches through acts of terrorism). Those resources and tools should include the following:

- Studies of near-term and long-term trends in droughts and floods using historical hydrologic monitoringnetwork data and paleorecords, such as sediment cores in riverine slack-water areas, coastal areas, and lakes.

Where possible, these studies should extrapolate trends to assist communities with hazard risk analysis.

- Studies to analyze floodplain dynamics, such as the effect of soil type on flood response, velocity distributions, and depth distributions.

- Pilot projects designed to examine the flood and drought response of geologically complex areas, such as karstic areas. These studies could be combined with water-quality monitoring to understand the potential pathways of toxins and impact of those toxins on water resources in these areas.

- Studies of causes and dynamics of debris flows in a variety of settings and lahars in volcano hazard areas.

- Studies of the processes associated with riverine and coastal erosion that would allow communities to identify areas of high potential erosion.

- Studies of the impacts of sea-level rise on coastal communities and ecosystems. 
- Geospatial products, developed in collaboration with partners such as FEMA, that identify all potential hydrologic hazards areas that a community might be exposed to and that convey information that is understandable to users such as community planners, emergency managers, and first responders.

Strategic Action 19.-Develop scientific data, information, and analyses to help communities understand their exposure to extreme hydrologic events.

\section{Objective 2: Development and Deployment of Observational Systems for Identifying and Tracking Hydrologic Hazards, Making Operational Decisions During Extreme Hydrologic Events, and Providing Data for Recovery}

The USGS operates a large earth observation network that includes hydrologic monitoring stations used extensively to monitor extreme hydrologic events such as large floods. Building on its observational capabilities, the USGS should become a national leader in permanent and short-term hydrologic observation networks that provide (1) real-time data for emergency response during events such as floods and coastal storm surge and (2) data for science-based disaster recovery actions. This national observation networks program should develop new sensor and telemetry technologies to better monitor conditions that can lead to water-related emergencies and should lead to the installation of monitoring stations that can provide data for multiple hazards.

Strategic Action 20.-Develop new sensor and telemetry technologies to better detect conditions that can lead to waterrelated emergencies, and install monitoring stations that can provide data for multiple hazards.

This national observation networks program should include the identification of data gaps in geographic coverage and observed parameters and installation of new observation stations and development of methods for synthesizing needed data in unobserved areas (such as developing streamflow statistics for streams that are not monitored by streamgages). Additionally, existing science-based tools should be enhanced and combined with new tools that use observation network data to assist communities with hazard planning, response, and recovery, such as

- Flood-inundation mapping linked to USGS streamgages and National Weather Service (NWS) flood-forecast points, as detailed in the Priority Actions section of this report (fig. 12);

- Alert/warning systems linked to USGS hydrologic observation networks (such as WaterAlert) that provide automated data and information alerts to users in response to observed conditions;
- Science-based tools to assist the NWS in improving flash flood warnings and flood forecasts for small drainage basins; and

- Web-based tools based on hydrologic data from observation networks, such as the existing USGS WaterWatch and StreamSTATS programs, that provide hydrologic information usable for planning, response, recovery, and mitigation in regards to hydrologic hazards.

Strategic Action 21.-Develop new science-based tools and enhance existing tools, such as flood-inundation mapping, that use observation-network data to assist communities with hazard planning, response, and recovery.

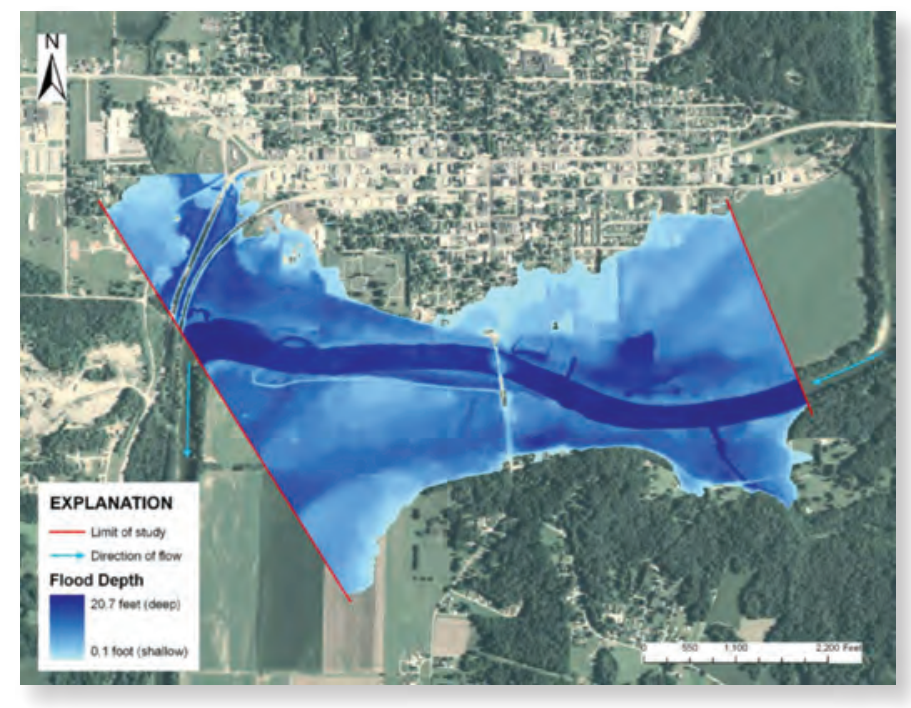

Figure 12. Example of flood inundation map.

\section{Objective 3: Through an Understanding of the Conditions Leading to Water Shortages that Result in Conflicts, Provide Assistance to Communities in Finding Science-Based Solutions When Conflicts Occur}

Water shortages can be caused by drought, by damage to infrastructure from floods or geological hazards such as earthquakes, by impairment of the quality of water supplies, and by imbalances between groundwater recharge and pumping. Periods of water shortage leading to conflict can be characterized by antecedent hydrologic and climatic conditions, as well as spatial and temporal patterns of water use. Vulnerability of water-supply infrastructure to floods and geological hazards also can be identified in advance. Application of groundwaterflow models can identify conditions that lead to undesirable lowering of groundwater levels and groundwater withdrawals in excess of recharge (commonly referred to as "groundwater 
Lake Michigan near Sheboygan, Wisconsin, July 2009. Photograph by Gael Kurath, USGS.

\section{Kalamazoo River Oil Spill and Flood}

In July 2010 a crude oil pipeline ruptured, spilling more than 800,000 gallons of crude oil into Talmadge Creek, a tributary of the Kalamazoo River near Marshall, Michigan. The effects of the spill were exacerbated by high streamflows that moved the oil downstream quickly and distributed it out onto the flood plain (fig. 13). Digital flood-inundation maps for a 15-mile reach of the Kalamazoo River from Marshall to Battle Creek, Michigan, were created by the U.S. Geological Survey (USGS) in cooperation with the U.S. Environmental Protection Agency to help guide remediation efforts after the spill (fig. 13B). Streamflow data recorded at USGS streamgages in Marshall and Battle Creek, Michigan, were used in conjunction with field measurements of river channel geometry to develop a hydraulic model of the river. The model was used to construct flood-inundation maps for the stream conditions at the time of the oil spill and to estimate the extent of inundation of the floodplain with a 10-, 4-, 2-, 1- and 0.2-percent probability of occurrence. These maps assisted in identifying areas that were affected by oil, as well as areas that may be affected by future flood events (Hoard and others, 2011).

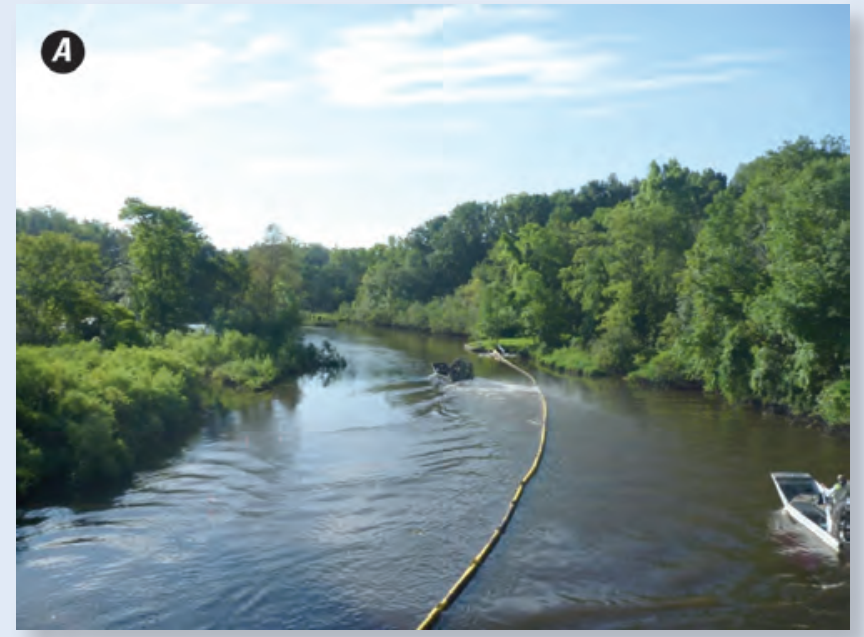

Figure 13. A, A tributary of the Kalamazoo River near Marshall, Michigan, July 2010. B, Floodinundation map for a 15-mile reach of the Kalamazoo River from Marshall to Battle Creek, Michigan, July 2010.

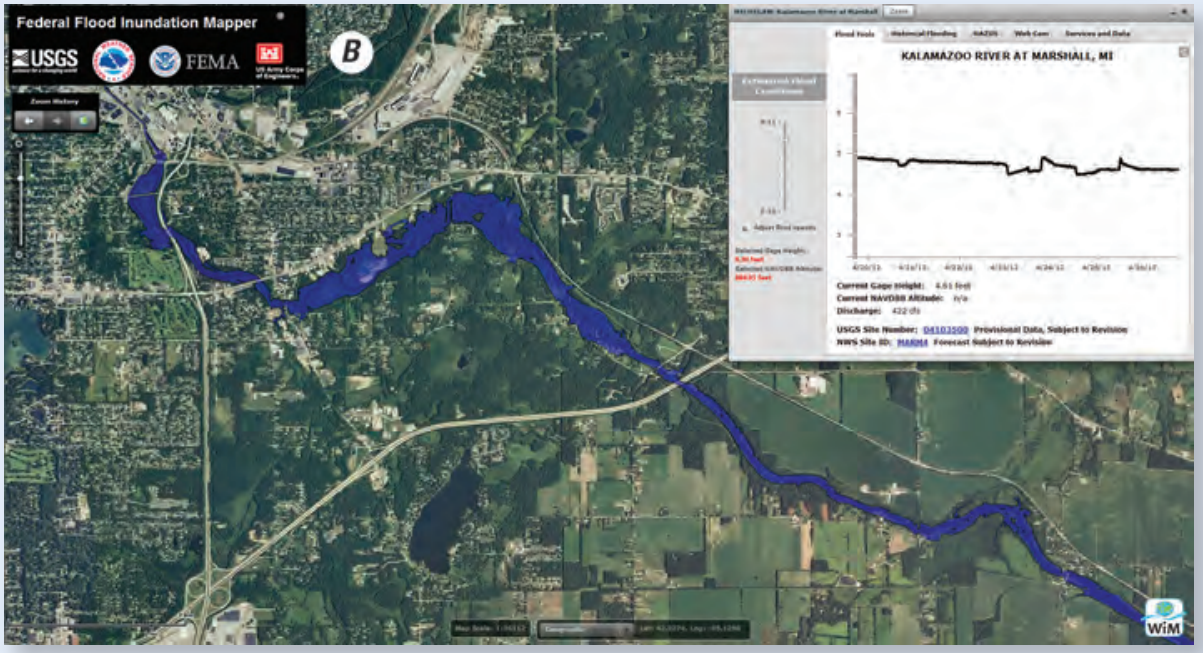




\section{Goal 5: Deliver Timely Hydrologic Data, Analyses, and Decision-Support Tools Seamlessly Across the Nation to Support Water- Resource Decisions}

For each goal discussed in this report, scientific objectives and strategies have been proposed to meet the goal. These strategies consist of products and actions focusing on the specific scientific capabilities of the USGS to understand major components of the water cycle. This final goal supports the previous four by developing strategies to effectively deliver scientific information and data to those who would use it to answer the major questions for each goal. For delivery of timely data, scientific analyses and results, and decision-support tools, the concept of interoperability becomes extremely important. Interoperability means that tools and data can be shared easily within and outside of the USGS and that those tools and data are delivered in user-friendly formats that are as universal and broadbased as possible. By making technologies such as scientific databases, Web services, and data from earth observation networks interoperable within the USGS and with USGS partners, information can be conveyed much more efficiently to users. Another critical feature of delivery of USGS water-science data, analyses, and tools is that they must be understandable to the people who will use them to make important decisions in regards to water resources. The USGS must, therefore, include social scientists to ensure that science products and information are understood and used to solve the problems discussed so far.

The USGS will continue to develop comprehensive Web- and applications-based data delivery, models, and decision-support systems to advance approaches to communicate hydrologic science. By leading the Nation in delivering hydrologic data, the USGS can strengthen partnerships nationally and internationally.

The relevant questions are the following:

- What is the future of hydrologic data delivery?

- What products and delivery systems are needed to serve integrated data?

- How can the USGS take advantage of visualization techniques for science research and develop it for communication tools for decisionmakers, policymakers, and the public?

- What products and tools are needed to integrate USGS water science with our partner organizations?

\section{Objective: Development of New, Integrated Information Dissemination in Formats Appropriate for the 21st Century to Aid Scientists and Decisionmakers}

New integrated technologies need to be developed for dissemination of information, such as delivering data through the World Wide Web by way of real-time and smart-phone applications, expanded map-based search capabilities, integrated database warehouses, 3-D and 4-D visualization products, and dynamic model archives. This objective includes the development of interoperable decision-support systems that connect with earth observation networks across the disciplines.

The future of delivering timely and useful hydrologic data lies in using Web- and applications-based systems to support short-term decisions and long-term planning. Data [not just real-time data, but historical data contained in the Instantaneous Data Archive (IDA) and the National Water Information System (NWIS)] need to be integrated to maximize their usefulness in various science activities and need to be seamless across the Nation for consistency purposes. In the next 5 to 10 years, all databases related to hydrologic information from all science centers should have national search and display formats and be served from a single data warehouse. Users of USGS information need to be able to find the data they need rapidly and easily without intensive searching. Multiple search functions that anticipate the way users locate data should be available. For example, users should be able to retrieve USGS data spatially by searching a specific location or region on a map or image. In other instances, users may need to search on specific timeframes. We also may find that it is important to link hydrologic data from other Federal agencies, such as the U.S. Environmental Protection Agency, Department of Energy, National Oceanic and Atmospheric Administration, and environmental health agencies. In the short term, the USGS should work with these agencies to integrate our data, ensure cyber security, and define "ownership."

Strategic Action 25.-Ensure that a wide variety of hydrologic information is obtainable through map interfaces available on the Web that allow the user to geospatially search, locate, and link hydrologic parameters, access historical information and conduct trend analyses, and construct wateravailability analysis tools, such as water budgets.

Over the last decade, the use of conceptual, digital, analytical, and statistical models has increased to help scientists and others understand complex earth systems. Although these various models were developed for a specific purpose, they often have value into the future as integrated aspects of larger 
models related to the water cycle. In an effort to maximize the use of these models, the USGS should construct a model "clearinghouse" where dynamic models can be built upon by others and archived for future use. The USGS Office of Groundwater within the Water Mission Area already supports groundwater model software and serves it publicly by way of the Web. A future model clearinghouse should include not only groundwater models but also surface-water and water-quality models. The USGS Science Strategy (U.S. Geological Survey, 2007) calls for refinement of existing groundwater and watershed models and development of new ones. Models will be used to understand earth science systems interactions, to describe and calculate uncertainty, and to predict changes in the water cycle from short-term emergencies (that is, floods) to long-range effects (that is, climate change and droughts).

A variety of 3-D and 4-D visualization and interactive products and techniques will be needed to support integrated science, communicate science results to decisionmakers and policymakers, and educate the public on how the water cycle affects their lives and environment. Pilot projects in the USGS have shown that 3-D immersion technology can bring scientists of different disciplines together to better view, discuss, and understand integrated earth systems. The scientific results from the models can then be visualized to show decisionmakers and policymakers how the groundwater system works and how resource-management decisions can affect the aquifer, humans, and the natural environment over time. In addition, these visualizations can be used to educate the public by running simplified models over time to show how human activities can affect the environment.

Improvement will be needed in integration of databases related to water use that exist outside of the USGS, such as the use of modeling and statistical designs in water-use estimation; improving the geospatial information on site-specific water-use features; consumptive-use estimation; quantifying and locating interbasin transfers; and linking water-use information with water budgets, watershed and aquifer analyses, and StreamSTATS.

Strategic Action 26.-Provide timely hydrologic data and develop dynamic integrated models and visualization products in formats appropriate for the $21 \mathrm{st}$ century that enhance water science, educate the public, and communicate to policymakers.

In 2010, the USGS launched WaterAlert, a Webbased application that notifies subscribers by way

\section{USGS WaterAlert}

The U.S. Geological Survey WaterAlert Service (http:// water.usgs.gov/wateralert) allows subscribers to receive updates at any of the sites where the USGS collects real-time water information (fig. 14A). Realtime data from USGS streamgages are transmitted by way of satellite or other telemetry to USGS offices at various intervals, usually once every 1 to 4 hours. Emergency transmissions-for example, during floods (fig. 14B) - may occur at more frequent intervals. The WaterAlert system sends notifications or updates to subscribers either daily or hourly by way of text message or email when the current conditions at a given site reach or surpass user-definable thresholds. The development and maintenance of the WaterAlert system is supported by the USGS and its partners, including numerous Federal, State, and local agencies.

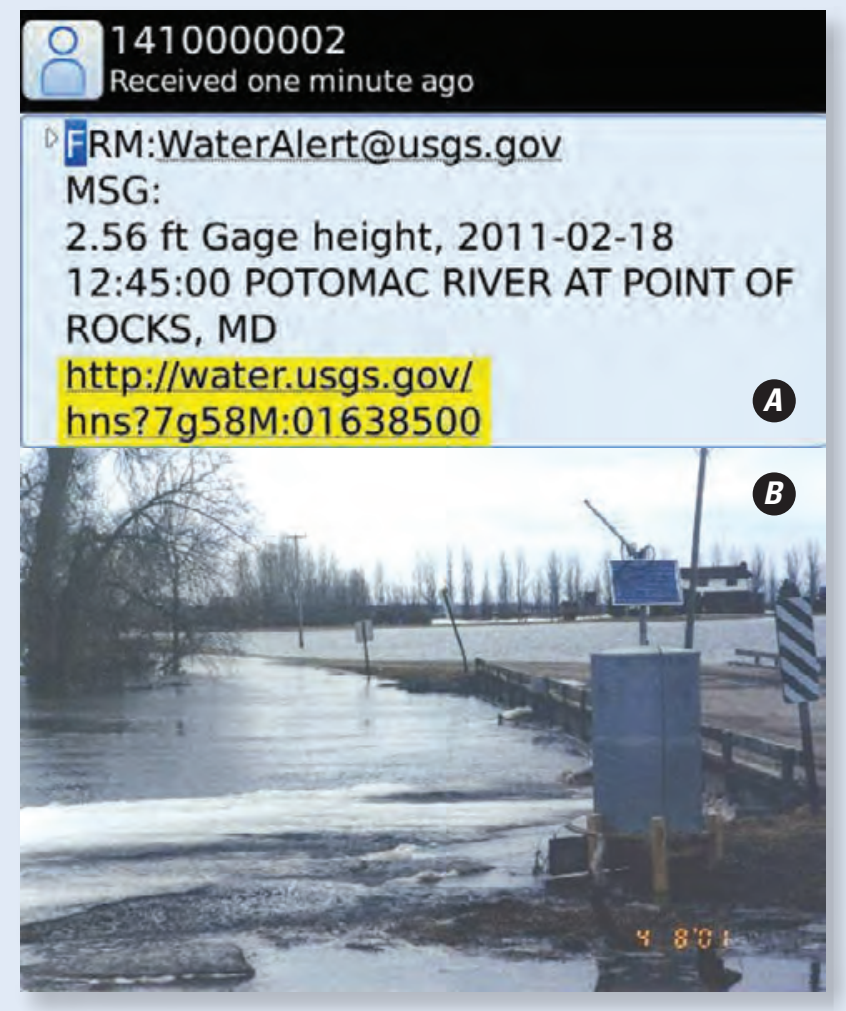

Figure 14. $A$, Screenshot showing real-time data collected from the U.S. Geological Survey streamgage on the Potomac River at Point of Rocks, Maryland (1410000002), and $B$, photograph of the streamgage. 
of email or text message when certain parameters (such as streamflow, gage height, groundwater level, water-quality parameters, or precipitation) measured by USGS real-time data-collection stations exceed user-definable thresholds. In addition, the USGS is launching FIMI (Flood-inundation Mapping Initiative), which is a map interface product that integrates USGS data and analysis with the National Weather Service forecasts and U.S. Army Corps of Engineers (USACE) operations to predict flood inundation at various locations around the country. USGS data also are used to support the National Weather Service AHPS (Advanced Hydrologic Prediction Service), as well as USACE river operations. Working with partner agencies such as FEMA, USACE, and NOAA, the USGS should develop geospatial tools that will help communities identify their vulnerabilities to multiple hazards that could cause water-related emergencies and conflicts in the next 10 years and beyond. Decision-support tools in development for applications in regional land-use management for water quality include a Web-based application of the SPARROW model for estimating nutrient export loads in streams and rivers based on watershed characteristics and loadings. Others could include stream transport models for predicting migration of chemical or biological hazards introduced into moving waters. Tools such as these could be developed in concert with risk-analysis tools so that communities can assess their risk from identified hazards. Furthermore, applications such as these should provide a community with information on vulnerability to hazards such as floods, droughts, earthquakes, high-hazard dams, hazardous-material spills, and degradation of the quality of water. Ideally, these tools should leverage existing resources such as FEMA's RiskMAP program and the USGS Hazards Gateway and the Integrated Water Resources Science and Services (IWRSS) initiative.

Strategic Action 27.-Develop decision-support systems to aid resource managers and policymakers.

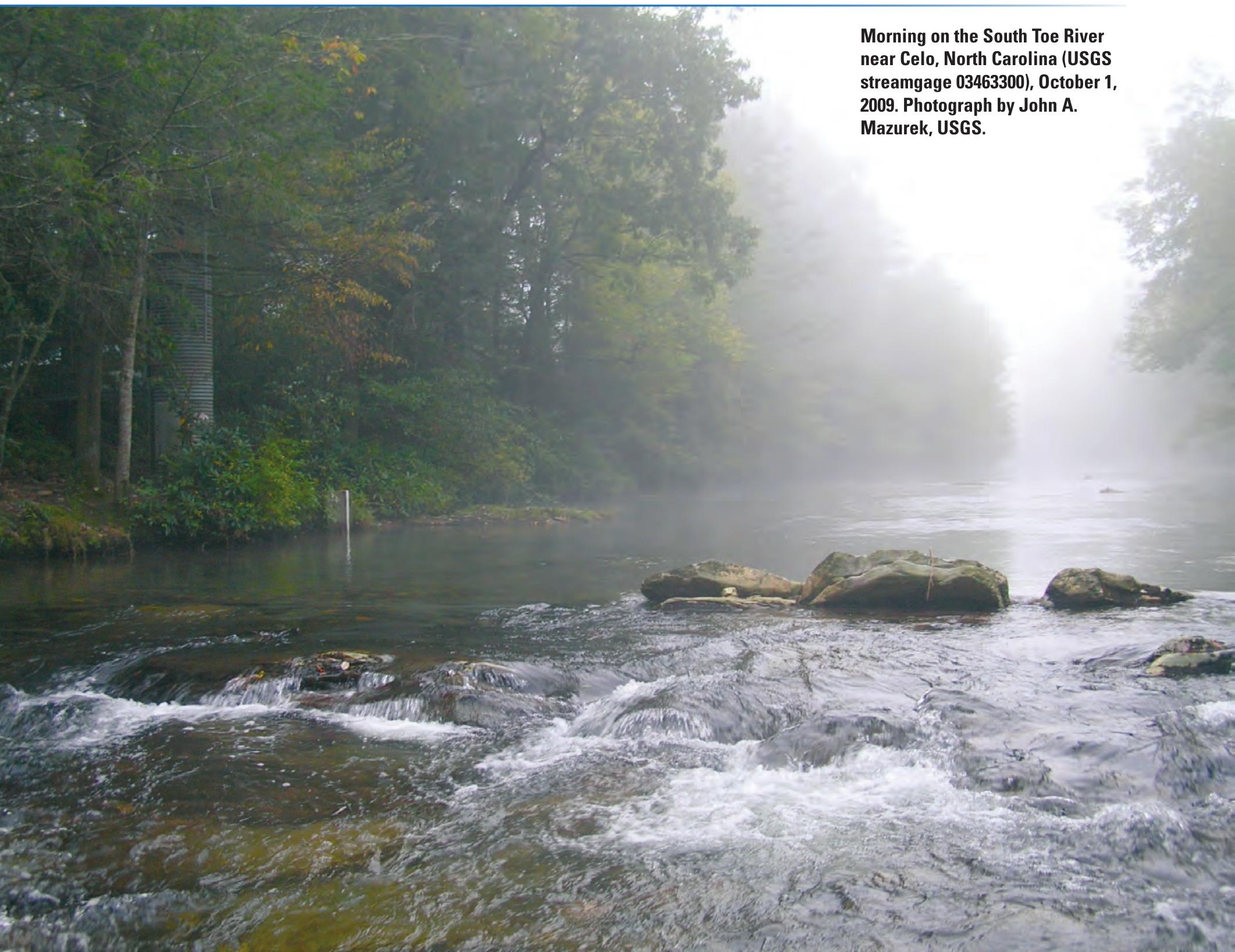




\section{Communicating Science to Society: Inform—Involve-Educate}

Providing water data and information is and has always been a vital service to customers, stakeholders, partners, Tribal nations, academia, and the general public. Communicating the data and information in language and formats that are relevant to specific users is a challenge that our scientists and technicians have not shied away from, and many accessible datadelivery tools, methods, and approaches are available.

Interpreting these streams of data into "common language" and explaining their meaning in appropriate contexts for greater understanding and application by the public serve to bring water science to the forefront of public discourse about water quality and availability. Informing the public also instills broader understanding of water as an essential resource for humans and other living species, for environmental health, and for economic prosperity, as well as a potential hazard by way of droughts, floods, icing, debris flow, and contaminant transport.

\section{Local Communication and Outreach}

Communicating water-science information to the Department of the Interior and the Executive Branch, Congressional members and staffs, State governments, local resource managers, countless partners and stakeholders, the media, and private citizens is now and will continue to be a high priority within the Water Mission Area. An array of communication channels, methods, media, and technology will be used to convey water data and information to diverse audiences to ensure that reliable water data and information are timely, easily accessed, useful, and usable within and outside the USGS.

USGS Water Science Centers (WSCs) are in an ideal position to communicate water-related news and information to local populations, the ones most receptive to what is going on in their local areas. Each WSC should have a full-time or part-time staff member dedicated to communication and outreach and working in conjunction with their respective Office of Communications and Publishing contacts. A robust water-science information system will become increasingly critical as the Nation steps up to challenges brought about by increased population and industrial demands; energy challenges; ecosystem impacts; health and safety threats from floods, drought, and contaminant transport; and other issues. Delivering local water science and technology information to the public through local news outlets can be important not only to increase the public's understanding of water science but also to inform the public about the work the WSC performs on behalf of the State's citizens. The need and value of water research and data gathering are most apparent and appreciated when understood within a familiar environment.

USGS hydrologist is interviewed by media in downtown Minot, North Dakota, as the Souris River flooded during the summer of 2011. Photograph by Dave Ozman, USGS.

\section{Social Media}

In response to a 2009 Executive Order, use of social media in the U.S. Department of the Interior and the USGS has increased significantly and has proven to be a powerful tool for reaching wide and varied audiences. Many WSCs have begun to use social media to their advantage in communicating studies and findings in their respective States to educate and inform their local populations, particularly during water-hazard events. Social media appeal to citizens who are becoming more technically savvy and attuned to receiving immediate information, as well as to the scientist, partneragency official, academic, or resource manager interested in quantifiable, scientifically sound information.

The USGS Office of Communications and Publishing's protocols, based on the Department of the Interior Social Media Policy, will be applied, as appropriate, at local, State, and national levels. A comprehensive, well-defined strategy for social media, incorporating local, State, and national elements will be developed as part of a coordinated communication strategy addressing a variety of goals, audiences, and media for use by WSCs, technical offices, and Cooperative Water Programs to bring water-science information to the attention of users and the general public.

\section{Integrating Resources}

The Associate Director for Water, the Associate Director for Core Science Systems, and the Director of the Office of Communications and Publishing will maintain a practice of supporting comprehensive and evolutionary communication and data transmission planning and delivery. By leveraging and coordinating resources and expertise, as needed, the valuable and often life-saving data, information, and products of the Water Mission Area will continue to be available to employees, the Department of the Interior, Congress, stakeholders, cooperators and partners, the general public, and any entity to whom the information serves a vital purpose.

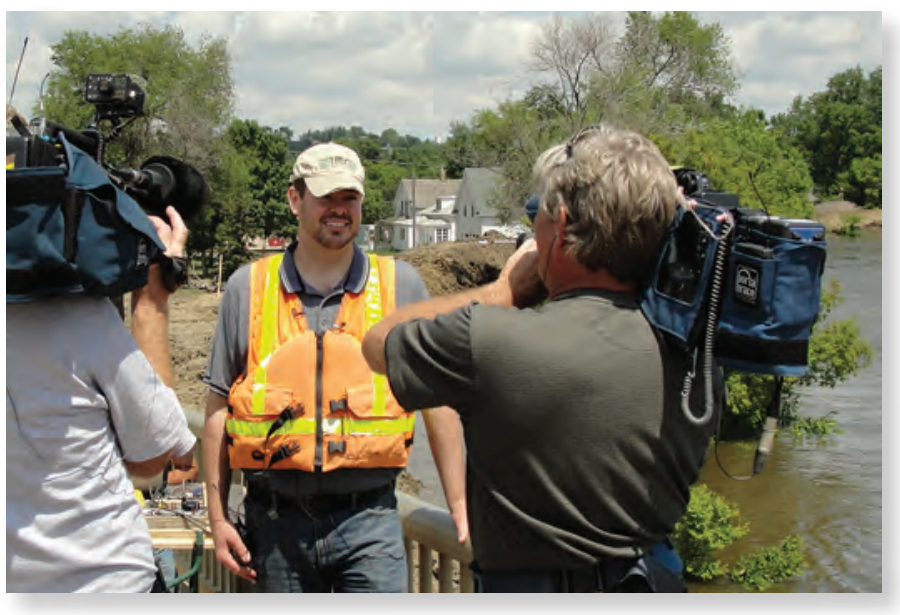




\section{Crosscutting Science with Other USGS Mission Areas}

The success of the USGS strategy of integrated science depends on deliberate interfaces between all Mission Areas. The following are recognized linkages between the Water Mission Area and the other Science Mission Areas within the USGS.

\section{Climate and Land Use Change}

To address 21 st century water-resources issues, as well as to better understand and predict 21 st century climate and land-use changes and their eventual impacts, the Climate and Land Use Change Strategic Plan incorporates water-resource linkages including dedicating one of its seven scientific goals to water, Goal 5 . The water cycle and climate are intimately linked. USGS expertise and tools are well suited to understand and predict impacts of climate and land-use change on water resources, and contribute to integrated resource management to ensure available water for human activities and protection along with balancing ecosystem flows. The following crosscutting efforts must be well coordinated between the Climate and Land Use Change and Water Mission Areas of the USGS:

- The National Water (Availability) Census has recognized that its methods and findings will need to accommodate and address the potential influences of climate changes and variations in the 21 st century in designing and interpreting its investigations and findings. Much of the Water Census plans are already focused on the historical and future roles that land-use changes play in determining water demands, water uses, and overall resource availability. Similarly, the Water Census will be the most up-to-date and complete available data and interpretive framework for assessing potential impacts of climate and land-use change.

- As the effects of land-use and climate changes become increasingly important to the Nation's water resources, existing and planned monitoring networks that address a variety of water-resources management needs should be reevaluated where possible to ensure that they remain well suited and configured for their historical uses, as well as for (and in) the changing landscapes that they attempt to characterize. Where possible, additional monitoring may be required to detect and characterize climate-induced hydrologic and geochemical changes even more quickly and with greater precision than may be possible with some existing components of USGS monitoring programs.

- Extreme hydrologic events, including floods and droughts, are expected to play critical roles in initiating and directing many expected landscape, hydrologic and biospheric responses to climate and land-use changes in the 21 st century. Thus, the Climate and
Land Use Change strategy calls for a national-scale assessment of the potential impacts of climate change on future probabilities of floods and droughts. Such an assessment will be successful only if the Climate and Land Use Change and Water Mission Areas coordinate closely on the underlying science and eventual assessment reports.

- The Climate and Land Use Change strategy recommends a national assessment of historical and projected climate-change impacts on water quality. The National Water-Quality Assessment (NAWQA) Program, now entering into its third decade of observations and research, has produced many important products linking land uses and water quality across the Nation. Future NAWQA activities will continue to rely heavily on land-use science. Also, NAWQA may be expected to begin addressing the likely effects of climate changes on the Nation's water quality.

- The Water and Climate and Land Use strategies include actions for developing decision-support tools, data resources and models to understand resources and predict the future. With these two Mission Areas collaborating, the USGS can develop hydrologic projections and provide important information for scenario-based assessments for water-resource management and better understand model uncertainty. Integrated models of climate and land-use change and the water cycle can help in the understanding of streamflows, sediment transport, aquatic habitats, and ecosystems.

\section{Core Science Systems}

Use of a wide range of process simulation modeling tools is needed to achieve USGS goals for quantification, understanding, and prediction of water availability, emergencies, and conflicts. Such tools demand substantial data resources as inputs, often putting a large burden on researchers to find, access, and manage the diverse datasets they need to even begin an investigation. Communicating the results of these investigations can be equally challenging. The Core Science Systems Mission Area is well-positioned to provide valuable support and assistance with these problems in a partnership with the Water Mission Area. By building critical spatial data infrastructure, and facilitating the access, exploitation, and visualization of large earth science datasets, Core Science Systems can help increase the productivity of water-science researchers, including potential breakthroughs that would otherwise be impossible because of limited capacity for computation and data management.

Assessment of hydrologic information requires interdisciplinary science to integrate hydrologic data with information 
that describes or explains the associated hydrologic processes through time. The descriptive information can include land cover, land use, water use, geology, ecology, biologic distributions, climate, population and other socioeconomic information. The Core Science Systems Mission Area can help the Water Mission Area to integrate information that helps describe the hydrology and the various factors that influence it. Core Science Systems provides much of the descriptive information, through its various geospatial databases, needed to undertake this level of analysis. The understanding of water availability requires specific knowledge of boundary conditions that includes the geologic, topographic, and biologic frameworks of a water system. Geologic mapping and 3-D/4-D modeling of these systems provide critical information on surface and subsurface geologic properties, including the stratigraphy, fault structures, and associated rock properties, such as porosity and permeability. In addition, the Earth's surface can be considered a boundary for water systems and the use of digital elevation models, LiDAR, topographic maps, and remote sensing provide interdisciplinary opportunities with Core Science Systems. This Mission Area is critical for hydrologic analysis as it is the primary developer and planner for foundational datasets, like the National Hydrography Dataset (NHD) and the National Groundwater Monitoring Network Dataset. Another area of collaboration for Core Science Systems and Water Mission Areas is in the integration and serving of data important to the public and decisionmakers. Core Science Systems and Water Mission Area science strategic plans emphasize the integration of observation networks, integration of databases, and the use of visualization techniques to understand earth processes. These two mission areas are capable of coordinating in the following ways:

- Understanding geologic controls on groundwater, surface water, and water quality; understanding geomorphic changes associated with land-use change; integrating the paleoclimatic record with hydrologic studies; and identifying the role geology plays in assessing and mitigating hydrologic risks (karst terrains, hydroseismicity, subsidence).

- Developing analytic, visualization and modeling techniques for water science and using them as a research and communication tool to address societal challenges.

- Collecting and maintaining high-quality data that span a wide range of spatial and temporal scales, followed by integrating the resulting databases for effective water science.

- Developing new technologies for organizing, understanding, characterizing, synthesizing, and delivering water information (for example, smart-phone applications) and improving Web-conferencing capabilities.

- Structuring effective information security, proprietary information, and privacy limitations for data acquisition and dissemination.
- Development of the NHD and similar water datasets and expanding their use in the understanding of the natural hydrology and the linkage of human water use to the natural system.

\section{Ecosystems}

The Water and Ecosystem Mission Areas have many crosscutting themes and have the potential for extensive multidisciplinary research. In particular, Goal 2 of the Ecosystem Science Strategy report, "Advance understanding of how drivers influence ecosystem change" requires data, understanding, and analysis regarding changes in hydrology that may drive changes in ecosystems. This goal integrates with the first three goals of the Water Mission Area: "Advance hydrologic monitoring networks and techniques," "Advance understanding of processes that determine water availability," and "Predict changes in the quantity and quality of water resources in response to changing climate, population, land use, and management scenarios." In addition, major challenges identified by the Ecosystem Mission Area including developing tools, technologies, and capacities to inform decisionmaking also are shared with the Water Mission Area. Integrated work to address these challenges by both Mission Areas will produce powerful results that are relevant across the Bureau.

Priority actions proposed by both Mission Areas highlight the crosscutting activities. The Water Mission Area report proposes "Advance ecological flow science" as a priority action and the Ecosystems Mission Area, within Strategic Priority 2-Promote the use of interdisciplinary ecosystem science - proposes a priority action to "evaluate ecological responses to hydrologic alteration." The Water Mission Area also proposes the development of rapid deployment teams for water-related emergencies. This priority action corresponds well with the Ecosystems Mission Area proposed action to respond rapidly to environmental disasters with ecosystem science. These pairs of priority actions could be pursued in concert between the Mission Areas. This work would result in a more comprehensive understanding of the changes in water resources and needs in response to various drivers and the attendant impact of these changes on ecosystems, and would formalize the response of USGS to emergencies to provide needed science on which to base decisions.

Other areas of research that would increase our understanding of the linkages between ecosystem science and water resources include the following:

- Science that examines the effects of water contamination and pollution on the functioning of ecosystems.

- Science that improves our understanding of adaptation strategies to assist in the conservation of plants and animals in ecosystems that experience change in water supplies in response to climate variability.

- Science that supports the ability to restore and conserve aquatic ecosystems. 
- Science to understand how drought, flood, and fire influence hydrology and ecosystem stability.

\section{Energy and Minerals}

Water is used in every stage of the lifecycle of energy and mineral resources (from discovery, extraction, production, and use, to recycling and disposal). A holistic understanding of the interaction of the hydrologic cycle with the lifecycle of energy and minerals is therefore required for a comprehensive assessment of water resources and energy and mineral resources. This fact is recognized by overlapping goals and strategic actions in reports of the Water Mission Area and the Energy and Minerals Mission Area. Energy and Minerals Goals of "Understand the environmental behavior of energy and mineral resources and their waste products" and "Understand the effects of energy and mineral development on natural resources" demand key data, analysis, and understanding that also are called for in the goals of the Water Mission Area. In particular, objectives in the Water Mission Area that overlap and tie into those in the Energy and Mineral Mission Area include "Assessment of water resources and their suitability to meet water-availability purposes for human use," "Comprehensive understanding of human interactions with water availability," and "Prediction of availability of alternative water sources, including saline, marginal water, and water reuse."

Opportunities for crosscutting activities also include basic research focused on processes that affect fluid pathways, and form a basis for understanding and forecasting the interactions between the hydrologic cycle and the lifecycle of energy and mineral resources. Three priority actions in the Water Mission Area- "development of 3-D/4-D hydrogeologic framework models at multiple scales," "clarify the linkage between human water use and the hydrologic cycle (natural hydrology)," and "integrated watershed assessment, research, and modeling" - tie into three Energy and Minerals strategic actions, those being "develop 3D framework models to understand the fundamental processes of energy and mineral resources," "investigate perturbations to natural landscapes," and "provide information on development to large landscape conservation initiatives."

Other areas of research that link energy and minerals science with water science include:

- Understanding major geochemical cycles (for example, carbon and nitrogen).

- Transferring insights between laboratory and fieldbased studies.

- Understanding the socioeconomic drivers for water-use trends.

- Predicting the consequences of major water stressors associated with the energy and minerals lifecycle such as mineral production (including mineral fuels), $\mathrm{CO}_{2}$ sequestration, biofuel production, and damming and undamming of surface water.

- Using the understanding the USGS has of future energy and mineral development to predict future stresses on water supplies.

- Identifying the science intersections related to the water-energy-food nexus.

- Synthesizing information on the kinds of hydrogeology (for example, karst) that may be at increased risk from unintended consequences of energy and mineral development, such as subsidence, hydroseismicity, and sinkhole formation.

\section{Environmental Health Science}

The distribution of natural and anthropogenic contaminants and pathogens in aquatic and terrestrial environments is tied to and often driven by the hydrologic cycle. Furthermore, understanding the role of the hydrologic cycle in these processes is critical to determining ecological and human exposure to these contaminants. Fundamental understanding of the natural and human factors that affect water quantity, movement, and quality is required to define various sources of contaminants and pathogens, to determine their persistence and fate in the environment, and to characterize environmental settings that may be more vulnerable to various environmental health concerns. Consideration of the many hydrologic factors that influence the health of the environment is important for determining the specific causes of adverse environmental health outcomes and identifying the best management alternatives.

The Water and Environmental Health Mission Areas have many crosscutting linkages that provide the potential for multidisciplinary research. For example, Goal 1 of the Environmental Health Science Strategy report "Provide the science to identify, prioritize, and detect contaminants and pathogens of emerging environmental concern" is related to objectives from Goals 1, 2, and 4 of the Water Science Strategy report: "Advancement of hydrologic monitoring networks and techniques," "Comprehensive understanding of human interactions with water availability," "Identification of current and future threats to communities from water-related hazards," and "Providing tools that allow managers to detect and respond to emergencies related to water-quality degradation of all kinds - natural, accidental, and intentional." In addition, strategic actions related to transport, fate, and management of contaminants and pathogens in Goals 2 and 3 of the Environmental Health report have parallels throughout the Water report in monitoring, assessment, understanding, and prediction objectives. Responses to water-quality emergencies are featured in Goal 5 of the Environmental Health report and in Goal 4 of the Water report. Coordinated efforts to address these challenges by both Mission Areas will be essential for producing interdisciplinary and relevant results. 
To achieve the most scientifically critical and relevant results, the Environmental Health Science Strategy will coordinate closely with the Water Science Strategy in the following ways:

- Participate in large quantity- and quality-assessment programs to make added use of national datasets in interpretations of environmental health issues. This could include understanding anthropogenic tracers that can be used for contaminant source-tracking and for hydrologic and sediment transport studies.

- Develop new tools and methods to identify and address emerging environmental health concerns, including methods to measure emerging contaminants in the environment. Development could include analytical methods development for rare chemicals in water, sediment, and biota and could include approaches for multicomponent source tracking (environmental forensics). In addition, methods, data and models could be developed for detecting and responding to water-borne contaminant emergencies.

- Use newly developed tools and methods to make initial assessments of the relative priorities of various emerging contaminants with the intent to improve understanding of physical, chemical and biological processes affecting transport and fate of contaminants and pathogens in the hydrogeologic context.

- Make environmental health information available to the Water Mission Area in its implementation of systematic national monitoring and assessment activities. Such as coordination of monitoring activities for relating contaminant behavior with water quantity, movement and quality.

\section{Natural Hazards}

The Natural Hazards Science Strategy report describes broad science goals and strategic actions to help protect the safety, security, and economic well-being of the Nation. A number of the Natural Hazards Mission Area goals and actions are common with those of the Water Mission Area. Those science goals and actions that crosscut between the Natural Hazards and Water Mission Areas include the following:

- Conduct observations of natural hazards to improve fundamental understanding, assessments, warnings, and situational awareness, including the following:

- Expanding and enhancing monitoring networks (Water Mission Area Priority Action); for example, expanding the National Streamflow Information Program network of streamgages that are critical to flood observation and forecasting.
- Developing and deploying observation systems for detecting and tracking conditions leading to waterrelated emergencies, such as the rapid deployment of storm-surge sensors for hurricanes and tsunamis and rapid-deployment, noncontact water-stage sensors for riverine flooding.

- Advance and apply fundamental understanding of hazards to improve assessments, warnings, and situational awareness, including the following:

- Studies of near-term and long-term trends in floods and droughts using monitoring network data and paleoflood studies to determine flood peaks in the pre-observational time period.

- Studies of the processes associated with riverine and coastal erosion, and of the dynamics of debris flows in a variety of settings.

- Design projects to examine the flood response of geologically complex areas, including multidimensional models of flood processes.

- Monitor precipitation and streamflow in wildfire burn areas to provide warnings and scientific process understanding.

- Perform research to improve understanding of the effects of hazards on water quality.

- Assess hazards to inform decisions that minimize risk, including the following:

- Scientific data, information, and analyses to help communities understand their exposure to extreme hydrologic events, such as studies of the processes associated with riverine and coastal erosion and the causes and dynamics of debris flows.

- Static flood-inundation map libraries and near-real-time dynamic flood-inundation mapping applications to meet a host of needs ranging from flood response and mitigation to dam- and leveebreak simulations (Water Mission Area Priority Action).

- Provide situational awareness to improve emergency response, inform the public, and minimize societal disruption, including the following:

- Development of new and enhancement of existing alert/warning systems linked to USGS hydrologic monitoring networks (such as WaterAlert) that provide automated data and information alerts to users in response to observed conditions.

- "Rapid deployment teams" consisting of USGS experts that would interface with local responders to ensure the Bureau responds properly to water-related emergencies and conflicts (Water Mission Area Priority Action). 


\section{Acknowledgments}

The authors would like to recognize the contributions of James R. Douglas for the preparation of the water cycle diagram (fig. 8) and Susan Wells for her input in communications. The report was improved by reviews from Mark T. Anderson and Francis H. Chapelle.

\section{(1)}

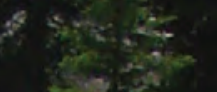

, 繁 $\operatorname{lin}(2)$

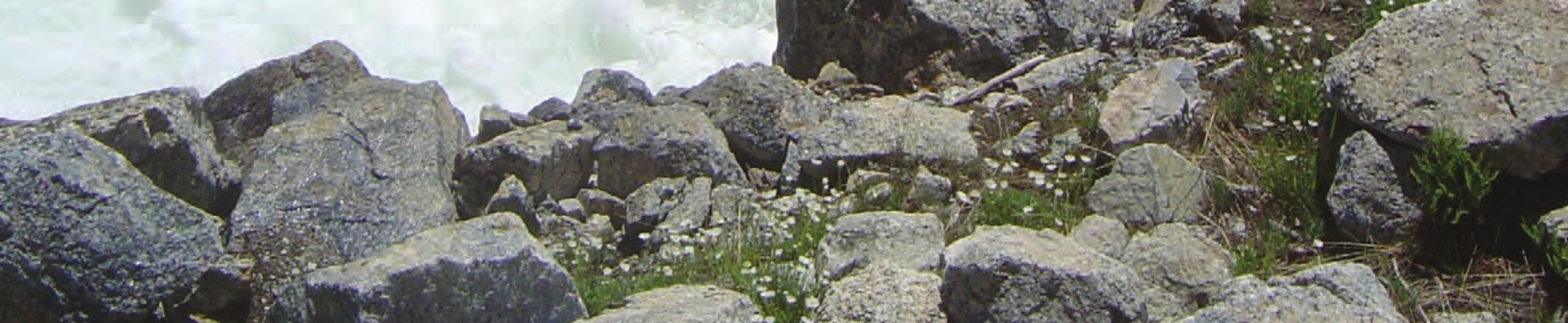




\section{References Cited}

Advisory Committee on Water Information, 2009, A national framework for ground-water monitoring in the United States: 74 p. (Also available at http://acwi.gov/sogw/pubs/ tr/index.html.)

Beven, Keith, 2009, Environmental modelling-An uncertain future? An introduction to techniques for uncertainty estimation in environmental prediction: London, Routledge, $310 \mathrm{p}$.

Bredehoeft, J.D., 2002, The water budget myth revisitedWhy hydrogeologists model: Ground Water, v. 40, no. 4, p. 340-345.

Bryant, Edward, 2005, Natural hazards (2d ed.): Cambridge, U.K., Cambridge University Press, 313 p.

Bureau of Reclamation, 2011, Colorado River Basin water supply and demand study: Bureau of Reclamation Interim Report No. 1, 69 p.

Callender, Edward, and Van Metre, P.C., 1997, Reservoir sediment cores show U.S. lead declines: Environmental Science \& Technology, v. 31, no. 9, p. 424A-428A.

Colorado River Basin Water Supply and Demand Study Team, 2011, Colorado River Basin water supply and demand study: Bureau of Reclamation Interim Report No. 1, 69 p.

Committee on USGS Water Resources Research, 2002, Estimating water use in the United States - A new paradigm for the National Water-Use Information Program: Washington, D.C., National Academy Press, 176 p. (Also available at http://www.nap.edu/catalog.php?record_id=10484.)

Dubrovsky, N.M., Burow, K.R., Clark, G.M., Gronberg, J.A.M., Hamilton, P.A., Hitt, K.J., Mueller, D.K., Munn, M.D., Nolan, B.T., Puckett, L.J., Rupert, M.G., Short, T.M., Spahr, N.E., Sprague, L.A., and Wilber, W.G., 2010, Nutrients in the Nation's streams and groundwater, 1992-2004: U.S. Geological Survey Circular 1350, Reston, 174 p.

El Paso Water Utility, 2011, Setting the stage for the future, accessed July 26, 2011, at http://www.epwu.org/water/ desal info.html.

Fishman, Charles, 2011, The big thirst - The secret life and turbulent future of water: New York, Free Press, 388 p.

Gundersen, L.C.S., Belnap, Jayne, Goldhaber, Martin, Goldstein, Arthur, Haeussler, P.J.; Ingebritsen, S.E., Jones, J.W., Plumlee, G.S., Thieler, E.R., Thompson, R.S., and Back, J.M., 2011, Geology for a changing world 2010-2020Implementing the U.S. Geological Survey Science Strategy: U.S. Geological Survey Circular 1369, 68 p. (Also available at http://pubs.usgs.gov/circ/circ1369.)
Healy, R.W., Winter, T.C., LaBaugh, J.W., and Franke, O.L., 2007, Water budgets-Foundations for effective waterresources and environmental management: U.S. Geological Survey Circular 1308, 90 p.

Hill, M.C., and Tiedeman, C.R., 2007, Effective groundwater model calibration - With analysis of data, sensitivities, predictions, and uncertainty: Hoboken, N.J., John Wiley \& Sons, $455 \mathrm{p}$.

Hirsch, R.M., Hamilton, P.A., and Miller, T.L., 2006, U.S. Geological Survey perspective on water-quality monitoring and assessment: Journal of Environmental Monitoring, v. 8, p. 512-518.

Hutson, S.S., Barber, N.L., Kenny, J.F., Linsey, K.S., Lumia, D.S., and Maupin, M.A., 2004, Estimated use of water in the United States in 2000: U.S. Geological Survey Circular $1268,46 \mathrm{p}$.

Hoard, C.J., Fowler, K.K., Kim, M.H., Menke, C.D., Morlock, S.E., Peppler, M.C., Rachol, C.M., and Whitehead, M.T., 2010, Flood-inundation maps for a 15-mile reach of the Kalamazoo River from Marshall to Battle Creek, Michigan: U.S. Geological Survey Scientific Investigations Map 3135 , 6-p. pamphlet, 6 sheets, scale 1:100,000.

Hutton, J., 1785, The system of the earth, its duration, and stability, quoted in Albritton, C.C., ed., 1975, Philosophy of geohistory-1785-1970: Stroudsburg, Pa., Dowden, Hutchinson \& Ross, p. 24-52.

Interstate Council on Water Policy, 2011, Integrated Water Resources Science and Services (IWRSS), accessed August 29, 2011, at http://www.icwp.org/cms/conferences/ IWRSS.pdf.

Jacobsen, L.J., Glynn, P.D., Phelps, G.A., Orndorff, R.C., Bawden, G.W., and Grauch, V.J.S., 2011, U.S. Geological Survey-A synopsis of three-dimensional modeling, in Berg, R.C., Mathers, S.J., Kessler, Holger, and Keefer, D.A., eds., Synopsis of current three-dimensional modeling in geological survey organizations: Illinois State Geological Survey Circular 578, p. 69-79.

Johnson, C.D., Lane, J.W., Jr., Walsh, David, and LeBlanc, D.R., 2011, Comparison of nuclear magnetic resonance (NMR) logs in wells completed in glacial sediments in the northeastern United States: Geological Society of America Abstracts with Programs, v. 43, no. 5, p. 224.

Kauffman, L.J., Baehr, A.L., Ayers, M.A. and Stackleberg, P.E., 2001, Effects of land use and travel time on the distribution of nitrate in the Kirkwood-Cohansey aquifer system in southern New Jersey: U.S. Geological Survey WaterResources Investigations Report 01-4117, 49 p. 
Kenny, J.F., Barber, N.L., Hutson, S.S., Linsey, K.S., Lovelace, J.K., and Maupin, M.A., 2009, Estimated use of water in the United States in 2005: U.S. Geological Survey Circular 1344, 52 p. (Also available at http://pubs.usgs.gov/ circ/1344/.)

Kleinhans, M.G., Buskes, C.J.J., and de Regt, H.W., 2010, Philosophy of earth science, in Allhoff, F., ed., Philosophies of the sciences-A guide: Chichester, West Sussex, U.K., Wiley-Blackwell, p. 213-236.

Larson, T.M., 2009, USGS science-Addressing our Nation's challenges: U.S. Geological Survey General Information Product 93, 12 p. (Also available at http://pubs.usgs.gov/ gip/93.)

National Research Council, 2009, Toward a sustainable and secure water future-A leadership role for the U.S. Geological Survey: Washington, D.C., National Academies Press, $114 \mathrm{p}$.
Orndorff, R.C., Lyttle, P.L., Bybell, L.M., and Quintana, Lydia, 2008, The National Cooperative Geologic Mapping Program and insights into the future of geologic map production, in, Soller, D.R., ed., Digital mapping techniques '07-Workshop proceedings: U.S. Geological Survey Openfile Report 2008-1385, p. 47-52. (Also available at http:// pubs.usgs.gov/of/2008/1385/.)

Preston, S.D., Alexander, R.B., and Wolock, D.M., 2011, SPARROW modeling to understand water-quality conditions in major regions of the United States-A featured collection introduction: Journal of the American Water Resources Association (JAWRA), v. 47, no. 5, p. 887-890, doi:10.1111/j.1752-1688.2011.00585.x.

Preston, S.D., Alexander, R.B., Woodside, M.D., and Hamilton, P.A., 2009, SPARROW modeling-Enhancing understanding of the Nation's water quality: U.S. Geological Survey Fact Sheet 2009-3019, 6 p. (Also available at http:// pubs.usgs.gov/fs/2009/3019/.)

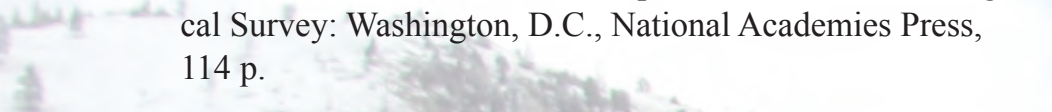


Rasmussen, P.P., Gray, J.R., Glysson, G.D., and Ziegler, A.C., 2009, Guidelines and procedures for computing time-series suspended-sediment concentrations and loads from instream turbidity-sensor and streamflow data: U.S. Geological Survey Techniques and Methods, book 3, chap. C4, 53 p. (Also available at http://pubs.usgs.gov/tm/tm3c4/.)

Rosen, M.R., Alvarez, D.A., Goodbred, S.L., Leiker, T.J., and Patiño, Reynaldo, 2011, Sources and distribution of organic compounds using passive samplers in Lake Mead National Recreation Area, Nevada and Arizona, and their implications for potential effects on aquatic biota: Journal of Environmental Quality, v. 39, no. 4, p. 1161-1172.

Steefel, C.I., DePaolo, D.J., and Lichtner, P.C., 2005, Reactive transport modeling-An essential tool and a new research approach for the Earth sciences: Earth and Planetary Science Letters, v. 240, no. 3-4, p. 539-558.
Sweetkind, D.S., Taylor, E.M., McCabe, C.A., Langenheim, V.E., and McLaughlin, R.J., 2010, Three-dimensional geologic modeling of the Santa Rosa Plain, California: Geosphere, v. 6, no. 3, p. 237-274. (Also available at http:// dx.doi.org/10.1130/GES00513.1.)

U.S. Environmental Protection Agency, 2009, The national water quality inventory-Report to Congress, 2004 reporting cycle: U.S. Environmental Protection Agency EPA 841-R-08-001, $37 \mathrm{p}$.

U.S. Geological Survey, 2007, Facing tomorrow's challenges-U.S. Geological Survey Science in the decade 2077-2017: U.S. Geological Survey Circular 1309, 70 p. (Also available at http://pubs.usgs.gov/circ/2007/1309/.)

Winter, T.C., Harvey, J.W., Franke, O.L., and Alley, W.M., 1998, Ground water and surface water-A single resource: U.S. Geological Survey Circular 1139, 79 p. (Also available at http://pubs.usgs.gov/circ/circ1139/.)

\section{StreamPro measurement on the Clark Fork River, Montana, December 2010. Photograph by D.A. Bischoff, USGS.}

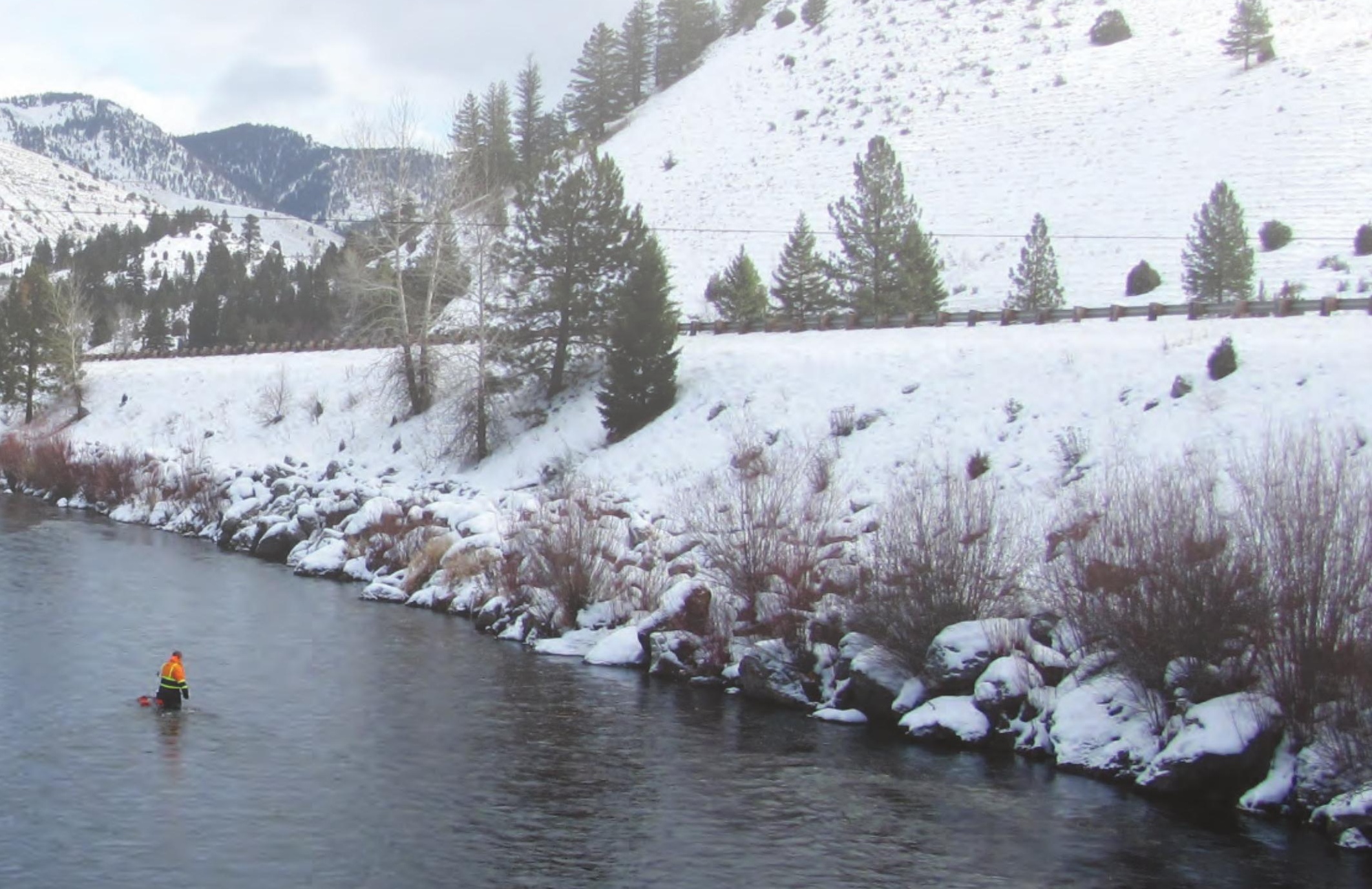




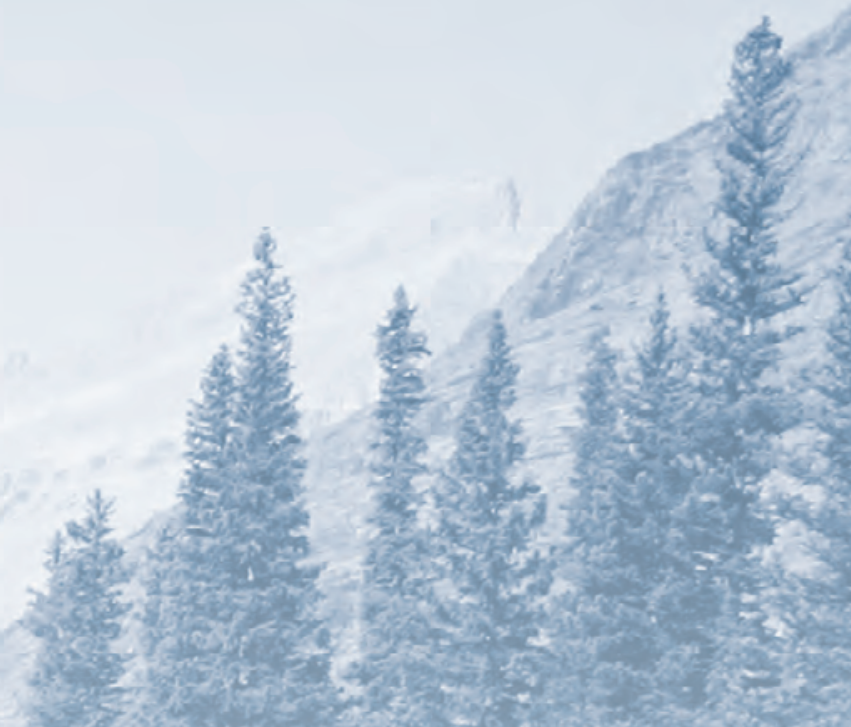

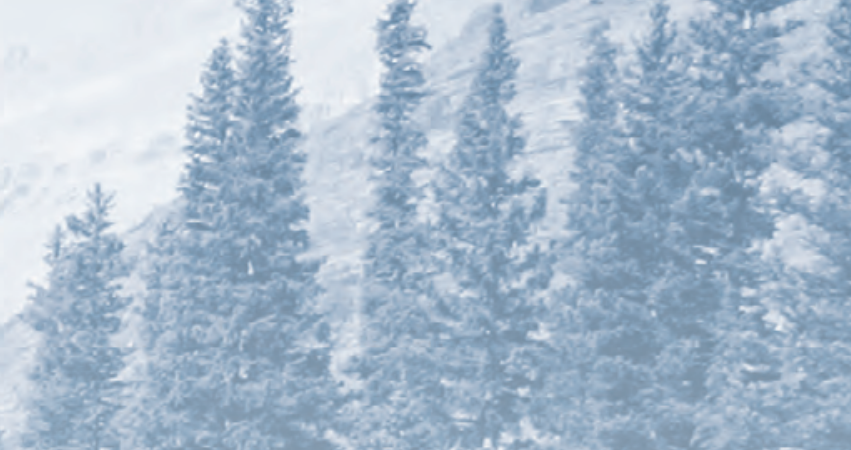

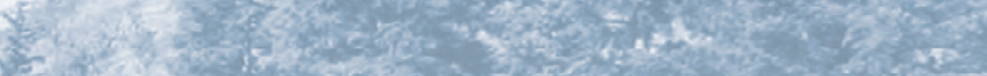

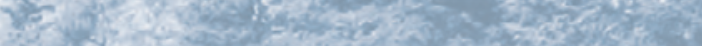
3.

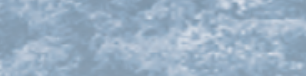
H.

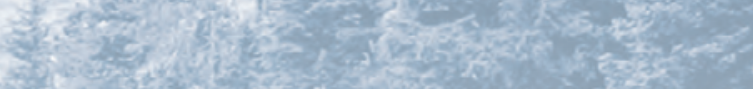

(y)

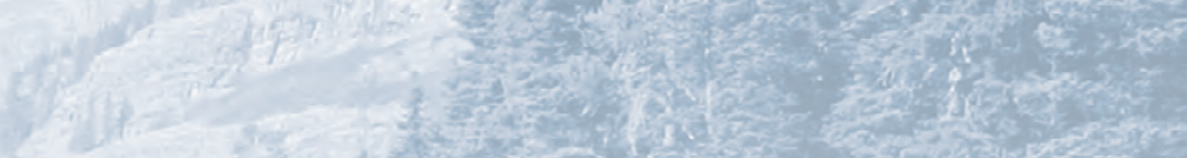

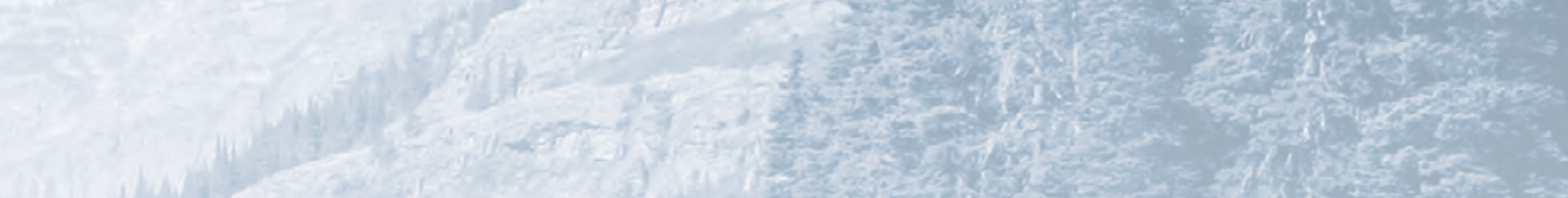

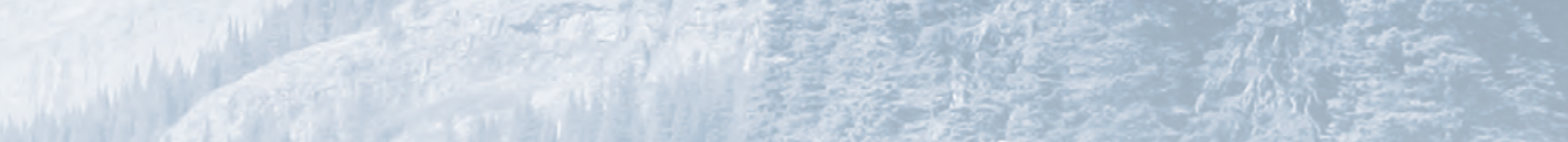

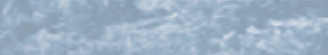

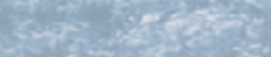

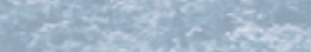

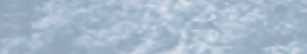
axis cotes

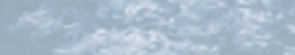
then ansentes

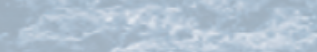
$30-5 x^{2}=3$

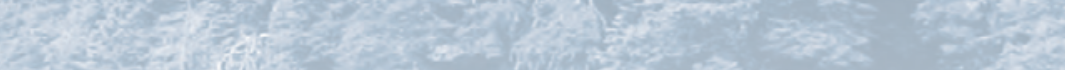

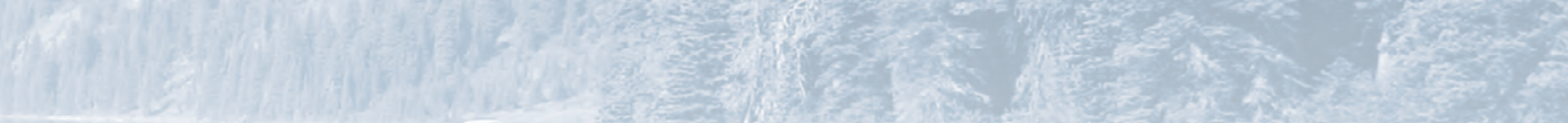

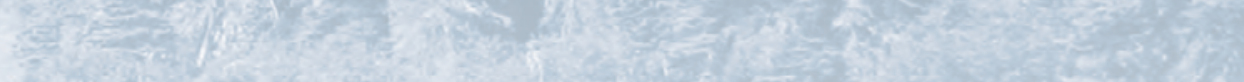

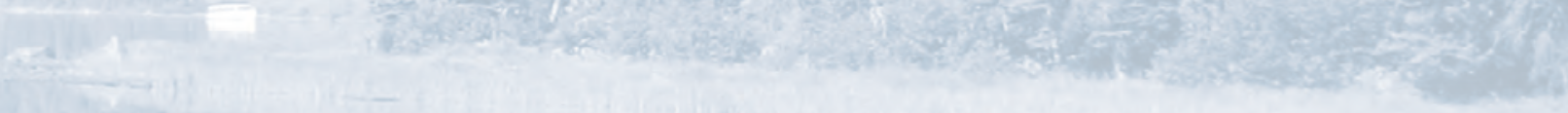




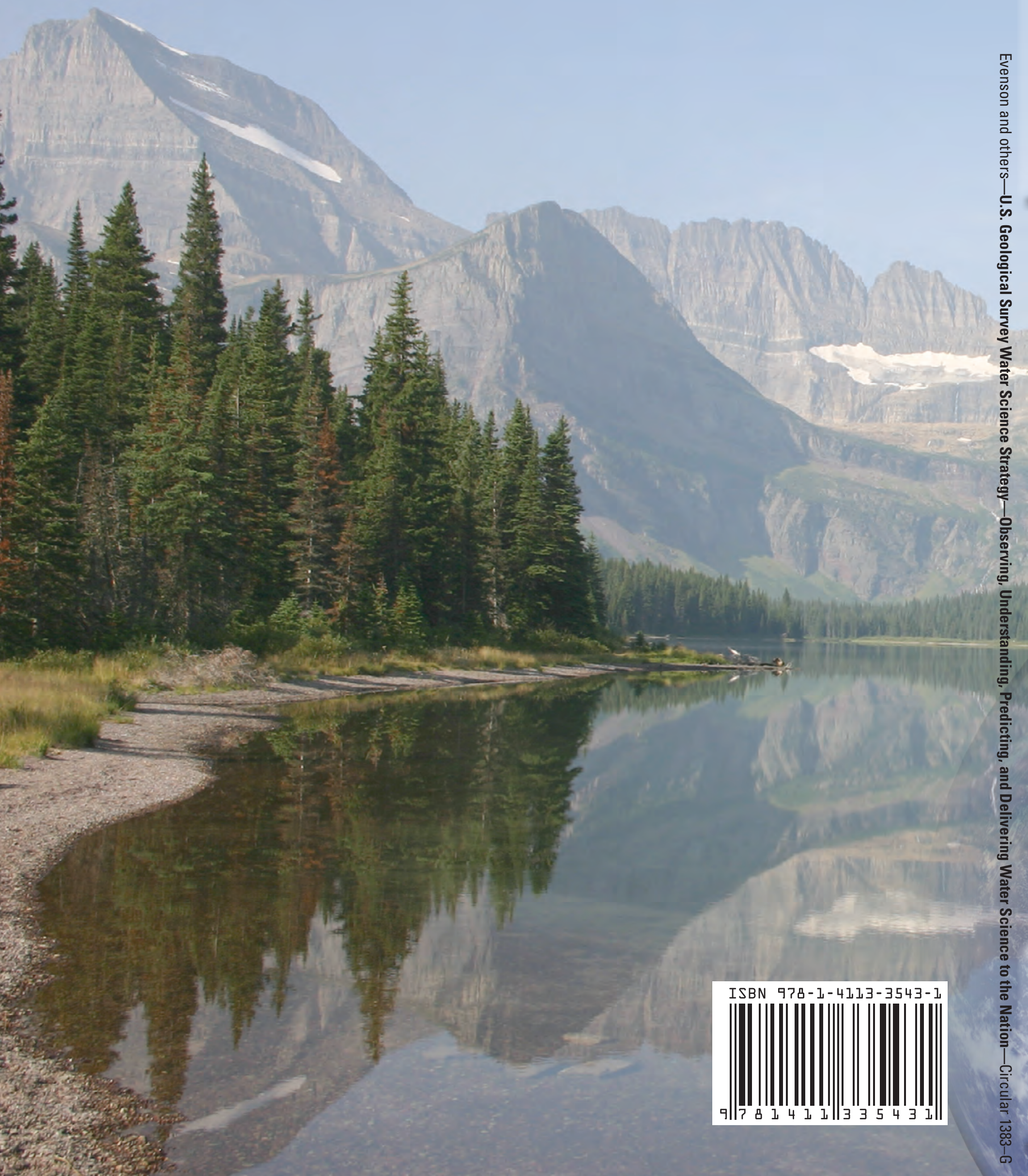

